Florida International University FIU Digital Commons

\title{
The Central European initiative : an approach to regional stabilization and democratic consolidation
}

\author{
Astrid Bettina Boening
}

Florida International University

DOI: $10.25148 /$ etd.FI14051178

Follow this and additional works at: https://digitalcommons.fiu.edu/etd

Part of the International and Area Studies Commons

\section{Recommended Citation}

Boening, Astrid Bettina, "The Central European initiative : an approach to regional stabilization and democratic consolidation" (2006). FIU Electronic Theses and Dissertations. 1710.

https://digitalcommons.fiu.edu/etd/1710 
Miami, Florida

THE CENTRAL EUROPEAN INITIATIVE: AN APPROACH TO REGIONAL STABILIZATION AND DEMOCRATIC CONSOLIDATION

A thesis submitted in partial fulfillment of the requirements for the degree of MASTER OF ARTS in INTERNATIONAL STUDIES by

Astrid Bettina Boening 
To: Interim Dean Mark Szuchman

College of Arts and Sciences

This thesis, written by Astrid Bettina Boening, and entitled The Central European Initiative: An Approach to Regional Stabilization and Democratic Consolidation, having been approved in respect to style and intellectual content, is referred to you for judgment.

We have read this thesis and recommend that it be approved.

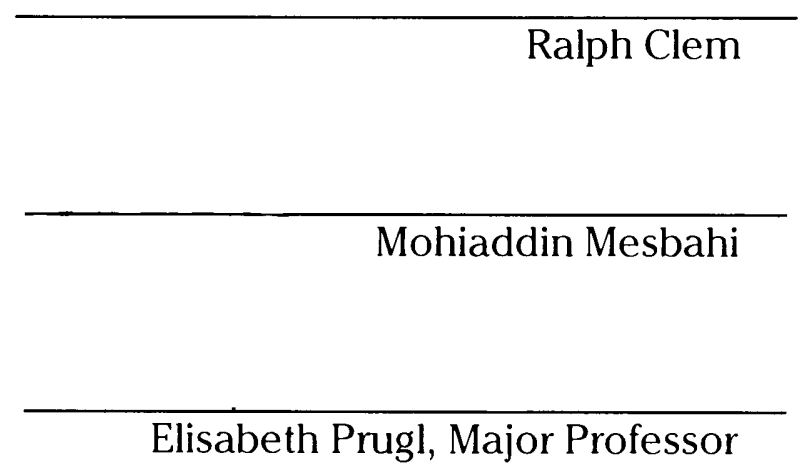

Date of Defense: July 10, 2006

The thesis of Astrid Bettina Boening is approved:

\begin{tabular}{c}
\hline $\begin{array}{l}\text { Interim Dean Mark Szuchman } \\
\text { College of Arts and Sciences }\end{array}$ \\
\hline Interim Dean Stephan L. Mintz \\
University Graduate School
\end{tabular}

Florida International University, 2006 
(C) Copyright 2006 by Astrid Bettina Boening All rights reserved. 


\section{DEDICATION}

To truth.

To justice.

To peace.

I dedicate this thesis in memory of my parents who taught me these values. 


\section{ACKNOWLEDGMENTS}

I wish to thank the members of my committee for their support, patience, and good humor. Prof. Elisabeth Prugl, my major professor, who not only encouraged me to apply to the International Studies program at Florida International University, but continued with gentle but firm direction to make this thesis see reality, and the other thesis committee members, Prof. Ralf Clem and Prof. Mohiaddin Mesbahi, for their inspiration and their belief in me, backed by their extensive knowledge and experience in guiding this project to completion.

Without the generous availability of CEI officers for the insightful discussions at their headquarters in Trieste, Italy, this project could have never taken wing. I deeply appreciate their openness and insights.

My sincerest respect is directed to the wisdom of all those involved in the CEI who dedicate themselves to contributing to the peace and stability in this region at the end of the cold war when many less desirable options could have led to the destabilization of a large part of Europe instead. 


\section{ABSTRACT OF THE THESIS}

THE CENTRAL EUROPEAN INITIATIVE: AN APPROACH TO REGIONAL

STABILIZATION AND DEMOCRATIC CONSOLIDATION

by

Astrid Bettina Boening

Florida International University, 2006

Miami, Florida

Professor Elisabeth Prugl, Major Professor

This thesis examines how multilateral institutions can contribute to democratization and regional stability. It is a case study of the Central European Initiative (CEI), a regional intergovernmental organization founded by Italy and Austria in 1989 to undertake a regional integration process, and of its role in stabilizing post-communist democracies. Documents were collected at the CEI offices in Trieste, Italy, and interviews conducted with CEI officers, and data obtained from the websites of related organizations and of CEI member countries.

The thesis probes the relevance of concepts derived from theories of international regimes and social constructivism. It shows that the CEI diffuses norms and institutional rules conducive to consolidating democracies, including the development of a free civil society, a relatively autonomous political society, rule of law, state bureaucracies that are usable by the new democratic governments, and functioning free market economies, addition, and fosters habits of dialogue, socializes participants, and supports the creation of supra-national identities. 


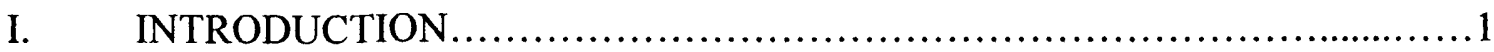

II. LITERATURE REVIEW AND THEORETICAL BACKGROUND.............12

Internal Parameters which Reflect Consolidated Democracies...................12

Dynamics in Consolidating Democracies..................................16

Space and Boundaries...................................................25

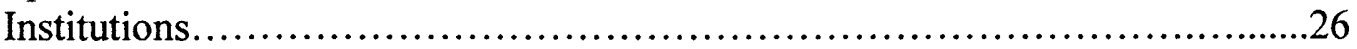

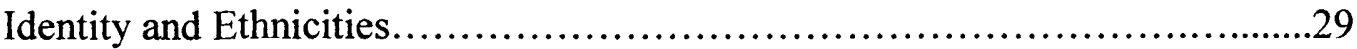

Agent - Structure: Norms, Internalization and Learning.......................37

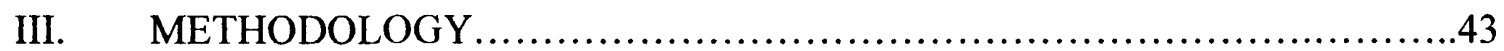

Data Collection Methods................................................44

Data Analysis Methods....................................................46

Limitations and Biases...............................................47

IV. RESULTS AND DISCUSSION ..........................................49

CEI History and Objectives...............................................49

CEI Organizational Structures/Levels of Involvement.......................53

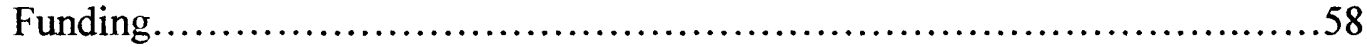

Working Areas/Projects...............................................64

V. CONCLUSIONS...................................................... 96

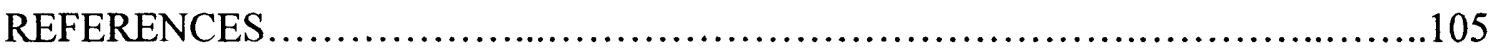

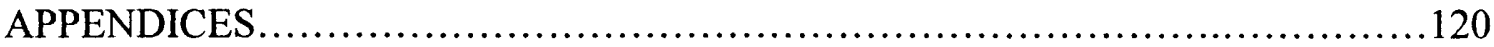




\section{LIST OF ACRONYMS}

CADSES INTERREG Central, Adriatic, Danubian, South-Eastern European Space Program of the European Commission for transnational cooperation in spatial development

CE

Current member states of the CEI (as in "Central European"), even though they encompass some Southern and South-Eastern European countries as well as Belarus, Moldova and the Ukraine.

CEGRM

CERGOP

CEI

EBRD

EGS

EMU

ENP

EU

FASTER

G8

GEODESY

GIS

IAEA

IAG

ICGEB
Colored Eco-Genetic Relationship Map

Central Europe Regional Geodynamics Program

Central European Initiative

European Bank for Reconstruction and Development

European Geophysical Society

European Monetary Union

European Neighborhood Policy

European Union

Fostering Alliances for Sustainable Transport in European Research (Project)

Group of Eight: Canada, France, Germany, Italy, Japan, Russia, United Kingdom, United States

Scientific discipline dealing with the measurement and the representation of the earth, its gravitational field and geodynamic phenomena, such as the polar motion, the tides and crustal motion in three-dimensional time varying space

Geographic Information System

International Atomic Energy Association

International Association of Geodesy

International Center for Genetic Engineering and Biotechnology 
ICS

ICTP

IFOR

IGO

KEP

KFOR

LDN

LEED

NATO

NIS

NGO

NPT

OECD

OSED

R.A.V.E. Space

SMEs

TAM

UN

UN/ECE

UNESCO

WG
International Center for Science and High Technology

International Center for Theoretical Physics

NATO Operation Joint Endeavor 20 December 1995 20 December 1996 in Bosnia and Herzegovina

Intergovernmental Organization

Know-How Exchange Program

NATO-led international force for establishing and maintaining security in Kosovo, starting 12 June 1999

Local Development Network

Local Economic and Employment Development Program

North Atlantic Treaty Organization

Newly Independent States

Non-Governmental Organization

(Nuclear) Non-Proliferation Treaty

Organization for Economic and Cultural Development

Organization for Security and Development in Europe

Raising Awareness of Values of Space through the Process of Education

Small and Medium Sized Enterprises

Turn-Around Management

United Nations

United Nations Economic Commission for Europe

United Nations Educational, Scientific and Cultural Organization

Working Group 


\section{Chapter 1:}

\section{Introduction and Historical Background}

This thesis focuses on strategies which have proven successful in the democratization process in Central- and Eastern Europe. Specifically, I will investigate the Central European Initiative (CEI) ${ }^{1}$, an intergovernmental regional organization founded by Italy and Austria in 1989 to undertake a regional integration process, and its role in stabilizing post-communist CE democracies at a time when Austria's and Italy's eastern borders were threatened by the neighboring political destabilization.

While West European integration progressed steadily since the founding of the European Coal and Steel Community in 1952, it stopped at the Iron Curtain until the 1980s. Although some Eastern Block countries had experimented with economic and political reforms in the 1970s, they had little success. Mikhail Gorbachev's reign of the Soviet Union, however, initiated an unstoppable trend of fundamental reforms through "glasnost", openness to popular political debates and participation, which he hoped would support "perestroika" (economic restructuring). By the late 1980s the populations became increasingly outspoken in the critique of their governments and glasnost opened the Eastern block far beyond what Gorbachev had intended. With press censorship receding, the media began, to the embarrassment of the authorities, to expose the severity of Soviet economic and social problems, such as "poor housing, food shortages, alcoholism, widespread pollution, creeping mortality rates and the second-rate position of

\footnotetext{
${ }^{1} \mathrm{CEI}$ membership as of June 2006 is comprised of the following eighteen countries: Albania, Austria, Belarus (this country represents an exception to regional membership but it does not influence the results of this case study), Bosnia and Herzegovina, Bulgaria, Croatia, Czech Republic, Hungary, Italy, Macedonia, Montenegro, Moldova, Poland, Romania, Serbia, Slovakia, Slovenia and Ukraine.
} 
women" (Glasnost - Wikipedia). This contrasted sharply with the very positive view of Soviet life previously promulgated by the authorities and it weakened the public's faith in their system.

The unintended consequences of glasnost spread to the Soviet Union's client states where nationalists swept elections. Labor turmoil in Poland in 1980 led to the formation of the independent trade union, Solidarity, led by Lech Walesa. Fearful of Soviet intervention, Polish Communist leader Jaruzelski, declared martial law in Poland on December 13, 1981, suspending trade unions and temporarily imprisoning its leaders. Solidarity continued to exist underground with the support of the Catholic Church and had become strong enough by the late 1980s to frustrate Jaruselski's reform attempts, particularly through the nationwide strikes of 1988 , forcing the government into dialogue with Solidarity. In April 1989 Solidarity was legalized again and allowed to participate in Polish parliamentary elections on June 4, 1989. "A Political Earthquake followed" (ibid.) when Solidarity won almost all available seats in parliament.

Hungary seized its independence next in 1988 when parliament adopted a "democracy package". It involved trade union pluralism, freedom of association, assembly and the press, a new electoral law and a radical revision of the constitution, among other measures. After the last Communist Party congress in October 1989 the Hungarian parliament adopted legislation providing for the transformation of the People's Republic into the Republic of Hungary with multi-party elections and direct presidential elections, guaranteeing human rights, and an institutional structure which included the separation of powers between the judicial, executive and legislative branches of government (Ibid.). 
By 1989 the Soviet Union had repealed the Brezhnew Doctrine in favor of nonintervention in the internal affairs of its Warsaw Pact allies (Ibid.). This facilitated the former Soviet client states seeking alternate alliances and internal government restructuring. For example, with the opening of Hungary's borders increasing numbers of East Germans began to emigrate through Hungary to West Germany. Mass protests at West German diplomatic facilities in other Eastern European capitals continued to grow. Unable to stem the continued exodus of their citizens, East German leadership caved in and allowed its citizens to leave via all border points of the Berlin Wall on November 9 , 1989. This proved fatal to the GDR (Ibid.) and the SED monopoly on power had ended. On October 3, 1990, East and West Germany were reunited.

By the end of 1989 revolts had spread from one capital to another, ousting the regimes imposed on Eastern Europe after World War II. Even the isolationist regime in Albania experienced political repercussions... Once it became evident that the feared Red Army would not intervene to crush dissent, the Eastern European regimes were exposed as vulnerable in the face of popular uprisings against the one-party system (Ibid.).

In Bulgaria, the Communist Party gave up its claim on power in February 1990 and the first free elections since 1931 were held in June 1990. In contrast to the other Eastern European countries, however, Romania had not undergone even limited de-Stalinization. Although Gorbachev actually asked Ceausescu to resign during the latter's visit to Moscow in November 1989, he refused and was re-elected for another five year term. Nevertheless, the dissatisfaction of the Romanian population had boiled to the surface by December 1989 and the Ceausescus were deposed and assassinated. Free elections were announced in Romania by an interim National Salvation Front Council for May 1990. 
At a time when Moscow faced a severe economic decline and needed Western support, Eastern Europe had become an additional economic and political burden. Rempel (1995) pinpoints the end of the Cold War to a declaration by the leaders of the two world superpowers at the Malta Summit on December 3, 1989. These events altered the balance of power globally and the subsequent collapse of the Soviet Union also marked the beginning of the Post-Cold War era.

Glasnost had inadvertently released the long-suppressed national sentiments of all peoples within the borders of the multinational Soviet states... One by one the constituent republics created their own economic systems and voted to subordinate Soviet laws to local laws (Ibid.).

On July 1, 1991 the Warsaw pact was officially dissolved at a meeting in Prague. At a summit later that month Gorbachev and President George H.W. Bush declared a strategic partnership on the basis of the U.S.-Soviet cooperation during the Persian Gulf War in 1990-1991, resolving bilateral and world problems (Ibid.).

The post-Cold War era in Central- and Eastern Europe brought extensive challenges of economic and political re-integration of this area with the West. Not only did the Czechs and the Slovaks decide to divide Czechoslovakia into two sovereign states, but the Balkan crisis is another example where the West was not able to react proactively quickly enough to avert a protracted humanitarian crises in light of the very rapidly crumbling of the Soviet Union: The thirty-five year rule of General Tito in Yugoslavia until his death in 1980 had successfully kept the lid on the smoldering multiethnic country on the Balkan peninsula. In the summer of 1991 Slovenia and Croatia, the most Westernized, anti-Communist republics in the federation declared their independence (Keylor 2001, 477) and the Serb minority in Croatia and Slovenia, in 
cooperation with portions of the Serb-dominated former Yugoslav federal army took up arms against these newly independent states. A UN-brokered ceasefire restored peace in 1992 to these two countries, only to flare up in Bosnia-Herzegovina and Serbia later in 1992. Neither side could be pacified by Alanticist and European cease fire proposals until NATO air strikes against Serbian positions (threatening UN-designated protected territory, inhabited mainly by Muslim civilians) was finally concluded with the signing of the Dayton Accord on October 12, 1995 (Ibid., 480/1). This agreement effectively established a NATO protectorate in Bosnia-Herzegovina.

While the UN IFOR peace implementation force in Bosnia oversaw the restabilization in Bosnia, another conflict boiled over in Serbia itself. The ethnic Albanians in Kosovo, long tired of perceived discrimination by the Serb-dominated government in Belgrade, proceeded to press for secession. President Milosevic sought to repress the rebellion by sending in his troops to terrorize restless Kosovans into leaving their country. When Russia supported Serbia ${ }^{2}$ in rejecting the peace agreement at Rambouillet in February 1999, NATO intervened again with almost 10,000 bombing missions over seventy-nine days (Ibid., 483). After Milosevic finally agreed in June 1999 to let the Albanian refugees return to Kosovo, the latter reciprocated with some revenge ethnic cleansing on their own (Ibid.), forcing Kosovo Serbs to flee to Serbia proper. A NATOled multinational ground force (KFOR) remains in Kosovo to oversee the return of Albanian refugees and to restore law and order in the devastated country.

\footnotetext{
${ }^{2}$ Serbia was referred to formally as "Serbia and Montenegro" between 2003 and May 21, 2006, when Montenegro voted for independence .
} 
In light of these huge geo-political realignments due to underlying socio-political instability, Western Europe became alarmed at the prospect of a spill-over effect of civil wars and political upheavals. Though the concern was not in terms of spreading political unrest (since the underlying circumstances in western Europe were different), the prospect of hundreds of thousands of refugees, illegal weapons trading and other activities reflective of lawlessness due to ineffective new governments were cause for grave concern in countries bordering Central- and Eastern Europe. This study seeks to examine how democratization could be made more successful and regional stability achieved. Specifically, how has the Central European Initiative contributed to the stabilization of the new, post-communist Central European $(\mathrm{CE})^{3}$ democracies?

${ }^{3}$ The acronym "CE" will be used in this study to refer to the current member states of the Central European Initiative. CEI member states currently also encompass some Southern- and South-Eastern European countries as well as some NIS states, such as Belarus, Moldova and Ukraine.

By comparison, in geographic terminology, Central Europe refers to "the region lying between the variously and vaguely defined areas of Eastern and Western Europe. In addition, Northern, Southern and Southeastern Europe may variously delimit or overlap into Central Europe. The understanding of the concept of Central Europe varies considerably from nation to nation and also has from time to time. The region is usually used to mean: Germany, Switzerland, Liechtenstein, Slovakia, Poland, Czech Republic, Austria, Hungary and Slovenia (Wikipedia, Central Europe). This region is defined by its geographic boundaries, the Baltic countries in the north and the Apennine peninsula (Italy) across the Alps. The eastwest borders are culturally more fluid (Ibid.), since these countries were historically part "of the central European kingdoms and empires, such as the Holy Roman Empire, the Kingdom of Hungary, the Habsburg monarchy, the Polish-Lithuanian Commonwealth, and Imperial Germany" (Ibid.). Within the cultural definition the following countries belong to Central Europe: (western) Belarus, Croatia, Lithuania, Romania (Transylvania), Serbia (Vojvodina), Ukraine (Galicia, Volhynia, Pdolia) and Italy (South Tyrol, Friuli-Venezia Giulia) (Ibid.). Historically, following World War II, Poland, Czech Republic, Slovakia, Hungary and Slovenia were considered Ccentral European to distinguish them from those behind the iron curtain (i.e. Balkan-, Baltic and Russian Orthodox and Muslim countries) (Ibid.).

In contrast, Southern Europe refers geographically to the southern half of the landmass of Europe (Southern Europe - Wikipedia). "This definition is relative, with no clear limits" (Ibid.). While the Alps represent a north-south barrier in the eastern part, this boundary disappears further west. While the official $U N$ designation does not include France, a climatic definition would only include the immediate land strip bordering the Mediterranean. Linguistically and culturally, one could divide Southern Europe into the Iberian Peninsula (Portugal, including Azores, Madeira), Spain (including Baleric Islands, Canary Islands), Andorra, Gibraltar, and Southern France (including Corsica), Monaco, the Italian peninsula (including Sicily, Sardinia, Vatican City and San Marino), the Balkan Peninsula (Albania, Bosnia and Herzegovina, Bulgaria, Croatia, Greece (including Ionian Islands, Aegean Islands, and Crete), Macedonia, Montenegro, Serbia, Slovenia and the European part of Turkey (Rumelia) plus the Mediterranean States of Cyprus and Malta (Ibid.). 
This thesis focuses on strategies which have proven successful in the regional stabilization and democratization processes in Central- and Eastern Europe. Specifically, I will investigate the Central European Initiative $(\mathrm{CEI})^{4}$, an intergovernmental regional organization founded by Italy and Austria in 1989 to undertake a regional integration process, and its role in stabilizing post-communist $\mathrm{CE}$ democracies at a time when Austria's and Italy's eastern borders were threatened by the neighboring political destabilization.

The CEI was the first regional cooperation forum on the political map of Central-, South Eastern- and Eastern Europe (CEI website). Today it has the longest tradition and covers the largest territory of all multi-lateral efforts in the region. Its origin lies in the agreement signed on November 11, 1989, just a few days of the fall of the Berlin wall, by Italy, Austria, Hungary and Yugoslavia, "establishing a platform for mutual political, economic, scientific and cultural operations" (CEI website). It was called at the time

Eastern Europe is similarly vaguely defined geographically as the region between Central Europe and Russia (Eastern Europe - Wikipedia), with the "eastern limit either the Ural Mountains or from the pacific coast of the Russian Far East [and] its western limit is the boundary between the European Union and the Commonwealth of Independent States (sometimes excluding Kaliningrad)" (Ibid.). The overlap and fluctuation in regional boundaries extends politically to Eastern Europe covering "all of northeastern Eurasia, since Russia is one single transcontinental geopolitical entity. Cyprus is also frequently taken to be a European state, although geographically it is in Asia. The same approach is also sometimes taken with the post-Soviet states of Georgia, Armenia, and Azerbaijan in the Caucasus" (Ibid.). With the fall of the Iron Curtain, Eastern Europe refers retroactively sometimes to that European region which was part of the Soviet Union (Ibid.). Culturally Eastern Europe was defined by $19^{\text {th }}$ century German nationalists "synonymous with 'Slavic Europe', as opposed to Germanic (Western) Europe" (Ibid.).

Albania, Bosnia and Herzegovina, Bulgaria, Croatia, FYR Macedonia, Greece, Montenegro, Romania, Serbia, Slovenia and Turkey are also sometimes referred to as Balkan countries.

As we can see, the geographic and cultural boundaries in this region are vague and socio-politically dependent (more on the topic of "fuzzy boundaries" in the sections on "Space and Boundaries" and "Identity and Ethnicity" of the literature review in Chapter Two).

${ }^{4}$ CEI membership as of spring 2006 is comprised of the following eighteen countries: Albania, Austria, Belarus (this country represents an exception to regional membership but it does not influence the results of this case study), Bosnia and Herzegovina, Bulgaria, Croatia, Czech Republic, Hungary, Italy, Macedonia, Montenegro, Moldova, Poland, Romania, Serbia, Slovakia, Slovenia and Ukraine. 
"Quadragonal Co-operation," and later "Pentagonale" and "Hexagonale" with successive enlargements. As other Central European countries became members ${ }^{5}$, it was renamed “Central European Initiative." The CEI has expanded from its original four members ${ }^{6}$ to presently eighteen member states ${ }^{7}$, extending its membership to south-Eastern Europe and beyond (see Figure 1). In 1993 the Secretariat for CEI Projects started operating at the European Bank for Redevelopment (EBRD) in London.

My general research question is: How can an Intergovernmental Organization (IGO) affect post-Communist democratic consolidation in Central Europe through regional stabilization? Specifically, how has the Central European Initiative contributed to the stabilization of the new, post-communist Central European (CE) democracies?

Democratization is neither automatic nor necessarily permanent once endeavored. Yet the significance of democratization in the world, and in particular the successful democratization of $\mathrm{CE}$, which was before - and after - Communism politically extraordinarily unstable, is obvious. Huntington (1991) has identified three stages in a country's democratic transition from authoritarian rule, the last one, democratic

\footnotetext{
5 This paper takes the national boundaries of its member states as given according to the internationally accepted definition of each state (i.e. the boundaries of the states resulting from the disintegration of Yugoslavia, including the disposition of Kosovo, Czechoslovakia and Serbia and Montenegro were accepted by the CEI as defined by the UN.
}

${ }^{6}$ Quadragonale: Albania, Austria, Italy, Hungary and Yugoslavia, and with additional enlargements later: Pentagonale (adding Poland) and then the Hexagonale with the addition of Czechoslovakia.

${ }^{7}$ Austria, Belarus, Bosnia and Herzegovina, Bulgaria, Croatia, the Czech Republic, Hungary, Italy, Macedonia, Moldova, Montenegro, Poland, Romania, Serbia, Slovakia, Slovenia, and Ukraine, seven of which are also EU members. 


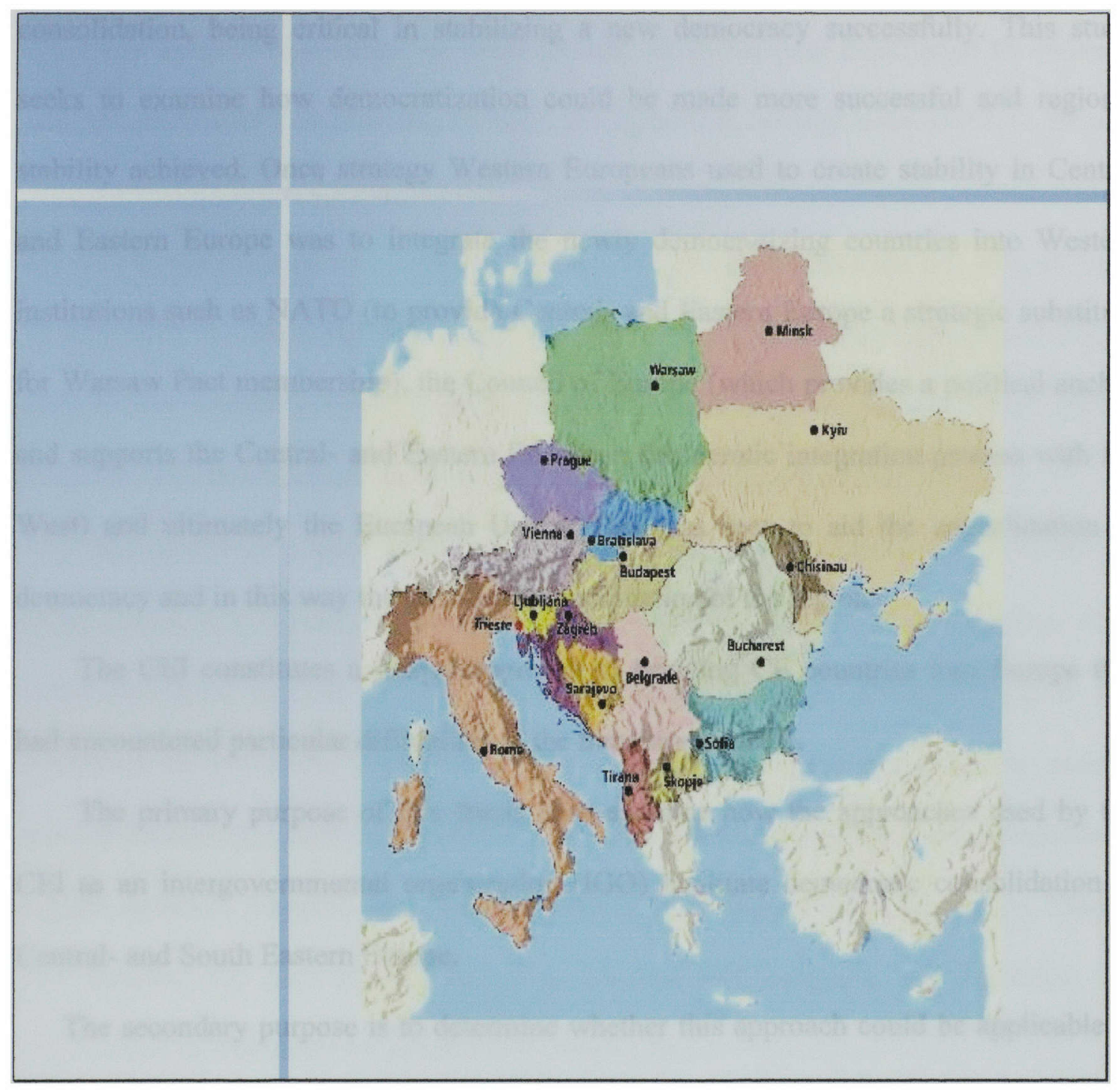

Figure 1: Map of CEI Member States

Source: www.CEINET.org 
consolidation, being critical in stabilizing a new democracy successfully. This study seeks to examine how democratization could be made more successful and regional stability achieved. Once strategy Western Europeans used to create stability in Central and Eastern Europe was to integrate the newly democratizing countries into Western institutions such as NATO (to provide Central- and Eastern Europe a strategic substitute for Warsaw Pact membership), the Council of Europe (which provides a political anchor and supports the Central- and Eastern European democratic integration process with the West) and ultimately the European Union. This was seen to aid the consolidation of democracy and in this way the post-Soviet pacification of the region.

The CEI constitutes a unique approach to bringing $\mathrm{CE}$ countries into Europe that had encountered particular difficulties in the transition process.

The primary purpose of this thesis is to examine how the approaches used by the CEI as an intergovernmental organization (IGO) facilitate democratic consolidation in Central- and South Eastern Europe.

The secondary purpose is to determine whether this approach could be applicable to democratic consolidation in other countries.

There are three facets to the research problem: First, what challenges does postCommunist $\mathrm{CE}$ face in consolidating its democracies? Second, how has the CEI contributed to fostering democracy in CE? Third, what institutional assistance (e.g. via an IGO) has proven useful to the democratic consolidation process in $\mathrm{CE}$ ? 
The study is significant for three reasons: First, the post-communist transition of and its concomitant political (in-) stability is a significant security issue for those Western European countries bordering CE (and others, of course). Second, since democratization is currently progressing more rapidly globally, lessons learnt from the $\mathrm{CE}$ process might be applicable to other regions. Third, the role of IGOs, including institutional efforts, such as the European Union's (EU) accession proceedings or the EU Neighborhood Program, is to be evaluated for its contribution to the democratization process.

This thesis is a case study which examines how the activities of a particular intergovernmental agency, the Central European Initiative, affect the consolidation of the post-Communist Central European regional democratization process. Chapter two contains a review of the literature and the theory of democratic consolidation, national identity formation, regional cooperation and constructivism synergies within international regime structure. Chapter three addresses the methodology used in this thesis. Chapter four contains the data analysis and discussion of CEI programs and activities. The conclusions of this thesis are presented in chapter five. 


\section{Chapter Two}

\section{Literature Review and Theoretical Background}

While there is no literature on the specific role of an IGO in the consolidation phase of democracy, there is abundant literature on the characteristics of stabilized democracies. The data analysis serves to establish whether and how CEI programs play a role in stabilizing the new democracies of $\mathrm{CE}$ by identifying the necessary pre-conditions as well as characteristics of a consolidated democracy outlined in the following literature review. First I will analyze the available literature on democratization from a standpoint of the internal parameters which reflect consolidated democracies. Then I will proceed to investigate some of the dynamics other scholars have found to support democratic consolidation, including theories on state and identity formation and a constructivist approach to the agent-structure synergy of the CEI and its member states within the parameters of an international regime.

Internal parameters which reflect consolidated democracies

There is an extensive literature on democracy in political science. Lipset (1959) was interested in mechanisms which contribute to successful democratizations. He identified three necessary components for this process. They are the following: Economic and social background conditions, such as high per capita income, widespread literacy, prevalent urban residence and a broad middle class without extreme income polarization.

Rustow (1979) concurred with Lipset that certain beliefs (civic attitudes) such as the belief in consensus including consensus about the right to differ, and the willingness to participate are essential ingredients of successful democratization. The degree of a 
democracy's legitimacy can be measured by how well the system performs, e.g. institutions are not threatened and groups have access to the system.

According to Lijphart (1992), just as Lipset had also pointed out, democratic stability requires conflict and reconciliation in the political process as well, i.e. democratic values need to be congruent not only in the political arena, but also in authority structures throughout society, such as businesses, trade unions and culture. Or in Schumpeter's classic words "democracy is a system of governance in which rulers are held accountable for their actions... through the competition and cooperation of their elected representatives" (Schumpeter 1943, cited by Schmitter and Karl 1991, 76).

Thus, the literature on democracy has emphasized the key role of civic values and economic conditions. However, central to the establishment of democracy are institutions. Huntington $(1991,6)$ defines a democracy as characterized by "sources of authority for government, purposes served by the government, and procedures for constituting a government". The central procedure of democracy is "the selection of leaders through competitive elections by the people they govern" (Huntington 1991, 6), including a choice of parties, as well as "the existence of those civil and political freedoms to speak, publish, assemble, and organize that are necessary to political debate and the conduct of electoral campaigns" (Huntington 1991, 7).

At the simplest level, Huntington $(1991,35)$ observes three stages to a democratic transition from authoritarianism:

- the end of an authoritarian regime,

- the installation of a democratic regime, 
- the consolidation of the democratic regime (stabilization phase). This latter observation is similar to the "habituation phase" identified by Weber (1949) and echoed by Linz and Stepan $(1996,6)$. In this study I will refer to this stage as the "consolidation" phase.

The challenges faced by a new democracy can be, according to Huntington $(1991,208)$, categorized into three types:

- First are transition problems stemming from the event of regime change from authoritarianism to democracy, e.g. new constitutional and electoral systems, changing/abolishing authoritarian agencies and institutions, such as the secret police or the one-party system.

- Second, contextual problems endemic in the country pose a challenge to any government, authoritarian or democratic, such as regional antagonisms, communal conflicts, poverty, and low rates of economic growth (Huntington 1991, 36) and are not coincidental to the transition. In this context Max Weber's work (1949) is often cited. He argued that differences in national patterns often reflect key historical events which set a certain process in motion in one country and a different one in another.

- Third, systemic problems are those resulting from a working democracy, such as the inability to reach decisions, remnants of overly concentrated decision making, deficient feedback, and dependence on performance legitimacy.

Consolidation success, according to Huntington (1991) can be influenced by several factors: 
- Characteristically, democracies do not succeed in creating a stable democracy with their first attempt (Ibid., 270);

- A high correlation exists with the level of economic development (Ibid.), and

- A supportive external/international environment and foreign actors are conducive to consolidation (Ibid., 273).

Huntington tests successful consolidation via the "two turn-over test" (Ibid., 153), whereby a party which is in power in a country, but looses the next election, is able to regain power in a subsequent election.

Pietrzyk (2003) discusses in his article the continued usefulness of the historical term "civil society" in the context of the challenges faced by post-communist Central European countries in their transitions to liberal democracies. While the idea is deeply rooted in the tradition of political thought, it emerged in modern philosophy along with the rise of capitalism and liberalism and was used by Smith, Hegel and Marx in referring to the bourgeoisie. Pietrzyk (Ibid.) argues that one of the main tasks in CE is the establishment of this civil society not only as a descriptive category but also as a normative one. In the context of post-communist democratization the revival of this term can be useful when applied to political ideas in changing the social and political world as representing a goal in the struggle against the totalitarian state. Civil society in this sense refers to that

sphere within which citizens may freely organize themselves into groups and associations at various levels in order to make the formal bodies of state authority adopt policies consonant with their perceived interests... and can be said to support the maintenance both of a strong constitutional-democratic 
system and a more human and equitable version of the market economy (Ibid., 38-39).

Pietrzyk also suggests that the development of civil society and the democratization of the "social and political spheres should be seen as a mutual process leading to political and economic stability" (Ibid., 38).

\section{Dynamics in consolidating democracies}

Having thus identified internal parameters which reflect consolidated democracies, we now turn to a review of works which deal with the transition to democracy in terms of how to actually establish these parameters in practice, i.e. different approaches to studying the dynamics of establishing consolidated democracies. For this purpose, I draw on literature in International Relations. While this may be counterintuitive, I pursue here Huntington's suggestion that a supportive international environment is conducive to democratic consolidation. Theories of cooperation and constructivist theories on the relevance and diffusion of norms are particularly relevant to this suggestion.

Keohane points out that

if we use rational-choice theory properly, we should expect a substantial amount of cooperation in the international relations of the advanced marketeconomy countries, that the rational-choice theory and the theory of collective goods help to show why institutions are significant in world politics, and even crucial to successful cooperation (Keohane 1984, 70).

In other words, even though realists are often viewed as almost diametrically opposed to constructivist views in international relations, Keohane argues that rational-choice is actually an integral part of cooperation in the context of a collective good. In this study the collective good is "peace" - a good which is more likely to be achieved if there is 
democracy as democracies traditionally have not waged war against one another. Furthermore, democracy is facilitated through a collective action process of the countries concerned, in this case CE.

Following this thought process, I am first linking literature on the action of states domestically and internationally to policy outcomes (the policy outcome under discussion in this thesis is regional stability through democracy consolidation and regional integration) via different pathways. Ikenberry, Lake and Mastanduno (1988) distinguish two approaches in linking the state to policy outcomes: The first views "the state primarily as an organization structure, or set of laws and institutional arrangements shaped by previous events. In this view, institutions, once formed, tend to endure" and develop non-linearly only at moments of crisis. "The second approach conceives of the state as an actor and focuses directly on politicians and administrators in the executive as independent participants in the policy process" (Ibid., 10) According to these authors, institutions are petrified behemoths which do not contribute to the evolution of the state internally or externally and only politicians and administrators can affect the policy process.

Peter Haas (1992), in contrast, proposes a more dynamic approach of how decision makers, unfamiliar with the technical aspects of a specific problem in the international context of institutions, define state interests and develop viable solutions. With respect to issues of international cooperation, he raises the issue of "determinism versus free will and about the ways in which the international system is maintained and transformed and ...whether national behavior is determined or broadly conditioned by system-level 
factors, unit-level factors, or some complex interplay between the two" (Ibid., 1). His

findings were six-fold:

- Ideas inform policies (Ibid., 26)

- Actors' understanding of the world and the formulation of alternative actions are shaped by belief systems, operational codes, and cognitive maps (Ibid., 28)

- Consensual knowledge may contribute to policy coordination and to more comprehensive policies (Ibid., 29)

- Policy choices are often made by discrete networks of actors (Ibid., 31)

- Coalitions are built trans-governmentally and trans-nationally (Ibid., 32)

- Organizations are not always captured (Ibid., 33).

In other words, applying his ideas to positioning the domestic challenge of democratic stabilization in a foreign policy context, P. Haas also examines the processes through which international policy coordination and cooperation and order, i.e. regional stability in this case study, emerge.

Recognizing that human agency lies at the interstices between systemic condition, knowledge, and national actions [his approach examines the] "role that networks of knowledge-based experts - epistemic communities - play in articulating the cause-and-effect relationships of complex problems, framing the issues for collective debate, proposing specific policies, and identifying salient points for negotiation (Ibid., 2).

With other words, P. Haas addresses what would later be recognized as the mutual construction of agents and structures in the democratic process. Expanding this approach to include the external context of this process, Katzenstein (1996, cited in P. Haas 1992, 2) distinguishes more specifically between the extent to which nation-states differ in the 
centralization of the state and society and "the range of foreign policy instruments available to state officials in the conduct of foreign economic policy". This observation is an extrapolation of the examination of modi operandi effective in the internal consolidation of democracies. In this thesis I show how the external role of the CEI in the domestic democratization processes in $\mathrm{CE}$ is essential to the regional integration.

Returning to the concept of epistemic community, Ruggie (1998) developed this idea further and refers to it as "a network of professionals with recognized expertise and competence in a particular domain and an authoritative claim to policy-relevant knowledge within that domain or issue area" (Ruggie 1998, 83). He developed the idea between "the power of broader visions of reality, or epistemes, that provide the assumptions from which policies follow and shape the pattern of politics over the long run" (Ruggie quoted in P. Haas 1992, 26) from an institutionalizational grid of the state and the international political order through which behavior is acted out: Epistemes can serve to visualize political relationships (Ruggie in Ibid.).

Ruggie gleaned the term "episteme" from Michel Foucault (1979) and developed it further into the idea of "international regime" within the meaning of international relations theory. According to Kenneth Waltz' model (1975) of international structure which does not consider any type of transformation, Ruggie (1998) explored "the basis on which the constitutive units of the system are differentiated from one another and on the basis of which they assume their identity as constitutive units" (Ruggie (1998, 132). I find the significance Ruggie attached to the uniqueness of the units (such as the culturally very different states of $\mathrm{CE}$ ) as being able to assume an identity as constitutive units (e.g. "CE" in this case). Ruggie developed the concept of 'regime' to go beyond the realists' 
perception (such as Waltz, Morgenthau and Lippmann) that “international politics was all about 'interest defined as power" (Morgenthau quoted in Ruggie 1998, 4) "so that power itself becomes the proximate interest of any state's foreign policy" (Ruggie 1998, 5). Instead, Ruggie points out that

no one in any position of authority anywhere in Europe responded to the most profound geopolitical changes of the postwar era - the collapse of the Soviet Union's East European empire, of the Soviet Union itself, and German reunification - by advocating, or quietly preparing for, a return to competitive bilateral alliances. All of the options on the table concerning the external mechanism for achieving security in Europe, East and West, were multilateral in form (emphasis mine) (Ibid., 197).

These authors recognized the potential of multilateral integration not just for the sake of power but to build a transformational structure for the purpose of regional stability. However, little has been written about actual modi operandi which would contribute to the consolidation of these young democracies. In particular, the role of international regimes has not been studied in this context. Samuel Huntington (1991) refers to the third stage of democratic transitions as the "consolidation" phase. If this phase is not accomplished successfully within a country, democracy will not persist. Consolidation, according to Huntington, requires successful institutionalization and stabilization. These two factors are necessary simultaneously and have a reciprocal effect on one another. While consolidation was originally thought to consist of defining the core rules of democratic competition agreed upon in earlier stages of democratization, the consolidation phase was viewed as characterized primarily by an increased importance of routinized institutional structures that start to influence the behavior of political actors (Kopecky 2000,520 ) rather than simply actors struggling at will to define the postauthoritarian political landscape. 
This study applies Huntington's conceptualization and probes processes of institutionalization and stabilization. It also draws on an additional body of theory taken from the field of International Relations to argue that the aim of the CEI is regional democratic institutionalization, leading to the formation of an international regime, a transnational socio-political governing process (Ruggie 1998; Keohane and Nye 1971). The liberal theory of peace and war incorporates the hypothesis that economic interdependence promotes peace with the theory of international (democratic) institutions (Russett and Oneal 2001). For some this represents the systematization and empirical testing of Kant's (1796) conception of perpetual peace based on democratic institutions, free trade and international law and institutions.

The theory of neofunctionalist integration focused on regional and later, with a pluralistic polity postulated as a precondition, on global integration (E. Haas 1958, 1961, 1964). In the 1970s, E. Haas later realized that the integration process was more direct and politically driven than the circuitous and largely technocratic mechanism he had specified in his theory (Ruggie 1998, 6). He then turned his focus to the role of international interdependence and regimes. Neorealist and neoliberal institutionalism were hence merged into the theory of constructivism (Onuf 1989). My theory about the role of an international regime, such as the $\mathrm{CEI}$, in the consolidation of new democracies extrapolates from Ernst Haas' model of international cooperation based on learning, i.e. scientific, consensual understandings as factors in politics, to a synergistic constructivist process in regional integration and democratic consolidation in CE.

Keohane (1988) weighed in on the debate about international institutions by distinguishing the rationalistic approach from the reflective approach, "which stresses the 
impact of human subjectivity and the embeddedness of contemporary international institutions in pre-existing practices" (Keohane 1988, 379). He promoted a synthesis of the two perspectives "to form the basis for historically and theoretically grounded empirical research" (Ibid.). This thesis addresses this "subjective" regional cultural heritage as it is synthesized into contemporary institutions through CEI programs within an international regime. While realist and neorealist theories are avowedly rationalistic, one has to bear in mind that "behavior can be adjudged objectively to be optimally adapted to the situations" (Simon 1985, 294, cited in Keohane 1988, 379). In this thesis I show how the programs of the CEI offer the opportunity within this international regime structure for member states to engage in cooperative behavior for the purpose of regional integration and democratic consolidation.

While cooperation is an active deed which occurs in (or is necessitated by) the absence of harmony but which actors choose to avoid discord, this undertaking requires the actions of separate individuals or organizations - which are not in pre-existent harmony - be brought into conformity with one another through a process of policy coordination (Keohane 1984, 51). Incorporating a sociological approach with a rationalist approach to the study of institutions entails combining the role of impersonal social forces with the impact of cultural practices, norms, and values that are not derived from calculations of interest (Gilpin 1981 cited in Keohane 1988, 381). In this case study I have examined how the regional integration process through the cooperative programs of the CEI do not simply entice member states purely for reasons of power, but through socialization and norming to integrate $\mathrm{CE}$ and consolidate their democracies. 
Embedded in this process is the concept of cognitive evolution (Adler 1991; P. Haas 1992) as a constructivist interpretation of collective social learning, involving innovation, selection and international diffusion, the notion of institutionalization of collective understanding, and contributions made by Wendt (1992 and 1994) to understanding security community-like collective identity formation. Other scholars who also elaborated on institutionalist approaches as applied to collective security systems, regional security communities and alliances are Kupchan and Kupchan (1991), and Haftendorn, Keohane and Wallander (1999). In particular, Schroeder (1994), RisseKappen (1996), and Adler and Barnett (1998) have taken the constructivist approach to the study of institutions, alliances and security communities and emphasized the role of norms and collective identity.

Buzan (1993) and Hurrell (1993) approached constructivist ideas as part of the English school by stressing the existence of an international society which is driven by norms and identity. While there were, of course, extensive debates by other schools, e.g. German scholars like Kratochwil, who also contributed to the constructivist debate between instrumental rationalists and communicative rationalists, I do not think that these nuances are relevant to my analysis of the function of the CEI in democratic consolidation at this point, however.

Instead, this thesis examines the CEI in 2005 as a regional regime made up of the elements described in the international relations literature on international regimes. These include: 1. A shared purpose, which is in this case the achievement of regional stability through consolidated democracies, 2. shared norms, rules, procedures and institutions, 3. 
a hegemonic impetus in its establishment and 4. the hegemon is not predominantly involved in the continued maintenance of this regime. Or, as Ruggie, states:

insofar as international regimes embody principles about fact, causation, and rectitude, as well as political rights and obligations that are regarded as legitimate, they fall closer to the consumatory end of the spectrum, into the realm of political authority. Thus, the formation and transformation of international regimes may be said to represent a concrete manifestation of the internationalization of political authority (Ruggie cited in Krasner 1983, 196).

Additionally, constructivist versions of international regime theory conceptualize socio-political cooperation as ideational and normative: In this study I also draw on these approaches to analyze the activities of the CEI in Central Europe on the state level. Furthermore, I analyze CEI programs from a system level perspective, asking how has the normative element of CEI activities as explicitly designed to consolidate democracies AND develop regional cooperation, affect trans-national cooperation and institutions regionally in $\mathrm{CE}$. This synergistic approach, delineated in my analysis of the CEI"regime", differs from Waltz' model of the international system (1979). According to Waltz, "structural features are sharply distinguished from unit-level processes, and structure is the productive agency that operates at the level of the system. Accordingly, only structural change can produce systemic change. But as Ruggie has noted, in Waltz' model nothing produces structural change. According to Ruggie,

the problem with Waltz' posture is that, in any social system, structural change ultimately has no source other than unit-level processes, and these somehow must be linked to structure if it is to be capable not merely of recording change after the fact, but explaining and predicting it (Ruggie 1998, 153).

In this case study I view the CEI and its programs within the structure of an international regime since Ruggie's regime theory comes closest to explaining the efficacy of CEI 
programs in consolidating democracies in $\mathrm{CE}$ via the interaction of agency at the transnational/regional, the state and the local level of political and civic actors with the structure of institutions which are developed by the actors through CEI programs.

Kopecky echoed this approach in confirming that the synthesis of structural and agent approaches

must allow for forward [structures select agents and determine their choices], as well as backward linkages [choices and agents define institutions and rules which in turn alter or nullify structural determinants]. Comparative democratization theory should revise its strong assumptions about the state and nation as given units, as well as its assumptions about democratization as being primarily a domestic political process (Kopecky 2000, 528).

\section{Space and Boundaries}

"Europe as a space of political organization and institutionalization has no clear boundaries" (Risse 2004, 258). However, he refers to studies which have shown that "the more Europe is identified in civic rather than cultural-ethnic terms, ... and the more cultural diversity is emphasized, ... the less in-group [and the greater the European identification] projection might take place" (Risse 2004, 259/60). If this argument were to be extended to CEI member states, it would mean that ethnic conflicts would be minimized as civil society increasingly defines the domestic and regional cultural discourse.

Parallel to this development Risse (2004) suggests that the socio-psychological concept of "entitativity" which refers to the reification of a common fate, increased salience, and boundedness, will lead to collective identification and hence peaceful behavior among group members. This contrasts with political processes of exclusion which promote regional instability as e.g. Bosnia-Herzegovina and Kosovo have shown 
(these processes of "destabilization" had started before the CEI's programs were able to assist the integration of these countries politically and socially). In fact, I observe that some CEI programs detailed in Chapter Four: "Results and Discussion" focus specifically on regional civic development among its member states in order to "transcend" previous in-group projections, such as between the Slovenians and the Croats or the Czechs and the Slovakians, while simultaneously supporting those programs which increase CE "entitativity", such as the Central European University and the CEI Youth Orchestra among many others. These developments are especially significant in the region encompassing CEI member states as they augment the social and political stability sought by the founders of the CEI in light of the recent fragmentative history in this region.

Additionally, the CEI focuses substantially on the physical concept of "space" and "space development", such as those programs raising consciousness and those pertaining to the protection of the environment, e.g. through joint geo-spatial university courses as well as those projects which contribute to defining the new post-soviet political space of CEI member states in this region. Hence focusing on space and overcoming cultural boundaries among the people in $\mathrm{CE}$ is intended to deepen the sense of common fate and enhance collective identification in this region as a shared purpose (one of the criteria of an international regime), i.e. regional stability and peace.

\section{Institutions}

Herrmann and Brewer $(2004,1)$ emphasize the usefulness of international institutions as conflict managing strategies and as forums for pacific settlements. This basic neofunctionalist strategy promotes shared identities beyond an exclusionary 
commitment to the nation-state through cross-border functional cooperation so that eventually "communities of common identity" (Hermann and Brewer 2004, 2) would spill over into broader sectors of society, not only to reduce the possibility of war but to secure individual liberties and to provide normative patterns for the development of their civil society. Hermann and Brewer $(2004,2)$ note that institutions (such as the CEI) not only provide information and coordinate transnational programs but also contribute to the solution of issues (such as crime and public health) which exist especially in countries in political transition. They function to enhance the confidence of new democracies, and to compensate for the deficit in trust among some former enemies which would prevent cooperation today and in the future. The normative feature of an international regime such as the CEI is partially due to the shared rules of its programs which augment the confidence and trust of the young democracies in $\mathrm{CE}$.

V. Tilly $(2002,171)$ concurs that the formation of democratic states in post-Soviet CE involves not merely the government, but also the development of international institutions, i.e. that complex of rules and norms generated by interactions with international society to obtain an entity-like presence in international law and politics. Institutionalism has also been referred to as norm-oriented constructivism and has its roots in sociology. For Skocpol (1992) and Finnemore (1996) states' interests are in part "constructed through social interaction ...[and] shaped by internationally shared norms and values which structure and give meaning to international political life" (Finnemore 1996, 2-3). "Prominent norms - and changes in those norms - can alter states" interests and behavior [and] ... shift patterns of global relations (Burch 2002,66). This study shows how the programs and policies of the CEI re-structure political processes, beyond 
the notion of institutions constituting actors, but by integrating post-Soviet $\mathrm{CE}$ with a myriad of international and West European institutions to assist the democratic consolidation process. In this case the shared purpose of regional stability of the CEI as an international regime leads to the states' external environment reflecting inward to affect elite and nationalist thought about all aspects of socio-political significance, from the role of minorities, to economic and infrastructure development and scientific and cultural collaboration. This strongly favored institutional compatibility also imports certain behavioral and procedural standards into the civil design of post-communist $\mathrm{CE}$ states (Finnemore 1996), thereby enhancing civil society.

While Putnam (1993) argues would that it is lack of civic engagement which leads to lacking democracy, Tarrow (1996) also sides with the argument for the institutional significance in democratic consolidation by stating that

the pattern of state building effects indigenous civic capacity...State agency shapes public culture more than historical vagaries in $\mathrm{CE}$ today: if we define democracy as effective polity performance, we run the risk of falling into an elitist definition of democracy (Ibid., 245)... But if...we follow the classics and define it as popular sovereignty and individual rights, ... history gives us little reason to expect a strong association with institutional performance ... "The causes are structural: attacking the lack of social capital by encouraging association is attacking the symptoms not the causes of the problem (Ibid., 247).

I agree with Tarrow that without well developed democratic institutions (whether public and private), civic engagement will be compromised which in turn impedes democratic consolidation. This need for well structured democratic institutions is addressed by a number of CEI programs (which are detailed in the data section of Chapter Four) which foster broad institutional development on the national and transnational political, economic and social levels in $\mathrm{CE}$. 
Institutional reform in $\mathrm{CE}$ through $\mathrm{CEI}$ programs within international regime structure intersects with different contextual styles of politics to produce a synergistic effect between the shared purpose of CEI member states (i.e. the common good of "peace"/regional stability through democratic consolidation which can also be viewed as the impetus for the civic - and political - engagement of the member states along the thought process of Putnam) and the norms and values which are reflected in the institutional implementation of CEI programs. Hence cultural interpretation and public choice (in contrast to the Soviet era, when the public had little choice over the design of its public institutions) have a common ground in the programs within the international regime structure of the CEI. From this angle structuralists can approach the concept of social capital as structural as well as having a normative dimension.

\section{Identity and Ethnicities}

The disintegration of the Soviet Union, and with it that of Yugoslavia and Czechoslovakia, drew attention to the importance of state identity in the first place and (as discussed in the previous section on space and boundaries) it actively focused on the need for pan-national state identities in the region of the CEI (Herrman and Brewer 2004, vii) for the purpose of developing legitimate governance. The reason the concepts of identity and ethnicity are of particular significance in this region in that following the disintegration of the Soviet Union the concepts of space and place were not longer synonymous with national identity in many cases as discussed in the first chapter of this thesis. Furthermore, the political leaning "closer to Europe" following the disintegration of the Soviet Union brought a completely new identity into play in CE. As we will see in 
the data section, certain CEI programs specifically address concepts of space and place and some dealing specifically with identity, ethnicity - and their evolution and re-shaping in this transition from the former Soviet influence new and changing nation states and the expression of ethnicities and national vs. regional identities.

Katzenstein (1996) defines the formation of the national state identity in a foreign policy context. The formation of state identity can be stabilizing on alliances with other states, or the consolidation of an anti-hegemonic posture or of crafting its membership in a security community (defined as sharing some kind of deep commonality built on a concept of principles). In post-Soviet $\mathrm{CE}$, with some nations themselves dissolving, developing a new state identity, both in a regional security framework as well as within economic, cultural and scientific shared principles have been significant in stabilizing these new democracies as well as the security of those countries bordering them, especially to the West.

The literature on national identities is vast, but suffice it to say that identities can be nested in one another like Russian nesting dolls, cross-cutting with partial overlap of several identities, or they can be completely separate from one another, or they can partially blend (Wendt 1999). The CEI plays a significant role not only in the creation of national and transnational socio-political identities among its member states, but it also contributes to the formation of post-national identities with considerable security implications. If $\mathrm{CE}$ can extend its identity to a broader Europe, the CEI contributes to stabilizing Italy's and Austria's borders via its international regime structure and the regional identity developing through it. 
While the specific boundaries of "Europe" may not matter definitively in this discussion, the question of "what is Europe?" is one of "fuzzy boundaries" in Risse's (2004) terminology. Since Moldova and Belarus are also CEI member states, the "fuzzy boundaries" dilemma extends to this study. Europe is rife with examples of fuzzy boundaries. For example, while the Council of Europe includes Ukraine and Russia, the Organization for Security and Cooperation in Europe (OSCE) includes the United States and Canada as well. The EU might expand as far south-east as Turkey, but the European Monetary Union (EMU) encompasses only 12 EU member states, and the Schengen accord does not extend to the U.K., but includes Switzerland and Norway. In other words, "'Europe' as a space of political organization and institutionalization has no clear boundaries" (Risse 2004, 258).

The feeling of regional "boundedness" is more than just a feel-good goal of the CEI, but rather an utmost political aim: Risse (Ibid., 264) sees this as disconfirming C. Tilly's (1975 and 1985) idea that community building and nation building are inherently linked to war making. On the contrary, "if the EU defines what it means [in the sense of personal identity] to be European, the European integration process has left its marks on the deepest levels of state- and nationhood in Europe" (emphasis mine), (Ibid., 264). This confirms Habermas' (1994, 1996) "vision of a post-nationalist European identity and statehood" (Risse 2004, 264), where European-ness centers around a civic identity of liberal values such as human rights, democracy, a market economy and the welfare state (Ibid., 264). CEI program activities are designed towards accomplishing equivalent goals in member states: One of the CEI's purposes from inception has been to bring CE closer 
to Europe (a sentiment expressed numerous times during my interviews at the CEI in Trieste).

The phenomenon of transforming a group into an entity following the development of perceptions of common fate, proximity and boundedness is evident in the structure of the CEI as an international regime and the region of its member states. The significance of the transformation of CEI member states towards a collective self in the context of an international regime for socio-political purposes, such as regional stability, lies in the structure of its cooperative programs which encourage and enable this development.

Cooperation on the other hand can contribute to gains for both sides in cases where the parties did not formerly trust each other (as is the case in the prisoners dilemma) (Herrmann and Brewer 2004, 10). In this setting a "neutral" party, such as an IGO like the CEI, can provide information, verification, reassurance, increased efficiency, predictability and general confidence to take a transaction from an ideological goal to a realized construct (Ibid., 10). The trust which institutions are able to generate is notable in security dilemmas (historically a significant factor in CE) as well as in transactions lacking commercial efficiency, as can be the case in young democracies, inexperienced with open and competitive markets. Institutional strategies have been identified as promoting the construction of an overarching common identity among member states such as in the CEI (Ibid., 11). In the case of the CEI its rules and norms have become part of the social and power structure which define the member states' socio-political environment and are co-constitutive of each other (Ibid., 13).

The significance of identity in $\mathrm{CE}$ is a) that some of the democratic values of the hegemons (Austria and Italy) are being assimilated by the other member states, and b) a 
shared regional identity ("Central- and South-Eastern European") leads to increased cooperation and trust, positively influencing increased regional stability. Several CEI programs distinctly stress the construction of a "post-national civic identity" in the Habermasian sense (Habermas 1994, 1996), emphasizing democracy, human rights, a market economy, the welfare state and cultural diversity (Risse 2004, 256). Just as these values have become constitutive for the EU, they also appear to have become constitutive for CEI member states since CEI by-laws are obligatory for its members.

The cultural identity of (West-) Europeans is linked to their region as a whole, while their civic identity is attached to the EU (Ibid., 257). This concept of an EU culturalversus civic identity is similar in Central- and South-Eastern Europe, not only because some countries there have become EU members, while others actively aspire to do so, but also due to the normative influence of CEI programs and rules, many of which are modeled after the EU. In this context the CEI has created an atmosphere of mutual understanding, where large national projects and international programs can be discussed, planned, studied, financed and implemented. This strategy is aimed at contributing to a more cooperative, safe and stable Europe overall by re-integrating Central- and South Eastern Europe with Western Europe, as had been the case historically during different periods. The CEI is hence a model of national self-determination of sovereign peoples united into a community of shared rules, norms, principles and purpose.

The social-institutional adaptation of a group (e.g. a minority) or an entire political system to changing international conditions, including a Eurocentric adaptation, may be considered a cultural loss. However, cultural fluidity, i.e. change, is often required of groups and nation states following historical events which sever previous 
structures (V. Tilly 2002). Nevertheless, V. Tilly (Ibid.) points out that ethnic identities are not entirely malleable by the "ethno-architect". There is a limit to their fluidity since

they are attached to a myriad of social experiences, collective memories, and [their own] norms, which carry their own logics and inertia. Political claims may also embed in popular consciousness, shaping social perceptions of ethnic identities [and altering political behavior] (Ibid., 161),

i.e. deriving from deeper cultural traits or meaning systems. Hence recognizing in CE the shared, as well as the divergent, history between countries and the limits this might place on any plans for "instant democratization" is significant - and realistic. This would position "ethnicity" in the primordial Geertzian sense (vs. the instrumentalist approach which treats ethnicity as a social, political and cultural resource for different interest groups). In practice, the state template (in the case of $\mathrm{CE}$ as influenced by the synergistic effect of CEI programs) translates these international norms into standards which modify state elite perceptions and values concerning ethnic diversity and possibly even the social construction of ethnic identities itself (Ibid., 165). V. Tilly views this as "the cognitive terrain of nation building" (Ibid., 166) since part of a state's legitimacy rests on manifesting a unified nation willing to live under one government. This is not simply a theoretical concept but of great significance in $\mathrm{CE}$ as the disintegration of the Soviet Union led to disintegration of several $\mathrm{CE}$ countries due to ethnic conflicts based on longstanding cultural and religious differences discussed in Chapter One. Having respect for and integrating e.g. ethnic minorities is spelled out in the November 1994 "CEI Instrument for the Protection of Minority Rights" and is additionally an explicit component of several CEI programs and international agreements. This serves as one of the powerful norming influence in the formation of state templates regarding the 
treatment of ethnic minorities (an unresolved issue pre-1980s) in CEI member countries since the CEI advocates integrative, rather than fragmentative, identity politics.

There are two models to explain identity change due to institutional activity (e.g. an IGO in the form of an international regime, such as the CEI): The constructivist socialization model assumes that institutions by their existence create changes in the political environment which eventually alter the members' perceptions of community, interdependence, and trust (Herrmann and Brewer 2004, 14). Through this process identities/interests and institutions become endogenized over time and part of the social and power structure which "forms the social environment in which people act" (Risse 2004, 263). This is not a uniform effect and "socialization models allow for different degrees of experience with institutions among people in the same population, with corresponding differences in depth and level of identification with those institutions" (Hermann and Brewer 2004, 14). This may involve developing a dual identity, one representative of the "native" culture, the other reflective of the values of the newly introduced institution (Risse 2004,263 ), i.e. the values of the CEI promoting democracy, human rights, a market economy, the welfare state and cultural diversity.

The second, rationalist model, of identity change considers institutions themselves as active agents of change through the direct role which institutions play in creating and engaging corresponding social identities (Hermann and Brewer 2004, 15). This may be "a potentially valuable resource that can be drawn on to achieve legitimization, engage group loyalties, and energize collective effort" (Ibid.). Risse (2004, 261) does not consider this "rationalist" model as significant in the formation of European identity as the socialization model. 
Since my study focuses on the different social, political and cultural levels affected by the CEI in their member states, particularly for the purpose of democratization and regional stability, a liberal intergovernmentalist model applies in my opinion to certain aspects of the CEI and its programs. According to this model, "preferences are aggregated by national governments, which then negotiate binding agreements and institutions to insure credible commitments" (Ibid., 263). For the process of democratic consolidation, this is one of the most significant mechanisms of an IGO, such as the CEI, whose purpose is peaceful regional integration leading to democratic consolidation. It does not account, however, for all the other mechanisms also involved in the international regime structure of the $\mathrm{CEI}$ and its programs to achieve regional stabilization and democratic consolidation.

Regardless of whether one views the "group socialization" effect of CEI programs on officials and ordinary citizens in member countries as a result of the socialization- or the persuasion model (or a combination of the two), the CEI probably has a significant effect on the identity formation of the post-Soviet populations in $\mathrm{CE}$ in terms of conveying behavior, norms, and institutional rules conducive to the development of a free and lively civil society, a relatively autonomous and valued political society, rule of law to ensure legal guarantees for citizens' freedoms and independent associational life, a state bureaucracy that is usable by the new democratic government and an institutionalized economic society. 
Agent - Structure: Norms, Internalization and Learning

Wendt (1999) proposes three different theoretical paths in analyzing how norms matter through the degree to which they are internalized: Norms can be internalized to produce the same structure through "force", "price", and "legitimacy". According to Wendt, "it is only with the third degree of internalization that actors are really 'constructed' by culture, while the prior degrees of norm internalization simply represent culture affecting the actors' behavior or beliefs about their environment" (Wendt 1999, 250). An empirical question would be to determine the degree of internalization in order to show the degree to which the actors (states and their civilian representatives) are constructed through the culture of the CEI international regime. In this case study I am surmising that the norms and values which are made available to CEI member states both on the governmental as well as the civic values level are internalized by the actors on the legitimacy level, as they joined the CEI voluntarily. The availability of various project funds did likely encouraged this acquiescence however. It is important to contrast "force" as a criterion which was frequently applied in the Soviet Union to achieve compliance with the CEI's norms, rules and purpose within the international regime structure.

Cultural selection can take place through imitation, whereby standards are constituted by shared understandings but vary in the cultural and social learning context (i.e. the interaction of CEI member states in a cooperative and economically supportive environment) rather than e.g. leaving CE EU-applicant states to their own devices in figuring out the acquis communautaire (e.g. the "democracy" requirement) in preparation for their EU membership. Constructivist approaches highlight the possibility that learning may also have a constructive effect on identities and interests (Ibid., 327): identities and 
their corresponding interests are learned and then reinforced in response to how actors are treated by significant others (Ibid., 328). This is also known as "mirroring" because actors come to see themselves as a reflection of how they think Others see or "appraise" them, such as being treated as an enemy because "Other" views oneself as such. This phenomenon is essential in CE since CEI programs facilitate social learning among its member states through joint programs in an environment which generates trust.

Rationalists usually assume that learning and perspective-taking do not change actors or what they want, but only their ability to achieve their wants in a given social context (Wendt 1999, 333). In contrast, interactionists (constructivists) assume that learning may also change identities and interests. Finnemore (1996) has shown how individual agency led to the establishment of certain institutions which then in turn asserted their norms on individual state preference. Wendt (Ibid.) takes this argument further by pointing out that constructivism treats identities and interests as endogenous to interaction; they are thus dependent variables. This is exactly the effect of CEI programs on CE regional stability and democratic consolidation I hope to demonstrate: as the states (actors) become increasingly integrated in the international regime structure of the CEI, not only do their preferences change, e.g. by aligning their domestic policies with CEI program opportunities, but their civic and political goals change to a preference for cooperation rather than mistrust and hostilities. In fact, the development of a collective identity ("CEI member states") leads to a structural change of seeing the neighbor not through the lens of ancient animosities, but as a potentially trustworthy economic, scientific and cultural partner for tomorrow in a Kantian sense, making cooperation rather than military actions possible in $\mathrm{CE}$. 
In terms of agent-structure language, Cerny (1990) also points out that structure is both enabling and constraining and has constitutive effects. In the data section of this thesis in Chapter Four I will show how the CEI in CE offers through its programs access e.g. to institutional, political and social structures which support in this region democratic consolidation and regional cooperation as well as discourage disintegrative socio-political practices, a process which would become internalized by CEI member countries. Historical institutionalism has developed the agent-structure and co-constitution paradigms extensively, largely within sociological institutionalist approaches (Hay and Wincott 1998). The efficacy of ideational factors such as culture, norms and ideas and social efficacy are more significant than simply their functional utility however (Ruggie 1998, 33). In other words, "'norms count' because they constitute actors' identities and interests, which should be considered endogenous and socially constructed rather than exogenous and given" (Ibid., 16). In Onuf's (1989) words, rules are central to the process of social construction. In this paper I argue that norms are co-constitutive, i.e. they coconstitute actors and structures; collectivities having both causal, constraining effects (Lapid and Kratochwil 1996) in the structure of the CEI as an international regime. This study shows how social rules are a medium of social construction in CEI member countries transitioning from Soviet authoritarianism to democracy. The prior institutional forms of collective action were being demolished and reconstructed in a fashion strongly influenced by the new, prevailing forms of transnational societal self-identification in a historical transformation of the past regional (Soviet) system (Hall 2002, 122).

Constructivists also seek to explain the constitution of actors' identities and interest as a prelude to understanding their rational choices (Burch 2002, 62), i.e. the 
processes and the co-constitution of political actors and structures. Co-constitution of conditions (i.e. ideas and material conditions), according to Burch (Ibid., 25) involves three aspects: agent rationality, structure, and culture as a source of meaning. The norm of rationality often "becomes the accepted and legitimate form" (Ibid.) in organizations, a state, or in an IGO like the CEI with its guidelines and rules of procedure. According to Onuf (1989, 54-58), a comprehensive constructivist approach recognizes the coconstitution of conditions (ideas and material conditions) of society (agents and structures) and of subjective meaning among individuals and groups (emphasis mine). In other words, social structures constitute actors' identities, interests, or capabilities, just as actors' choices constitute patterned social structures, while rules are significant because they link the material and ideational aspects of social structures (Burch 2002, 69).

Constructivist "research highlights three fundamental questions: What is the source of the interests and identities of individual actors? Are prevailing structures material [in every sense, such as the most basic one of 'who provides funds': the EBRD or a Soviet institution] or also social? What are the processes through which agents construct structures and structures constitute agents" (emphasis mine) (Ibid., 62). In the case of the CEI the international regime structure represents a synergistic source of material and social structure (through its norms and shared purpose underlying its programs as well as funding options) which constitute the agents, as well as being constituted by the subjective (national, cultural) meaning CEI member states attach to them..

In fact, "Onuf's constructivism acknowledges that there are multiple sources of rules and norms constructing the world's social structure" (Kubalkova 1998, 197): Local identity and culture are both significant influences on the interpretation and creation of 
rules by agents, since norms and rules reflect national, ethnic, religious, and other identities which bear on the social processes in - or between - particular cultures (Kubalkova 1991, 197). Wendt $(1999,338)$ points out that a change in the structure of any internalized culture that is associated with a collective identity, involves also the breakdown of an old identity and the emergence of a new one. This would mean that in the case of CE the internalized old, authoritarian culture needs to be broken down and be replaced with democratic values.

The difference between CEI programs within an international regime and the usual interactions among participants of an IGO is that the latter are often the result of "Realpolitik", treating the Other in self-interested terms, "casting them as if they were nothing but objects" (Ibid., 341), while the CEI provides a mutually co-constitutive forum for the creation of new state identities, which are regionally linked. Wendt (Ibid.) defines this type of representational practice as "pro-social", which involves treating others as if one not only respected their individual security concerns but also "cared" for the individual, a willingness to help them even when this serves no narrowly selfinterested purpose, casting the Other as a friend rather than assuming an adversarial stance. To observe this in post-Soviet CE would mean to observe regional cooperation and stability rather than continued regional political and social fragmentation.

I propose that the model of international regime theory can be applied to the programs utilized by the $\mathrm{CEI}$ as contributing to regional stabilization and democratic consolidation in $\mathrm{CE}$, whereby Central European regional stabilization and democratic "consolidation" are dependent variables of the CEI's international regime structure and programs administered within this framework in a co-constitutive process. 
This study, by focusing on "international regime" building, does not approach democratization in terms of "nation building", e.g. factors of nationalism and ethnicity which Rustow (1970), and to a certain extent Weber (1949), have alluded to except as they relate to democratic values and other shared norms of the CEI. As Muller and Seligson (1994) warned: "causal models of the relationship between civic culture attitudes and democracy should be formulated to take into account the possibility of reciprocal causation between these variables" (Ibid., 635). In the context of the CEI this means that norms and institutions were not simply "handed down" (in the sense of "imposed on") to member states. Rather, the international regime was co-constituted also via a "bottom up" dynamic by the civil and local political actors in contributing to the continuous design and refinement of programs and socio-political approaches nationally and transnationally in CE. This thesis does not focus on the mechanisms of transition between phases that Huntington (1991) has exhaustively described. Rather, this study focuses explicitly on mechanism contributing to the consolidation of young democracies via regional stabilization within an international regime, keeping in mind the favorable context in which this third wave of democratization in $\mathrm{CE}$ has been taking place (Kopecky 2000, 531). This has involved a shift from previous coercive approaches to those requiring 'conditionality' (Whitehead 1996 in: Keystone 2000, 531).

While the literature is extensive on the elements necessary for democratic consolidation and regional stability, no analysis exists to my knowledge which identifies the pathways an IGO could specifically follow to achieve consolidated democracies for the purpose of regional security. 


\section{Chapter Three}

\section{Methodology}

The focus of this thesis is democratic consolidation, which Huntington identified as the third stage in democratic transition from an authoritarian regime and which must be achieved for a democracy to be stabilized. I hypothesize that the CEI assists through the unique structure of its programs in the regional stability and the consolidation of democracy in member countries ("CE"). It does so in two ways, as identified in the literature review. First, it seeks to achieve the internal parameters of a consolidated democracy, which can be summarized, following Linz and Stepan $(1996,7)$ as involving the following five areas:

First, the conditions must exist for the development of a free and lively civil society. Second, there must be a relatively autonomous and valued political society. Third, there must be a rule of law to ensure legal guarantees for citizens' freedoms and independent associational life. Fourth, there must be a state bureaucracy that is usable by the new democratic government. Fifth, there must be an institutionalized economic society (emphasis mine).

Additionally, the CEI programs utilize international mechanisms to contribute to the stabilization of new democracies in $\mathrm{CE}$, i.e. they involve member states in an international regime that values democracy and cooperation, and that constructs "entitativity", namely regional identities that transcend the nation. The co-constitutive mechanisms that produce these outcomes involve socialization and imitation, but also rational calculation. 
This is an individual crucial case study designed to test the theory whether democratic consolidation of a country can be facilitated by its international environment, specifically by becoming part of an international regime and its programs, whose specific purpose is regional stability. A single crucial case study such as this one of course is not designed to quantitatively support the pathways to democratic consolidation and regional stability through a delineation of CEI programs. However, it uniquely enabled me to explore some of the tools used, the mechanism activated, and the outcomes made possible.

\section{Data Collection Methods}

This case study utilized primary and secondary data in order to answer the research question, of what CEI programs, and how, they augment criteria of democratic consolidation as outlined in the literature and hereby contribute to regional stability.

The first stage of data collection involved an archival review of CEI activity- and project reports as well as the by-laws of the organization since its inception in 1989. These data were in part handed to me as documents by CEI officers at their offices in Trieste/Italy. Others are available on the websites of the CEI, the European Bank for Reconstruction and Development, and related organizations. I describe the path of the CEI and its establishment as an IGO within the framework of an international regime from the moment of inception in November 1989 through an Italian seed grant (as Italy had great immediacy to this project both in terms of external security and great familiarity in dealing with instability in $\mathrm{CE}$ during previous centuries ) throughout the following period of the disintegration of the Soviet Union and subsequent 
democratization of Central European countries until today. By analyzing official CEI documents, I examined democratic and civic culture norm transplantation, civil society learning and regional economic and political cooperation as part of CEI programs. I take successful norm transplantation (e.g. cooperation), defined as functioning democratic civil and political institutions, as an indication that the CEI as an international regime contributed to the stabilization of democratic institutions and values. I collected information in particular about programs which contribute a) to the establishment of civil society by promoting civic values (e.g. environmental projects or those enabling election participation) or b) to the establishment of political society (e.g. the annual CEI meeting of the heads of member states) or c) those projects which focus on cooperation (e.g. joint civil infrastructure projects between formerly adversary countries in $\mathrm{CE}$, such as the Central European youth orchestra or the Central European University) and d) those promoting other criteria identified in the literature as indicative of successful democracies, such as recognition of minority rights and a free market economy.

The second stage of data collection consisted of a field study of the CEI in Trieste, Italy, to substantiate my archival findings. The field study portion consisted of data-collection via semi-structured elite interviews of CEI officers at their headquarters in Trieste/Italy. These interviews were conducted with semi-open-ended descriptive and inferential questions to allow these officers to expand the discussion to topics with which I was not familiar before the interview. The interview guide is attached in appendix 1 , as is approval by the Institutional Review Board. 


\section{Data Analysis Methods}

My data analysis involved searching for social and normative patterns in the activities of the CEI which contribute to democratic consolidation. In addition, I probed those programs which bind the countries peacefully in this region in such a way as to reduce the likelihood of armed conflict, such as through socialization, imitation and rational choice. I suggest that the active involvement of the presidents of each country, the ministers of the particular area in which a project is being discussed, as well as the civilian representatives responsible for developing and implementing a particular project promotes democratic stabilization at different levels within the CEI regime (i.e. the transnational-, the national- and the local official- and civil representative level).

The theory underlying this study is that the programs of the CEI work in a dovetail manner to reinforce democratic processes in its member states. This happens not least due to the international regime structure of the CEI which necessitates peaceful cooperation per the rules (by-laws) and norms of the institution. Cooperation is defined in this study as conflict resolution without engaging in armed warfare. As mentioned in the literature review above, the rational actor model is applicable in this context as "peace" is a public good calling for cooperation of the concerned parties (i.e. CE) to maintain it.

If my hypothesis is confirmed, I expect to find that the unique structure of CEI programs is effective in contributing to characteristics other authors have delineated as essential to a democracy per se as well as to democratic consolidation, and we should find that none of the CEI member countries have reverted to authoritarian rule. 


\section{Limitations and Biases}

Since the CEI is a unique IGO in terms of the purpose for its creation and the extent of its programs, these programs cannot be compared directly to other IGOs, hence affecting the reliability of my interpretation of international regimes promoting democratic consolidation and regional stability. Furthermore, to my knowledge an IGO has never been studied within the frame work of a regional international regime for the purpose of contributing to democratic consolidation post-authoritarianism in a region. The validity of this case study is limited because I cannot compare my findings to another, similar case. Furthermore, even though the activities undertaken by the CEI appear to have a positive correlation (though of unproven causality) with the theoretical parameters of democratic consolidation and the actual stabilization of Central European democracies, they may not apply to other geographical regions striving for democratic consolidation. Causality itself is not established in this study.

Positioning CEI programs within international regime theory appeared to me as the most consistent with established international relations theory. However, another researcher, studying the same case, may prefer to develop the concept of democratic consolidation more specifically along other theoretical models, e.g. along theories about epistemic communities only, or in terms of cooperation in securities models. The findings could be subject to other interpretations, mostly with respect to the effect of intervening variables such as the democracy-supportive efforts by NGOs in CE and by isolating the normative effect itself of the prospect of future EU membership (as this effect constitutes a component of CEI modi operandi in certain programs). 
This study was confined to interviewing current CEI officers - and no past officers - and to publications made available by these officers as well as those on the CEI- and related websites. Also, I have not examined every single CEI document available which could lead to a different interpretation of the data - hence a potentially significant bias in the study. Nevertheless, since I detected consistency within the great abundance of data available to me, it is doubtful that any further data would present a completely different picture of the CEI.

No formal fieldwork was conducted in other CEI member countries. This might, however, also present a completely different angle of CEI programs as opposed to that presented at CEI headquarters in Trieste. 


\section{Chapter Four}

\section{Results and Discussion}

\section{CEI History and Objectives}

The Central European Initiative is an IGO which was established 1989 with a two million Euro seed grant from the Italian foreign ministry to further the political, economic and cultural cooperation of its member states in order to enhance regional stability in CE. It is the oldest and largest of sub-regional cooperation initiatives which emerged in Central and Eastern Europe after the collapse of the communist system. At that time its main aim was to assist its member states in the transition from post-soviet authoritarian governments "to come closer to the EU" (a phrase heard repeatedly during my field interviews to express the CEI's aim of coordination and cooperation among its member states as well as to integrate socio-economic and political processes in CE with Western Europe). There is no democracy requirement for member states (in contrast to the EU). Rather, in the beginning there was simply the desire on the part of the CEI to bring about socio-political and economic coordination and cooperation in $\mathrm{CE}$, based on democratic principles among its members for the purpose of regional stabilization. If this succeeded and indeed brought member states "closer to Europe" as a result of CEI programs, it would also be an indication of democratic consolidation, since a stable democracy is a membership criterion for the EU, and EU membership was in fact attained by some CEI member states.

With its latest enlargements the CEI re-focused its priorities on countries in special need such as Belarus and Ukraine. No longer belonging to the USSR and unable to meet 
membership criteria for the EU, these countries were unable to establish another bilateral institutional relationship at the time of joining the CEI. The CEI recognized this as a potentially regionally destabilizing socio-political influence and, although Belarus is geographically located outside Central- and Eastern Europe, the CEI agreed to engage this country in the process of democratic dialogue development and for it to also observe approaches to democratic cooperation. The ability to participate, especially in a nonthreatening, accessible institutional democratic setting may contribute to the development of civic attitudes according to Rustow (1979).

However, it is important to note that the CEI recognized the significance of not only engaging $\mathrm{CE}$ simply in dialogue, but it also recognized the need for these newly independent states to acquire the tools necessary for democratization. As was discussed in the literature review, not only are the establishment of democratic institutions important for the successful functioning of a democracy, but the political culture of democratic discourse needs to be cultivated in countries transitioning from authoritarian rule, as is the establishment of civic values and the development of civil society, supportive of a successful market economy.

Hence, although there is a focus to assist member countries in their EU applicant proceedings, the initial focus of the CEI was on the economic and political stabilization of this region for the purpose of maintaining peace along the Eastern border of Austria and Italy through the prevention of new dividing lines not only politically but also economically across Europe between the more and the less advanced countries. It is important to note that with the latest expansions, now including besides Moldova, Ukraine and Belarus also five South Eastern European countries (Albania, Bosnia and 
Herzegovina, Croatia, Macedonia and Slovenia), the CEI has shifted its focus on the strategic goal of pan-European integration. This means that the traditional goals of promoting member states' participation in the European integration process, comprehensive cooperation between member states, and the promotion of transitional processes in member states have been expanded to also fostering "the capabilities of the least developed member states as well as of those that urgently need accelerated economic development or economic reconstruction" (Website of the Slovenian foreign ministry, accessed 1/19/2006). This includes facilitating and co-financing transfer of know-how and developing negotiating experience for new member countries. The strategic goal of the CEI is pan-European integration by working to prevent the emergence or even deepening of new divisions in Europe, regardless of whether they be caused by the EU or NATO enlargement strategies or by differences in economic standards and development (Website of the Slovenian foreign ministry, accessed 1/19/2006).

The CEI today represents an integrated framework of dialogue, coordination and cooperation among its member countries in the political, economic, cultural and parliamentary fields, creating an atmosphere of mutual understanding in which national projects and transnational programs are being discussed, planned, studied and implemented (OECD website 2/4/06). The heads of state and foreign ministers meet once a year, usually in November. The rotating presidency is assisted by the CEI Executive Secretariat in Trieste. The presidency of the CEI rotates annually at the beginning of the calendar year based on the alphabetical order of the English names of CEI Member States, unless decided otherwise (see Appendix 3: CEI Guidelines and Rules of 
Procedure). These mechanisms, detailed more below, contribute to democracy as a system of governance in which politicians are held accountable to the public for their actions by their constituency (Schumpeter 1943, cited by Schmitter and Karl 1991, 76) in contrast to the absence of this possibility under authoritarian rule. These are also political patterns observed both in the UN (with whom the CEI cooperates closely) and the EU, indicating the normative influence not only of Western Europe but in fact of global institutions for cooperation.

The CEI language is (neutral) English and translations have to be borne by the party requiring them. Decisions in the $\mathrm{CEI}$ are taken as a rule by member consensus. Another indication of shared norms and common identification among CEI member states is the CEI flag. It is not by coincidence similar to the EU flag in colors and design in order to reflect the geographic identity and the socio-political integrative aspects of CEI member states with the EU (see figure 2).

\section{CE⿷匚⿳丨コ丨 CEITRAL ELROPEAII IITIATIIE}

Figure 2: CEI Flag

Source: CEI website, www.CEINET.org

The CEI's legal status is that of an intergovernmental organization, responsible for the administrative and conceptual support in the preparation and follow-up of democratically agreed upon programs and activities. It maintains a permanent office at 
the European Bank for Reconstruction and Development (EBRD) in London to assist the Executive Office in Trieste with economic, strategic, and investment projects (detailed later in this chapter), as well as with certain international events, such as the CEI Summit Economic Forum.

CEI Organizational Structure (Norms and By-laws)/CEI Levels of Involvement in Member States

CEI principles, objectives, membership and participation, organization and structure are defined in the "Guidelines and Rules of Procedure" (see Appendix 3) and are compulsory for all members. Non-compliance can result in the expulsion of a member state from the organization. This indicates the strong normative quality of democratic CEI principles.

The CEI has established an integrated framework of dialogue, co-ordination and consensual operation among its member countries in the political, economic, cultural and parliamentary fields in an atmosphere of mutual understanding in which national projects and transnational programs are discussed, planned, studied and implemented (EastAgri website, accessed 2/4/06). Civil society is hence not simply a descriptive category, but also a normative one within the CEI. The CEI is organized as an intergovernmental cooperation forum, which is not institutionalized in terms of specific goals, but instead attempts to be as flexible as possible in order to accommodate the unique historic-cultural dynamics and infra-structural realities of member countries in their process of democratic consolidation, in large part within the frame work of the CEI and its programs in which member states participate. This approach allows an "organic" development of the 
normative structures "bottom up" in member countries in addition to the "top down" effect of CEI norms, as shown in the programs I delineate in the rest of this chapter.

The CEI's general modus operandi is to build relationships and to strengthen communication between member countries. Their programs substitute partially for the role which Comecon previously played in CE. CEI programs also provide mechanisms for its member countries transiting from centrally controlled economies to participate in free market forums and training programs pertaining to free market operations. These help create epistemic communities, i.e. "networks of professionals [as reflected in the listing of Working Groups (WGs) below] with recognized expertise and competence in a particular domain and an authoritative claim to policy-relevant knowledge within that domain or issue area" (Ruggie 1998, 83). They contribute to shaping the pattern of politics from an institutionalizational grid of the state and the post-Soviet international political order through which behavior is acted out, or those through which regional and international political relationships are visualized as P. Haas $(1992,26)$ has described. This implies that the international structure of the CEI as an international regime represents a key dimension for transformation through the programs detailed below, by providing the basis on which the constitutive units (member countries and/or their programs) assume their identity as constitutive units and that basis on which the constitutive units are differentiated from one another (Ruggie 1998, 132). This allows for national individualization based on the democratic voices in different countries.

The details of the CEI's three-pillar organization are as follows: (Note that some criteria of the CEI structure are normed by those of the EU's European Council, European Commission, and European Parliament). 
The Governmental Dimension as the first pillar is composed of representatives (experts from various ministries and other governmental as well as non-governmental institutions) from all member states and lays the groundwork for good governance ${ }^{18}$ and multilaterality within $\mathrm{CE}$.

They develop activities within the framework of the eighteen WGs detailed later in this chapter. The governmental dimension includes:

The annual Meeting of the Heads of State of each member country ("CEI Summit" with its annually rotating CEI Presidency) whereby consensus is obtained from the highest level of government from each member country for various political, economic and social programs. There are also:

Annual Ministerial Meetings e.g. of the Ministers of Foreign Affairs and of the ministers of different economic sectors (such as transport, tourism, energy), in order to delineate the proper authority for implementing trans-border projects (e.g. the development of new train routes, the re-connection of those interrupted during the 1990's Balkan crisis, joint marketing of tourist destinations (such as "Balkan vacations"), or energy security (including open joint discussions about nuclear alternatives). While these topics may appear as inconsequential, one must keep in mind that the disintegration of the Soviet Union and with it that of several countries, such as Czechoslovakia and Yugoslavia, century-old animosities surfaced. This lead to the well-known military confrontations and destruction of infrastructure in some countries before their CEI membership. The result was a partial inability of some CEI member states to relate to each other politically and economically at times. The definitive structure of CEI by-laws, combined with the soft-power approach in guiding member state governments through 
politically charged times, provided the normative structure to lead members towards trans-national cooperation and to establish the socio-economic institutions which would facilitate democratic consolidation.

The Parliamentary Dimension (see Appendix 4) is the second pillar of the CEI. Parliamentarians are also regular participants at all high-level CEI meetings. They are involved in work group (WG) activities and develop their own ad hoc committees.

Parallel to the CEI Summit Meeting is the CEI Economic Forum which utilizes the presence of the heads of state in extending legitimacy to economic programs developed by CEI member countries to improve various aspects of the transition to a free market economy and to support each country's economic viability (which is one of the criteria identified as essential for successful democratic consolidation).

Sub- ministerial and sectoral events, monthly meetings of the committee of National Coordinators, and meetings and other activities of CEI Working Groups covering areas such as economics, human and institutional development, co-financing, plus conferences, workshops, and training courses as outlined in the "CEI Document on Working Procedures of the Parliamentary Dimension" (Appendix 4) not only increase transnational cooperation within the $\mathrm{CE}$ region among $\mathrm{CEI}$ member states at the civil society and local political levels, but contribute to the development of civic and democratic values, by requiring delegates to debate and vote on program proposals in a wide variety of sectors, as well as teaching them the institutional steps required for materializing their projects (e.g. utilizing CEI funds to undertake feasibility studies which are then submitted to the EU Commission or the EBRD for project funding). 
The CEI Working Procedures of the Parliamentary Dimension also explicitly emphasize multilateral cooperation, complemented by bilateral relations, the establishment and deepening of partnership structures based on principles of parliamentary democracy and of guaranteeing human rights, creative collaboration to facilitate reform processes and transition in Central and Eastern Europe, and to improve the European environment in member States ("CEI Document on Working Procedures of the Parliamentary Dimension". Appendix 4), such as respect for international law and humanity, justice and democracy (values also embraced by the UN which show that the CEI is not simply a mechanism of Western European expansionism).

The Business Dimension is the third pillar of the organization and acts as a regional forum for cooperation and consultation among the chambers of commerce in all CEI member states. This level reaches down to the local level of democratic institutions, and to constructing civic values and civil society, supported by a healthy economy.

The Summit Economic Forums, held annually following the CEI Summit of the Heads of Government, are a gathering of government officials, industry leaders, private industry executives, entrepreneurs, investors, financial institutions, international organizations, promotion agencies, representatives of local authorities, bankers, fund managers, and service providers, both within and beyond the CEI region, to search for tangible opportunities for investment and growth in $\mathrm{CE}$ and to identify solutions to institutional bottlenecks due to inadequately developed free market institutions and capabilities, to examine investment opportunities, to establish trade partnerships and cooperation agreements. The Summit Economic Forums function as a market for goods 
and services, to present project ideas and to find business partners (CEI Wholesale Markets Foundation News website, accessed November 29, 2005).

As mentioned previously, CEI projects and activities often complement and expand the programs of other European and international organizations (such as the EU, the Stability Pact for South Eastern Europe, the UN Economic Commission in Geneva, and UN specialized agencies and international financial institutions, such as the EBRD) and those concerning Central and Eastern European countries in particular (Appendix 5) in order to facilitate the integration of responsible CE democratic governments into global institutions. This also corresponds to the aim for multilateral alliances which were envisioned (Ruggie 1998, 197) in the international political arena following the disintegration of the Soviet Union to prevent new bifurcations in this region.

\section{Funding}

In addition to the seed grant by the Italian government in 1989, the CEI maintains four types of funds/funding activities (see appendix 5 for samples of projects and funding):

The CEI Cooperation Fund was established in 2002 and is based on annual contributions from member states. It co-finances activities in the various workgroup areas, provided that at least fifty percent of the resources are available from another donor. This encourages CEI member states to develop further multilateral institutional links to other organizations in order to procure the additional fifty percent financing. Since its inception in 2002 the CEI Cooperation Fund has supported more than eighty cooperation activities in member countries with a total contribution amounting to 1.5 
million Euro, or about sixteen percent of the total value of these projects (CEI website, accessed January 6, 2006).

This Cooperation Fund is additionally a good example of cooperation theory applied in practice: Those early CEI member states, which benefited greatly from the assistance of the more affluent founding members and the international resources they were able to summon for their own economic, human, technical and administrative development (contributing to their successful EU membership) are now expected by the CEI to assist their less advanced neighbors and newer CEI member states. This will start another cycle of regional "cooperation", envisioned to perpetuate regional stability in an area which has been historically less than stable and cooperative transnationally. This also counteracts the development of new dividing lines between the richer and the poorer member states which could become a source for new regional unrest. This approach also augments the establishment of a cohesive regional identity based on interdependence and identification with neighboring states to overcome the divisiveness of the past.

The fund - as all other CEI programs - also "showcases" the democratic evolution of its member states: embedded in the Cooperation Fund is the CEI Evaluation Unit, comprised of representatives from all member states, which oversees the distribution of funds assigned to the various activity areas and promotes a balanced allocation of funds among CEI member states and activities. This represents not only a democratic process in financial allocations and transparency, but also transnational (regional) cooperation and, most importantly accountability, including the freedom and duty to speak out, and be heard, in case of a suspected discrepancy: some of the most important building blocks of a consolidated democracy. 
The CEI Solidarity Fund, established in 1998, is based on voluntary contributions from member states and is managed by the CEI Executive Secretariat. It facilitates participation of representatives and experts from member states in special need (e.g. Albania, Belarus, Bosnia and Herzegovina, Macedonia, Moldova, Montenegro, Romania, Serbia, and Ukraine) at CEI events by reimbursing their travel and accommodation expenses. This program is significant, not for the actual amount of moneys involved, but to contribute to the legitimacy of CEI programs and structures: rather than member states simply using the CEI financially and politically to advance their internal development, member states contribute within their means to the continuation of the (cooperative) programs which they have set up among old and newer member states. This proactively integrates new members in this regional cooperative international regime which the CEI represents, both at the governmental and the civic level by incorporating the democratic and multilateral procedures, rules, and norms internally as well as in foreign relations and economic practices.

The third Modality of Funding is the CEI Funding Unit. With the impending EU membership (at the time of establishing this fund) of several CEI member countries (Slovenia, Hungary, Slovakia, Czech Republic, Poland) and three EU candidate countries (Bulgaria, Romania, Croatia), as well as five Western Balkan countries (Bosnia Herzegovina, Serbia and Montenegro, Albania and Macedonia) and three NIS countries (Moldova, Ukraine, Belarus) the CEI created this "Match-Making"-unit (in their terminology) in 2004 to attract EU regional funding (accession funds etc.) for certain CEI projects, for which some member countries were now eligible, hereby linking EU funds with CEI project funding (Appendix 6). 
Additionally, this unit seeks other outside funding for CEI projects and promotes the participation of CEI countries in trans-national projects at the European (including private) level (not necessarily EU level) by maintaining a data base ("Project Seeking Partners") of inquiries for project funding and coordinates the search for project partners in $\mathrm{CE}$. In cases where a CEI project involves $\mathrm{CE}$ EU-member state and one non-EU CE state the CEI will attempt to cover the non-EU member's share, such as in the "Town Twinning Program".

Since its inception in January 2004 until April 2005 this project supported the application of twelve EU-projects with a total value of fifteen million Euros, of which four projects with a value of approximately five million Euros were approved as of April 2005 (Kreid 2005). While this may seem like a small number, one must consider the lengthy application process for EU projects until approval. This approach is significant because many NISs are not familiar with EU bureaucracy and its procedures and would miss out on funding opportunities if left to their own resources. Instead, CEI assistance not only increases the availability for funding which would otherwise not have been attained, but it also serves to strengthen the ties between non-EU CEI member states and the EU. This increased familiarity with procedures and institutions not only facilitates future economic and political exchanges between the "new" and the "old" Europe on many levels, but also has a norming influence on CEI member states by exposing them to "best practices" approaches as well as to the opportunities per se available in free market economies.

The fourth CEI funding modality is the institutional link (via the Secretariat for Projects) with the EBRD through a trust fund since 1996, making both organizations 
also longstanding members of the Local Economic and Employment Development (LEED) program. LEED is an OECD program to support entrepreneurship, small- and medium sized enterprises (SMEs) and local development with offices in Trento, Italy. (OECD website, accessed 4/27/2006). In 2004, for example, the EBRD spent 2.2 billion Euros for investments in the CEI region (CEI Newsletter \#32, 2: April 2005). This investment led, among other things, to progress in Moldova and Ukraine in their advancement towards the EU-“perspective" (Ibid.).

Some CEI programs are detailed in the following sections of this chapter, such as those carried out by the Secretariat for CEI Projects in London which organizes and supports economic cooperation activities, such as training programs, conferences, workshops and other relevant international events. These cooperation projects are managed by the executive offices in Trieste and involve investment projects and technical cooperation projects (CEI website, accessed November 29, 2005). One example of a trans-regional cooperation project involved another regional organization, the Adriatic Ionian Initiative. This organization co-financed in 2005 a joint tourism project with the CEI in small communities which are ignored by main stream tourism despite their attractive cultural heritage and other assets with tourism potential in countries which belong to both organizations (i.e. Croatia, Albania, Bosnia and Herzegovina, Serbia and Montenegro).

The CEI also signed a memorandum of understanding (Appendix 8) with the United Nations Economic Commission for Europe (UN/ECE) for CEI programs with generaland country specific strategies, especially pertaining to trade and transport facilitation, small and medium enterprises, transport and environment in relation to the dissemination 
and implementation of ECE norms and conventions. These programs are carried out through cooperation (including UN financial support) with sub-regional groupings in order to provide a further forum for dialogue aimed at bringing about a better understanding of different aspects of the transition process and for the negotiating of normative technical and institutional frameworks in these areas.

The fifth CEI funding modality is the Trust Fund, briefly referred to earlier. The CEI is not a donor organization but utilizes the interest earned from the original seed grant established by Italy in 1992 not only to conduct member meetings and administrative functions for its programs, but also to fund feasibility studies for cooperative projects between member states (with the funding for the actual project coming from one of the sources described in the previous sections). The twenty-seven million Euro contributed by Italy as of 2004 is decidedly effective: For example, a CEI four million Euro project grant has facilitated (through technical cooperation with the EBRD investments worth 360 million Euros. The feasibility studies were designed to outline potential projects for building and improving small- and medium-sized enterprises, agricultural cooperatives and other institutional structures that would contribute to the success of the new political and economic order.

Cooperative projects are decided on by consensus, a significant exercise in democratic administration: They require the faith of CEI member states that, while a few countries had their project approved in any one year, the others will have an opportunity to have their own cooperative project approved in the future. In fact, the four million Euro, which the CEI had spent at one point on these initiatives ultimately generated some fifty million Euro in bank loans, while the ratio of seed money to EBRD investments 
equals one to eighty (International Centre for Theoretical Physics website: What is New? Accessed February 4, 2006).

\section{Working Areas/Projects}

Following EU accession of five CEI member countries in 2005, the 2004-06 Plan of Action (Appendix 9) shifted from the CEI's original goals of bringing the newly independent countries of Central Europe closer to the west to focus more on economic, human and institutional development and various horizontal issues. The purpose was to facilitate transfer of knowledge and best practices from CEI Member States acceding to the EU to those remaining outside it at the time. Specifically, the areas addressed included:

- Economic development and technical co-operation.

- Development of infrastructure in transport, energy, telecommunication, agriculture.

- Strengthening the democratic institutions and observance of human rights, including the rights of persons belonging to national minorities, and humanitarian matters.

- Protection of human environment.

- Cooperation in the field of science and technology, media, culture, education, youth exchange, tourism.

- Cross-border and interregional co-operation

- Consultations on political matters of mutual interest 
The above priorities and criteria are being realized by WGs consisting of civil society and governmental representatives from each member country. In the following sections I will discuss the areas in which the WGs were active (in alphabetical order). They are based upon the CEI Plan of Action 2004-2006. The WGs are headed by one country, rotating the chair annually among all member states.

These programs augment those factors which, according to Huntington (1991, 270, 273) support democratic consolidation processes, such as the level of economic development, and high per capita income with a broad middle class without extreme income polarization, and a supportive external/international environment as well as foreign actors who are conducive to the democratic consolidation process, widespread literacy, and congruent democratic values in the political arena and in authority structures throughout society, such as business, trade unions and culture.

I describe a few programs in greater detail to show how much can be achieved in terms of technical know-how transfer, civil society building, regional integration and economic development in a free market economy even within the existing means of these newly independent states. We need to keep in mind that one of the crucial challenges facing these countries, which existed "behind the iron curtain," is for the citizens to accept and accommodate the new demands and pressures of technological progress which took place during the past decades outside the Soviet Union, in addition to the establishment of democratic institutions and civil society.

\section{Agriculture}

One very important program supporting $\mathrm{CE}$ regional cooperation is the development of a micro-credit system (in cooperation with the World Bank and UN/ECE) for farmers 
and the establishment of agricultural wholesale and assembly markets ${ }^{19}$. The CEI provides a program for institutional development and technical assistance to modernize these processes and to calibrate some procedures with those of Western Europe. It is envisioned that good agricultural practices would be transferred to non-accession countries, based on EU directives and international conventions on food safety standards, protection of soil, water and habitat through application of ecological farming methods, rural infrastructure development, promotion of biological and environmentally sustainable agricultural production, agro-industry development, integration of databases and support for using GIS (Geographic Information Systems), and promotion of biomass ${ }^{20}$ for energy production (in cooperation with the WG on energy).

A practical example is EastAgri, a network of agriculture and agribusinesses working in $\mathrm{CE}$ which was established by the CEI to improve the quality of services and achieve common objectives through information sharing. The EastAgri CEI network covers the current eighteen member countries and serves as the hub of information relating to agricultural projects and sector knowledge. It seeks to promote innovative approaches towards agricultural/agribusiness investments among international financial institutions and banks operating in the region. It is not the goal to replace current channels of communication, but to facilitate them by broadening visibility with the aim of increased efficiency and effectiveness by creating synergy between the financial- and the operational levels.

\footnotetext{
${ }^{19}$ These are simple agricultural industries such as processing the milk and eggs delivered by individual (small) farmers to co-op style processing facilities to prepare them for sale to retailers.

${ }^{20}$ As an example, the use of sunflower oil (a renewable energy source) as a truck fuel has found good acceptance in Western Europe and one finds extensive acreages growing sunflowers in CE.
} 


\section{Civil Protection}

The main goal of the CEI in the field of civil protection is disaster prevention and accident intervention coordination of national rescue teams by adapting relevant EU/NATO procedures in $\mathrm{CE}$. The protection of the population against natural and technological disasters is being improved through modernized vocational training courses in the field of disaster management and risk prevention. An individual analysis of programs and operational approaches currently utilized in member countries is envisioned to lead to a coordinated approach between member countries, many of whom are neighbors and could potentially be similarly affected by a disaster. This concern is being addressed by an improvement of border-crossing procedures for persons and equipment entering the affected country from abroad, which is occasionally still difficult due to infrastructure which was destroyed during the unrest of the past decade and possible social tensions still remaining at the local level.

\section{Combating Crime}

Several IGOs, e.g. the Council of the Baltic Sea States, the Barents Euro-Arctic Council, the CEl's Working Group on Combating Organized Crime, and the AdriaticIonian Initiative met for the first time in January 2005 to discuss possible ways of future inter-IGO cooperation in training courses and seminars. Topics included trafficking in human beings and stolen vehicles, organized crime (including money laundering) and financial fraud with particular regard to illicit credit card use. The latter issues are addressed by involving international resources and organizations, such as VISA and MasterCard, the OECD Financial Action Task Force and banks. Illicit trafficking in human beings and stolen vehicles have gained momentum in CE, partially due to the gap 
in law enforcement since the end of authoritarian rule and the establishment of a functioning civil society with laws guaranteeing human freedoms and non-corrupt officials. This requires an energetic commitment to both training of law enforcement personnel and the rapid cross-border exchange of information among authorities despite possible lingering distrust among states.

The G8 network for computer crimes will be enlarged to $\mathrm{CE}$ in order to enhance and supplement traditional methods of assistance. The G8 created this network to investigate threats and other types of computer related crime in several countries. Instruments to fight corruption underlying all of these aspects in $\mathrm{CE}$ are an additional focus of CEI programs. Since these are global issues, the CEI coordinates local approaches with UN procedures for multilateral solutions to counteract the threat of parts of CE falling into lawlessness post-authoritarianism.

\section{Cross-Border Cooperation and Local Development}

The CEI will expand its interregional and cross-border cooperation and local development, especially in Eastern and South-Eastern Europe, through the implementation of tangible solutions in coordination with other WGs such as Culture and Education, Information and Media, Combating Organized Crime, Civil Protection, Tourism, Transport, Environment, Minorities, Migration and SMEs. In addition to CEI joint international events and cooperative projects which involve WGs detailed below, other programs specifically aiming at cross-border institution building are Commercial Law training I and II, and the CEI contribution to cleaning up of the Danube (which affects several CEI member countries). 
These programs reflect not only regionally shared norms and values (e.g. environmental protection), one of the characteristics of an international regime, but also global concerns of cooperation and security as discussed in the previous section. They contribute in the case of the CEI explicitly to that mutual socio-political development within and between $\mathrm{CE}$ countries which are constructive on all levels (local, state and international). They also support the socio-psychological concept of "entitativity" (Risse 2004), i.e. the reification of a common fate, increased salience, and boundedness, which, according to Risse (Ibid.) lead to collective identification and positively impact peaceful behavior in $\mathrm{CE}$.

Another pathway in which these programs also enhance regional stability and democratic consolidation is through that cognitive evolution which, according to Adler (1991) and P. Haas (1992), results from collective social learning. In Wendt's (1992, 1994) view these programs contribute to regional stability and democratic consolidation through the selection, international diffusion and institutionalization of collective understanding and contributions to the security community-like collective identity formation. Again, the CEI is affecting this on the regional CE-level, but it is a process which integrates $\mathrm{CE}$ with global developments espoused by the UN.

\section{Culture}

The key element of CEI cultural cooperation continues to focus on projects relating to the conservation of tangible and intangible cultural heritage (including museums, monuments, archaeological sites, music, art and traditional crafts). This is achieved through the development of know-how in cultural management and by advancing the ability of governments and civil society to support cultural policies as a 
contribution to socio-economic development (cultural industries development; cultural tourism; sponsorship and donations in the arts), as well as the promotion of cultural diversity (especially linguistic and religious). These programs aim at fostering a better understanding among people as well as among regional ethnic groups, particularly pertaining to cross-border cooperation in the mobility of individuals and groups in the arts. CE participation in existing programs by the EU, UNESCO and the Council of Europe is also promoted. These programs require the development of civic attitudes and that willingness to participate, which Rustow (1979) considers essential to successful democratization, and as an indication of a democracy's legitimacy based on how well a system performs.

Some specific examples of cultural promotion by the CEI in CE are: The CEI Youth Orchestra (discussed in greater detail in the category "Youth" below), the CEI Venice Forum of Curators of Museums for Contemporary Art, the CEI Writers' Meeting/Literary Roundtable of Vilencia, Slovenia, the CEI Journalists Forum, and the Mittelfest of Cividale, Italy, as an annual encounter of artists and performers from CEI countries. The involvement of the CEI in the Council of Europe's "Creating Cultural Capital" project is also under consideration. These programs are effective in contributing to democratic consolidation e.g. by enabling free written and artistic expression as an avenue for dissent - and consent - of civil society. In particular the youth programs seek to prevent restrictions on free expression which were placed on their parents under authoritarian rule. 


\section{Education}

The CEI recognizes the importance of education in enabling the newly independent states not only to catch up technologically but also economically. Hence it supports education in member countries in many aspects, such as improving education in rural areas and among groups having suffered from a lack of social inclusion to making the citizens of member countries IT-literate. This assists countries in improving their services, innovate faster, make better use of public funds and expose groups previously marginalized to values and ideas not accessible to them before in order to integrate them more equitably into society. Furthermore, the CEI has recognized that a well-educated population can produce more value-added products and services rather than developing its competitiveness based on cheap labor and good manual skills alone. The CEI supports member countries' IT policies and research infrastructure harmonization with EU standards as a first step in IT regional integration and cooperation with those CEI members which later became EU members.

The launch and expansion of the CEI University Network with currently eighteen coordinating universities from member states is the foundation of CEI cooperation in the educational field. The main concept of this program is to facilitate mobility of faculty and students among "coordinating" as well as "participating" universities in the CEI region as per the University Network Founding Charter (CEI website: Education, accessed November 29, 2005). This program offers grants and scholarships for joint programs in the fields of economics, communication, IT, and public administration for (post-) graduate study. As part of the CEI University Network, the CEI and the EU cooperate on a summer school program in Igalo, Montenegro, to support the next generation of law 
students from Central, Eastern and South Eastern Europe to gain a better understanding of European enlargement and corresponding legal reforms. These programs also contribute to the development of a common regional identity in the process and further transnational institutional transparency and participation.

Another CEI sponsored educational program is the "Masters for the Balkans". It consists of three separate master's programs ("Master's in Transport, Logistics and Economic Integration with the Balkan Area", "Master's in Geographic Information for Spatial and Economic Decisions", and the "Master's in Technological Transfer and Industrial Product Development Systems") and is organized by the University of Trieste within the framework of the CEI University Network and taught by its Faculty of Architecture, the Department of Geographical and Historical Sciences and the Department of Economic and Statistic Science of the Faculty of Economics. The program's aim is to promote the mobility of students and teachers in South-East Europe (see appendix 10 for a sample list of Joint Programs in 2004).

One can argue, following Finnemore (1996), that the strongly favored institutional compatibility observed in the programs described in the preceding paragraphs imports certain behavioral and procedural standards into the civil design of post-communist $\mathrm{CE}$, thereby enhancing civil society and ultimately contributing to the success of the democratization of this region. With other words, coordinating institutions with some of those in the west as well as with each other in $\mathrm{CE}$ will by necessity effect changes in behavior (e.g. modernization, even if at first only in a technical sense), partially because the population now has a much greater variety of options available to influence their lives 
on an individual level as well as on the community level, both politically and socially, and partially because cooperation becomes easier and hence feasible.

While Finnemore stresses how institutional compatibility has a reciprocal ("agentstructure") effect on the population, the mechanisms strived for in these programs are also echoed by Risse $(2004,256 / 7)$ and Habermass $(1994,1996)$ in terms of post-national European civic identity (emphasizing democracy, human rights, a market economy, the welfare state and cultural diversity) as becoming constitutive in $\mathrm{CE}$, while the cultural identity is associated with the local area. I refer also to Wendt $(1999,327)$ who stated that cultural selection can take place through imitation, whereby standards are constituted by shared understandings. In fact, learning both in a formal as well as in informal settings was specifically identified by Wendt (Ibid., 333) as contributing to a change of identities and interests. Hence the CEI's educational programs contribute to the diffusion of democratic norms, values and procedures to the "next generation" while at the same time remedying lack in technological knowledge and democratic awareness among adults. Additionally, by furthering mutual understanding throughout its programs, the CEI contributes to a more cooperative, safe and stable CE - and Europe - overall from the local level up to the national- and transnational levels and hopefully minimize the chances of further civil wars in the region.

\section{Energy}

Energy production and know-how transfer as well as the research and development of renewable energy sources are a top priority in the economic development of $\mathrm{CE}$ (which the literature recognizes as supportive of regional democratization and consolidation). Additionally, as the availability of energy is becoming more and more a 
security consideration, especially in relation to Russian oil and gas, renewable energy development is critical to the economic growth and political stability in CE. The CEI implements ad-hoc projects, programs and activities in order to assist in the development of these sectors. One goal is the use of biomass as an alternative source of energy. Other renewable sources of energy (solar, wind, etc.) in countries with relevant financing resources to make this type of project self-sustaining are also investigated. Another focus pertaining to energy is the improvement of fuel consumption efficiency and the reduction of energy and heat consumption. This area is particularly supported by Provincia di Bologna, Italy.

It is interesting to note that also Austria, as one of the "hegemonic impeti" of the CEI, is particularly involved in this field. One of the Energy-WG meetings was held in Vienna in 2004 with the Austrian co-chair of this WG, an official of the International Atomic Energy Association (IAEA). With excess nuclear materials from the former Soviet Union readily available, the CEI is notably pro-active in addressing various aspects of nuclear power - and likely in the context of the responsibilities and provisions of the Non-Proliferation Treaty (NPT) of which all CEI members are members.

\section{Environmental Protection}

Environmental protection under the CEI umbrella focuses on: noise, tourism, water, renewable energy, safety, spatial planning, sustainable consumption and transport. The projects of this WG have been supported particularly by Austrian consultants with financing provided by the World Bank, OECD, and others.

Environmental protection programs in the CEI do not simply involve programs to protect the environment in the conventional sense, but seek to raise the awareness beyond 
the environment to space, spatial planning, influencing sector policies in the fields of education and spatial planning, involvement of experts and semipublic and private organizations that are responsible for spatial planning issues and education in this field, and general awareness-raising through educational TV programs and the dissemination of the results of this project. A couple of examples of the CEI Space Project, founded officially in June 2005 in Podgorica, Montenegro, follow:

The CEI cooperates with R.A.V.E. Space ("Raising Awareness of Values of Space through the Process of Education $)^{21}$ which is a program focusing on spatial awareness and regional identity. It addresses trans-European cooperation on a transnational level, cross-border cooperation and trans-regional cooperation, and aims to achieve higher territorial and economic integration within the cooperation area, and promotes a more balanced and harmonious development of the European space. Other R.A.V.E. programs cover issues like spatial, urban and rural development and immigration, transport systems, access to the information society, landscape, natural and cultural heritage, environmental protection, resource management and risk prevention (European Union website: INTERREG III B CADSES, accessed 2/4/2006). The significance of these programs, beyond their obvious goals, is not only cooperation, but also furthering a consciousness of regional entitativity (i.e. seeing other CEI members as bound by a common fate, rather than as adversaries) and a shared identity in CE. Considering the historical background of this region these are an important sociological processes in order to augment regional peace and stability.

\footnotetext{
${ }^{21}$ This is a program of the EU Neighborhood Program's former INTERREG III B CADSES (Central, Adriatic, Danubian and South-Eastern European Space) programs. Portion "B" deals with problems of education about spatial planning and sustainable spatial development in primary and secondary schools.
} 
The R.A.V.E. Space project consists of nine partners from six countries (Greece, Italy, Montenegro, Poland, Slovenia, and Serbia) and was formed to raise awareness of sustainable development and current spatial needs in view of future generations, incorporating environmental, spatial, economic, demographic and other data. It meets the United Nations Economic Commission for Europe (UN/ECE) Strategy of promoting sustainable development through education (R.A.V.E. website, accessed 2/4/2006). As mentioned above, the concept of space is closely entwined with entitativity, common fate and collective identification. In other words, the R.A.V.E. project is not simply a matter of focusing on sustainable development, but also serves to focus on shared as well as national space as a regional commonality and on overcoming cultural boundaries among the population of $\mathrm{CE}$ and to indirectly deepen the sense of common fate, collective identification to the region and as a result, to contribute to regional stability. Again we see that with this series of programs the CEI is addressing the construction of civic values, civil society, economic development and cooperation to hopefully prevent future dividing lines.

Another CEI program in the area of environmental protection with potential for regional intelligence implications for CE is the Central Europe GPS Reference Network Integration in Geodetic and Geodynamic Programs of the CEI. These programs include the second phase of the European Project CERGOP-2/Environment (Central Europe Regional Geodynamics Program), which is financially supported by the European Commission. Projects include cooperation within the framework of the CEI Working Groups on Science and Technology Section C "Geodesy" in the application of satellite positioning systems as well as their regional analyses (e.g. the Romania Plate, Tatra 
Mountains, Balkan Peninsula etc.), university education standards, satellite navigation systems, and cooperation with the European Geophysical Society (EGS) and the International Association of Geodesy (IAG). These have led, among other achievements, to the establishment of the Colored Eco-Genetic Relationship Map (CEGRM) consortium of institutes. These are viewed as a seedbed of new European projects and initiatives requiring not only cooperation but also economic development. ${ }^{22}$

These programs are not only scientifically significant but politically and militarily relevant today. They also show how programs and policies of the CEI re-structure subsequent political processes, e.g. certain aspects of defense coordination beyond the notion of institutions constituting actors. Instead, the shared purpose of the CEI as an international regime continues as a thread through these programs to the states' external environment reflecting inward to affect elite and nationalist thought about all aspects of political and social significance (Burch 2002, 66).

\section{Human Resource Development}

CEI programs in this area focus on activities aimed at promoting life-long learning, including vocational training and adult education. This is inter alia significant in terms of "re-training" that part of the population which received its social and business education under Soviet auspices in order to enable the socio-economic transfer to a generation raised under authoritarianism practices entry into a free market economy today. Additionally, special attention is given to young entrepreneurs for start-up businesses by

\footnotetext{
22 The entire project makes available velocity field and strain maps for future geodynamical investigations and hazard mitigation, data for climate research and weather forecast, data for real time navigation and a seamless data-bank for scientific and public access (Sledzinski 2004).
} 
providing them with the necessary management skills, including English language training for those who had studied Russian as a second language, to successfully develop their companies. Another focus of this WG is to update bureaucratic working methods and the efficiency of the public service. Again, this is an area which under communism was notoriously inefficient and not service oriented to its "consumer", the public. Streamlining business approaches with those of the West and increasing efficiency and service will strongly augment the development of a free market economy which supports democratic consolidation in CE. Furthermore, institutional strategies for the development of human resources such as these have been identified as promoting the construction of an overarching common socio-political identity among member states, whereby the rules and norms become part of the social and power structure which define the member states' socio-political environment and are vice versa also co-constitutive of each other (Hermann and Brewer 2004, 10-13). The agency of institutions, i.e. "understanding how people think about institutional norms and rules, and the discourse they engage in, is as important in evaluating the significance of these norms as measuring the behavior that changes in response to the invocation" (Kratochwil and Ruggie 1988, 765). One of the results anticipated is the augmentation of a strong middle class to avoid extreme income polarizations in $\mathrm{CE}$ which have been identified in the literature on democracy as potentially destabilizing.

The CEI collaborates with a number of international institutions, a process which shapes actors' preferences as much as these are co-constitutive of the local institutions they spawn by adapting their structure to regional idiosyncrasies and preferences. While this may appear inane to the Western reader, it must be remembered that the population 
in $\mathrm{CE}$ had neither well-developed democratic institutions nor the modern business environment (such as norms, mechanisms or the necessary institutions to cooperate democratically and peacefully post-communism) necessary to succeed in a nonauthoritarian free market environment.

\section{Information and Media}

The focus of CEI cooperation in the field of information and media is the extension of cross-border television project, already operational between Italy and Slovenia, to other CEI countries and the review of media legislation. Examples of these cooperative broadcast activities are the "Neighbors without Frontiers"-TV series dealing with the preservation of cultural heritage, the renovation of old city centers and old castles, the preservation of languages and national identity, and the promotion of cultural events. Another TV production proposed is the project "What is it that Europe wants from us?", a series of programs focusing on the status of implementation of reforms in Serbia, Montenegro, Croatia, and Bosnia and Herzegovina in the fields of legislative system and jurisdiction, education, democratization of institutions, and human rights.

This television exchange represents a valuable contribution to CEI cultural and interethnic cooperation and is hoped to be expanded with EU funds to independent TV production groups for cross-border activities. While this may be one of the more "visible" forms of "Westernizations" or "Europeanization" resulting from CEI activities, offering at least a template for the free (political) expression of opinion in a democracy offers CE the learning experience to control future media content in their own programs. Additionally these programs contribute to building a "common European narrative" with an encompassing fusing identity as opposed to the divisive ones of the past. 


\section{Migration}

This topic currently addresses migration issues in Belarus, Moldova and Ukraine in particular as the other CEI members already have extensive regional and international mechanisms for regulating the movement of people across their borders. These issues involve the tandem concerns of trafficking in women and organized crime, and they involve special cooperation with the EU, the International Organization for Migration and other regional organizations. They involve additional training of immigration and police officers (in a temporary training center of one the above countries) as well as with more flexible visa requirements within EU limits. The extent of globalization, together with the drastic increase in the movement of people after the lifting of the Iron Curtain, necessitates broad European cooperation and extensive international coordination in this area.

\section{Minorities}

While states manifest externally as a unified nation willing to live under one government, West European countries guarantee the right of minorities to respect and integration into the main society. The CEI Instrument for the Protection of Minority Rights (Appendix 11) spells out in twenty-seven paragraphs for CEI member states to recognize that national minorities need to be addressed in a truly democratic political framework based on the rule of law, guaranteeing full respect for human rights and fundamental freedoms, equal rights and status for all citizens, condemning aggressive nationalism, racial and ethnic hatred, anti-Semitism, xenophobia, discrimination, and reaffirming the protection of national minorities to preserve and develop their ethnic, cultural, linguistic and religious identity. The CEI Instrument for the Protection of 
Minority Rights was designed to facilitate access by ethnic non-elite groups to government employment and even mass democratic access to the political system through the exchange of best practices regarding the economic conditions of minorities and facilitation of cultural contacts of minority groups separated from the main population either historically or by new borders in CE. These steps are being taken in coordination with other international organizations and institutions active in this field, such as the Council of Europe and NGOs.

The publication "Minorities and the Central European Initiative", published in October 2004 on the occasion of the $10^{\text {th }}$ anniversary of the "CEI Instrument for the Protection of Minority Rights", is now available in eleven languages (including the Romany/Roma language) to ensure that the populations for whom the protection is intended are aware of their rights. The CEI is also developing additional projects aimed at the promotion of minority languages in public life (media, schools, public administration), e.g. through support of cross-border TV programs in cooperation with the WG on Information and Media.

The significance of the CEI's focus on ethnicity and minorities lies in its founding imperatives, namely to prevent the spill-over into Western Europe (particularly Italy and Austria) of ethnic conflicts based on longstanding cultural and religious differences being rekindled (particularly in Czechoslovakia and Yugoslavia) upon the disintegration of the Soviet Union. Creating trust not only trans-nationally within CE but also internally in CEI member countries among different ethnicities is one of the greatest challenges in post-communist CE. The successful development of a collective civic identity is hoped to lead sociologically to a behavioral change of seeing the neighbor not through the lens of 
ancient animosities but as a trustworthy partner. The steps taken in CE address the lack of ethnic integration of minorities, such as the Roma, institutionally through rules, such as those spelled out in the Instrument for the Protection of Minorities.

\section{Science and Technology}

The CEI Science and Technology Network was established with five research centers in Trieste. It operates now through six lead scientific institutions in Trieste and partner/affiliated institutions in other countries, involving broad and comparatively sophisticated programs. It makes research grants available to $\mathrm{CE}$ scientists and cofinances scientific meetings in the fields of theoretical and applied physics, biogenetics and biotechnology, neurosciences and applied mathematics. A special grant enables scientists from $\mathrm{CE}$ to commercialize their research results. It also offers young scientists from $\mathrm{CE}$, especially those outside the $\mathrm{EU}$, the opportunity to participate in graduate courses, training programs and research activities in fields such as theoretical and applied physics, bio-genetics, neurosciences and applied mathematics. The successful implementation of Geodesy ${ }^{23}$ programs and Geodynamics, as well as Geophysics and Geohazards, with financial support from applicable EU programs (see below) also continues.

The CEI's founding purpose was to promote a dialogue and cooperation between systems (both with respect to the EU and intra-regionally) and ideologies that had previously viewed each other with suspicion and hostility. While Central and Eastern European countries traditionally enjoyed scientific excellence, additional new networks

\footnotetext{
${ }^{23}$ The scientific discipline dealing with the measurement and representation of the earth's gravitational field and geodynamic phenomena, such as polar motion, the tides and crustal motion in three-dimensional time/varying space.
} 
have been established by sponsoring the participation of scientists from member states in research and training activities (the CEI "primary" science and technology network), as well as a "secondary" network of direct contacts between certain institutes and member countries. Furthermore, additional agreements are sought with centers of scientific and technological excellence willing to dedicate part of their activities to the CEI region. The CEI is particularly looking for programs and partners which would further enhance information technology in member countries. Furthermore, the mobility of researchers and junior trainees will be facilitated, last but not least through the improved interconnection of the transportation infrastructure in CE.

The CEI has forged a partnership with the International Centre for Theoretical Physics (ICTP) in Trieste, Italy, itself operating under a tripartite agreement among the Italian Government, UNCESCO and IAEA, to foster advanced studies and research, especially in developing countries (Ibid.), and with the International Centre for Genetic Engineering and Biotechnology (ICGEB), Elettra Synchrotron Light Laboratory and International Centre for Science and High Technology (ICS) (Ibid.). Under these agreements scientists from CEI member states participate in ICTP workshops and conferences, e.g. pertaining to wireless communication, photonics, optics and plasma physics. This allows scientists from all member countries to work in international settings and to take full advantage of their skills and talents in an environment of mutual cooperation and exchange.

These programs offer a chance to build partnerships among high-level scientists from all member countries and improve the prospects of gaining the collaboration of these scientists in efforts to assist colleagues in the South-Eastern portion of the CEI (who have 
joined the CEI more recently) (G. Denardo, ICTP Website). This scientific integration also assists in the prevention of new dividing lines within $\mathrm{CE}$, be they economic, social, or political. These programs are examples of the complexity of peaceful regional integration also in the fields of science and technology, particularly since some of these programs are already in their "second generation" of grant renewals.

\section{Small and Medium Sized Enterprises (SMEs)}

As many international relations scholars have pointed out, democratic success hinges significantly on a country's overall economic success, and is particularly enhanced by a broad middle class. The CEI is especially committed to support both of these aims and has developed many programs for this purpose:

The Know-How Exchange Program (KEP)

This is a special financial instrument through which the CEI supports the transfer of specific knowledge for the economic transition and institution building which the new EU members (the Czech Republic, Hungary, Poland, Slovakia and Slovenia) have gained over the past decade. In light of the recent EU membership of five additional CEI members, this program was created so that these states will assist non-EU CEI-members (e.g. Bulgaria, Rumania, Croatia) by transferring their EU-accession experience. This program is financed through a special window in the CEI Trust fund at the EBRD.

The CEI had originally focused on improving the region's overall infrastructure, e.g. by upgrading local transportation and communication systems, and by increasing the reliability of local power networks. The CEI later expanded its efforts to the role which knowledge, especially the mobility of knowledge, plays in the region's future well-being (H. Kreid 2/4/2006 in ICTP website, accessed 2/4/2006). 
One specific example of a KEP is the "Company Incubator for Moldova" program

which

aims at creating a virtual 'permanent entrepreneurial development centre', something like a 'company incubator'... by enhancing the level of entrepreneurship in the area of micro and small companies... [and, among other program phases] 'sensitizing' and training private and public actors who will support start-ups; a 'promotional' phase for increasing awareness of entrepreneurial opportunities among young people in a specific sector followed by a promotional phase including at least three 'self-entrepreneurship sensitizing seminars' (CEI Newsletter No. 44, 3).

This program addresses the question of youth unemployment, insufficient marketing skills in post-Soviet $\mathrm{CE}$, lacking entrepreneurial personal initiative, the economic development of the middle class to prevent extreme income polarizations, the development of IT skills development and a transnational cooperation modus by tying this program to the Padua, Italy, Chamber of Commerce as an institutional anchor.

CEI participation in the Organization for Economic and Cultural Development's (OECD) Local Economic and Employment Development Program (LEED) program as part of the OECD's Centre for Entrepreneurship, SMEs and Local Development. These programs include such programs as "Employment and Skills at the Local Level", "Entrepreneurship at the Local Level", "Globalization and Local Authorities", "Local Governance and Partnerships", and "Social Innovations at the Local Level". These programs are clearly designed to support the region's economic development in a free market economy on all levels, from the local to the CE-regional. Europe-wide and globally.

Another example of SME development is the participation of the CEI LEED Program in the annual CEI Summit Economic Forum. The $8^{\text {th }}$ CE Summit Economic 
Forum's main theme was "Reforms as Key to Competitiveness": Assistance in the modernization of financial institutions and insurance companies in light of the privatizations in these sectors and the technical upgrading of procedures (e.g. in the areas of motor vehicles, property, personal accidents, life, travel and health insurance) are paramount in a region in which under communism there was a limited need for these products, but which are now essential in conducting business in a free market economy.

The CEI-LEED Local Development Network of Advisors is hosted by the LEED Trento Center for Local Development. It formalizes the first common permanent CEILEED initiative and structure (OECD website: LEED Programme). This initiative will enhance business best-practice know-how transfer, institutional development and further business opportunities.

The Chambers of Commerce of the CEI Member States

This association launched a cooperation program in 1994 with the collaboration of the Italian Union of Chambers of Commerce parallel to the CEI's international regime structure. It is also head quartered in Trieste (per the decision of the Chamber presidents of the participating countries). One of the immediate successes of this group was a conference on projects for reconstruction in Bosnia-Herzegovina (answers.com website by Columbia University Press, accessed 2/4/2006).

The CEI Enterprise Program

The main purpose of this program is to promote and support sustainable development of enterprises as well as the enterprise culture in CEI countries. This program is enhanced by the EBRD's TurnAround Management (TAM) program which provides industry-specific advisors to potentially viable SMEs, enhancing the knowledge, 
confidence and capabilities of their management and assisting transition towards success in market driven economies.

An extension of this program is the multi-donor program "EBRD/TMG Business Advisory Services in CEI Member States" which promotes the improvement of quality and competitiveness of SMEs. Yet another project is the "Challenges for global competition: new synergies between the Italian Trade Fairs System and the CEI Trade Fairs" to encourage broad business development in the free market economies of the young democracies to partake in globalization rather than be left behind.

The Local Development Network (LDN)

The LDN was designed toaugment cooperation across a "horizontal" flow of experience and know-how. It was envisioned to be a network of cross-border communities of experts and consultants in a variety of fields acting as local development advisors in SME support centers, responsible for the development of and advice to local institutions and SMEs directly and for promoting local employment and visibility. Expert assistance expands to the following areas: advisory missions, assistance in negotiations, assistance in the preparation of investment projects and applications for grant or aid programs, project evaluation, exchange visits of experts, management assistance for institutions in the beneficiary country, management workshops for strategy issues, need assessments, surveys of problems and performance, technology transfer for the application of research and innovation, preparation of manuals, promotional or technical materials, web sites, interactive computer-based trainings, setting-up administrative systems and computer software in institutions of a beneficiary country, translation of laws, treaties, manuals, (CEI know-how exchange program brochure, 2005) relating to 
foreign direct investment promotion, trade facilitation (liberalization, customs regimes and -best practices), privatization and private sector development, public administration and institutional development (including public finance management, public procurement regimes, the absorption capacity for EU programs and institution capacity building) and legislative reform in the above mentioned areas.

One need not point out that these goals not only enhance free market "economic society building" through institution building and privatization of business and government monopolies. These programs additionally further the development of safeguards against corruption by incorporating standardized public accountability mechanisms. Many of these programs also fall into the category which Wendt (1999, 339) referred to as "internalization of roles in identities which generate subjective commitments to objective positions in society" as a mechanism for building a collective identity, both domestically and regionally in CE. This group of CEI programs, like the others observed, contributes greatly to regional economic stabilization and cooperation which support democratic consolidation.

\section{Tourism}

Tourism represents an important source of income for many CEI member states. Hence the expansion of tourism through improved service and infrastructure standards and resources for attracting tourists is a priority in the economic development of this region. The main thrust of CEI activities in this area is the improvement of the tourism sector through horizontal cooperation by strengthening the ability to work on a multilateral basis. Eco-, rural and cultural tourism, including cruising the Danube Valley, the Joint Wine Route (Hungary, Romania, and Bulgaria) and spas, or the "Joint Project in 
Adventure and Extreme Sports Tourism: Rafting on the River Tara" are being promoted as is the harmonization of CE standards with those of the EU and other international organizations, such as the International Air Travel Association (IATA). To make the less advanced member states attractive for foreign tourism and tour operators, customer service and efficiency standards are being raised through seminars, training programs and traineeships for hotel personnel, managers, and tour operators. This aspect of harmonizing with prevailing (Western) market standards is an imperative norm transfer in a region where neither customer service nor technology were sufficiently developed during communism to make this sector competitive and viable today in a free market economy.

\section{Transport}

The transport sector in CE was in special need of development, partially due to the civil strife in several CE countries which lead to the destruction of roads and railroad tracks. CEI activities in this area focus on the promotion of inter-modal transport and the construction of airfreight infrastructure facilities to prepare for the anticipated economic expansion in member countries and to meet EuroControl standards to enable air connections to Western Europe. Railway and road networks in CE have a similar need for rehabilitation and upgrading of standards to support the tourism- and trade promotion programs mentioned above. Concerns in this sector also overlap with Energy, Environment, and Cross Border Cooperation WGs and are addressed by the relevant Working Groups.

A specific example of $\mathrm{CEI}$ involvement in the transport sector was the International Symposium "Port Planning - Urbanism, Economics, Design" in November 2002 in 
conjunction with the annual CEI Summit Economic Forum (compare Appendix 7 for a table of CEI investments in transport e.g. in 2002). The symposium was devoted to investment opportunities for port planning in $\mathrm{CE}$, covering methodologies and best practices for identifying and financing bankable projects for port infrastructure. Other topics discussed at the forums are transport issues in relation to projects and programs for institutional and business development in $\mathrm{CE}$, including the development of trade within the CEI region and towards global markets, infra-structure projects, agriculture, banking and financial products, technical cooperation projects, development of technology and human resources, local development systems, programs for EU integration and crossborder cooperation and EU enlargement (especially considering that several member states were, and are applicants). Additionally, the CEI cooperates with the EU Project FASTER (Fostering Alliances for Sustainable Transport in European Research), aimed at the participation of selected SMEs in the transport sector, which shows multilateral integration in CE not only politically but also e.g. in the transport- and SME economic sectors.

The CEI's effectiveness as a cooperative forum with the goal of regional integration and stabilization is especially highlighted in this sector since transport in a globalized economy by definition needs to be interstate. Transport also needs to be safe and efficient to be competitive. By augmenting this sector the CEI is assisting CE's democratization processes since this sector is essential to support economic stability, including preventing extreme income polarization through SME involvement, as essential for democratic consolidation. 


\section{Youth Affairs}

The Youth Forum

This program is an annually organized event in conjunction with the CEI Summit to provide an opportunity for young people from all eighteen member countries to meet, share information, exchange opinions on the most widespread youth problems such as unemployment, quality and security of jobs, education and training, information access, mobility, welfare and social security, equal opportunities for all ethnic, gender, religious and age groups, and to fight against illegal and unethical acts.

The CEI seeks to address two core issues in the area of youth affairs: promoting active citizenship by encouraging the involvement of youth in national and international political debates, and the prevention of youth crime and youth unemployment through policies creating more job opportunities for the young since youth unemployment is considered one of the prime causes for attracting inexperienced youth to a criminal environment. An example of an implemented program is the "CEI Youth Training Course on Organizational Management and Capacity Building of Youth NonGovernmental Organizations (NGOs)" for representatives of youth NGOs. The purpose is to strengthen the youth non-governmental sector in the region through training in organizational management, developing organizations, fund-raising, and strategic planning to build capacity in the youth civil sector.

Another activity was the international conference in 2004 in Rijeka, Croatia, on "Young People of Europe ...: The founding values of European integration". The topic "Which History in Schools?" was an integral part of the meeting with the participation of high representatives from ministries, rectors of universities, mayors and presidents of 
local and regional authorities from the CEI region as well as the Secretary General of the CEI University Network. A seemingly innocuous topic such as this is nevertheless critical in building a common narrative of a "new" joint regional history and cultural and civic identity. Augmenting regional social identity by teaching democratic practices to the next generation have been identified by authors such as Risse as contributing to regional cohesion and stability

\section{CEI Youth Orchestra}

This orchestra was founded in November 2004 to bring together some of the most talented young musicians from CE. It is the only one among European transnational youth orchestras to work with eleven to eighteen year olds. Its headquarters are in Brdo, Slovenia, and it performs during the summer and Christmas holidays as well as during the CEI Heads of Government November meeting. It involves young teenagers not only in a trans-national cooperative endeavor, creating trust and social capital (in Putnam's sense), it is hoped, in the "next generation". It is also a unique intercultural experience, providing an open teaching methodology which takes full advantage of the various approaches to musical education practiced in the countries of origin of the faculty. Furthermore, it increases the trans-national exposure of youth through recording sessions. Their work being heard internationally develops familiarity with the cultural centers of $\mathrm{CE}$ as well as bringing about an awareness of the meaning of an enlarged Europe by emphasizing the common heritage of the participants, rather than the divisive aspects of the past (CEI Youth Orchestra brochure). In other words, this program is designed to see "the other" not as different or "the enemy" but instead to recognize the familiarity and 
common identification which is hoped to enhance regional stability and contribute to democratic consolidation in the long term.

\section{Data Summary}

As is evident from this review of activities, CEI programs are developed by democratic consensus of all CEI members to enhance regional stability through cooperation and legitimate integration. They not only encompass the socio-economic aspects of development, but augment them by involving population groups which are currently active in socio-political life as well as the next generation. I find that the CEI is an example par excellence of what P. Haas (1992) has identified as the dynamic process in human agency which lies at the interstices betweens systemic condition, knowledge and national actions and

the role it plays in articulating the cause-and-effect relationships of complex problems (i.e. regional stability and democratic consolidation), framing the issues for collective debate, proposing specific policies and identifying salient points for negotiation (Ibid., 2).

In fact, the findings in this study concur not only with the criteria of an international regime in positively impacting its shared purpose of regional stability and democratic consolidation, but I also observed many of the elements identified by P. Haas (1992) in the dynamic approach of an international regime in the international context of how institutions affect decision makers (who were unfamiliar in the case of $\mathrm{CE}$ with many technical aspects of democracy and a free market economy), in defining their state interests and developing viable solutions to problems of post-communist transition. 
The list of successful projects detailed above is but a small sampling of actual projects undertaken by the CEI during its seventeen year history at this point. My hypothesis, that the effects of the CEI as an international regime contribute functionally to an increase in regional integration and democratic consolidation in member states through norm transplantation, civil society learning and regional economic and political cooperation through CEI programs is supported.

The CEI has successfully applied the liberal theory of peace and war, which incorporates the hypothesis that economic interdependence promotes peace, integrated with the theory of international (democratic) institutions (Russett and Oneal 2001) for the purpose of regional stabilization and progress in democratic consolidation in $\mathrm{CE}$, as measured by EU-membership (requiring stabilized democracies) of several CEI member states and continued peace once the post-soviet geo-political restructuring in $\mathrm{CE}$ had taken place.

Considering the regional stabilization effect of the CEI as an international regime on the unrest in the former Yugoslav republics and on the Balkan wars of the 1990's, however, one can only stipulate: Obviously, an institution which was founded at the very end of 1989 was not able to prevent ethnic warfare which in some cases had been pent up since the end of World War II when the borders around a new country, Yugoslavia, were drawn up irrespective of underlying ethnic and cultural incongruities and which date back centuries in other cases. Since this is not a quantitative study, I can only hypothesize that the framework which the CEI developed in CE culturally, socially, economically, and in identity and civil society norming as well as in assisting in the establishment of democratic institutions has been offering a peaceful alternative to the warring parties, and 
hereby possibly shortened the fighting which might have continued even longer despite UN, NATO, US and EU efforts to stop it. At a minimum it assisted significantly in rebuilding democratic and economic institutions and enhanced civil society post-conflict and/or authoritarianism in order to re-stabilize the countries at war and integrate them regionally for the purpose of making democratic consolidation a viable option.

In terms of the CEI's validity today, 2006, Ambassador Kreid (CEI Newsletter No.

$44,4)$ (emphasis mine) stated that

There is room for an organization such as the CEI that has demonstrated its capacity of serving its Member States in their efforts of transformation and in overcoming the barriers which still exist between many of them... While the accompanying role of the CEI in preparing for EU membership remains paramount, there is also a real need for fostering good neighbourly relations by means of well-targeted and well-defined co-operation projects among countries which were a few years ago still divided by ideology and ethnic strife, while some of them have only recently emerged as new nations. 


\section{Chapter Five}

\section{Conclusions}

According to Wendt $(1999,251)$

there are two problems of order in social life. One is getting people to work together toward mutually beneficial ends like reducing violence or increasing trade, and for this reason it is sometimes known as the 'cooperation problem'. This is what political theorists going back to Hobbes have usually meant by the problem of order, and it justifiably has been central to IR scholars and foreign policy-makers alike, given the difficulties of cooperation under anarchy and potential costs of failure. There is another problem of order however, what might be called the 'sociological' as opposed to a 'political' problem, which is creating stable patterns of behavior, whether cooperative or conflictual.

Wendt identifies the complexity of cooperation under anarchy for the common good which in this case study is "peace". In this study I outlined an approach utilized by the CEI to assist in the regional stabilization of CE. The programs of the CEI are designed to contribute to a solution to the political dilemmas faced by the post-Soviet societies in this region in the context of the current political and socio-economic reorganizations during the last seventeen years. The young democracies of post-Soviet CE faced a variety of threats due to ethnic unrest, ill-defined judicial, political and free market systems, unstable borders, memories of pre-1945 despotisms and historical conflicts (e.g. in Yugoslavia). To assist regional stabilization and democratic consolidation after communism in $\mathrm{CE}$ the $\mathrm{CEI}$ was founded as an international regime with the shared purpose of peace as well as with shared values and norms, upon the initiation of Italy and Austria as the regional hegemons. Analyzing the CEI as an international regime allowed me to address the political as well as the socio-economic mechanisms observed in this IGO geared towards regional stabilization. 
Within the CEI, the international regime is the medium for the discursive practices of democratic consolidation. Both the normative aspect of multilateralism and the transnational aspects of regional cooperation within CEI programs contribute to an institutionalized pursuit of the collective good, peace. In answering "what is the source of the interests and identities of individual actors? Are the prevailing structures material or also social? And what are the processes through which agents construct structures and structures constitute agents" (Burch 2002, 62), I found that in the case of the CEI the international regime structure seeks to alter both material (i.e. economic) and social (cooperative and democratic) structures and thereby contributes to the mutually constitutive process of regional integration and identity formation. The CEI is not operating as a colonizing institution for Europeanization, but rather as a cooperative forum within an international regime where the international regime produces both material and socio-political structure (through its programs) which are reciprocally and actively adopted by the actors (i.e. the member states through their political and civic involvement). The CEI functions through a variety of approaches promoting vigorous citizen participation and assisting extensive commercial, technical, scientific and cultural training of member state citizens within their regional cultural context. This is reflected in a well-organized, efficient bureaucracy, normed to a large extent by the best practices of Western Europe and giving them additional validation by frequently mirroring UN norms. This contributes to the integration of $\mathrm{CE}$ into a larger economic and political "present" (i.e. Western Europe replacing the former Soviet economic and political structures). The transparency of the CEI as well as its democratic organization set the 
stage and provide the framework for members to adopt these norms and utilize these models for their own new institutional structures.

The findings of this case study are congruent with the hypothesis of this thesis that the CEI assists through the structure of its programs - which can be enabling as well as constraining - in the regional stabilization and democratic consolidation of its member countries. Democratic consolidation in $\mathrm{CE}$ has been facilitated by the international environment (political, social, financial etc.), which the CEI. This unique structure of the CEI appears very effective in creating characteristics which have been delineated in the literature as essential to democratic consolidation. The unique structure of the CEI incorporates the following elements scholars have identified as defining regimes:

First, CEI member states have a shared purpose: Peace and regional stabilization of $\mathrm{CE}$ through democratic consolidation following the disintegration of the Soviet Union. This involves the establishment of new constitutional and electoral systems, changing/abolishing authoritarian agencies and institutions, and combating regional antagonism, communal conflicts, poverty and low rates of economic growth.

Second, the CEI embodies shared values, norms, rules and procedures. Central to these is the practice of cooperation. Cooperation provides a common language to express needs, dreams and goals of a region in renaissance, exploring and developing its political, economic, cultural and ethnic individuality, supported by investments in education, technology, infrastructure and business development. Member states are committed to democratic values, e.g. multi-party elections, popular sovereignty, and individual rights, and seek to achieve them through a synergy of programs via "top-down" (e.g. agreement by heads of state to cooperate) and "bottom up" processes (e.g. WGs design and execute 
civil projects). They seek to realize communities of common identity that are anticipated to spill over into broader sectors of society to reduce the possibility of war and to secure individual liberties and provide normative patterns for the development of civil society. They seek to accomplish these values through multilateralism in favor of bilateral relationships between countries.

Third, there existed a hegemonic impetus in the founding of the international regime: both Italy and Austria can be considered the regional hegemons in the case of the CEI. This study shows that not only the geographical proximity but also the shared history throughout centuries gave both countries the motivation to initiate this undertaking, the necessary sensitivity and political and economic means to carry this project out over almost eighteen years now.

Fourth, a hegemonic impetus may not be necessary after the initial formation of the international regime: Since CE has become increasingly economically, politically and socially stabilized, CEI member countries may theoretically not need the continued partnership of the hegemon(s). In practice, however, the CEI might loose its forward momentum were this the case.

The general research question of this thesis has been answered in my study of the $\mathrm{CEI}$ as contributing to the stabilization of the new, post-communist $\mathrm{CE}$ by establishing the institutions and behaviors identified by the literature on war and peace as essential for young democracies to consolidate. The specific research question of this thesis has been answered by locating a mechanism (international regime) through which the CEI develops and designs its programs on a multilateral basis among member states on all 
levels (local, national, transnational), utilizing both material and socio-political mechanisms.

The primary purpose of this paper was to examine the approaches used by the CEI as an international regime to facilitate democratic consolidation in $\mathrm{CE}$, such as a shared purpose (peace and regional stabilization), shared norms (democratic cooperation), shared values (national, regional and European identity formation), as well as multilateralism in favor of bilateral relationships between countries.

The secondary purpose was to find how the programs and mechanisms utilized by the CEI contribute to the consolidation of new democracies and can likely be applied in similar situations. I showed that applying programs which augment democratic consolidation within the framework of an international regime appear to greatly maximize these programs through their synergy as compared to applying them individually and without interconnectedness as is the case e.g. with programs administered by NGOs or stop-gap aid provided by individual governments. The multilaterality and synergy of programs and international regime structure resulted in what Seligson $(1994,635)$ referred to as reciprocal causation between the variables.

The CEI has contributed to fostering democracy in CE by supporting the internal parameters which are indicative of consolidated democracies. It has expanded the dynamics which contribute to consolidated democracies in $\mathrm{CE}$, such as fostering cooperation, the development of trust in institutions and multilateral approaches to solve economic and educational deficiencies. This has entailed the formation and transformation of an international regime and what Ruggie (cited in Krasner 1983, 196) has called a manifestation of the internationalization of political authority. 
The unique synergy of CEI programs, based on these norms, rules and principles for cooperation affects good governance. It also helps develop social interactions among the member states and civil society actors accommodating the new institutional structures of consolidated democracy. These programs produce a new structure manifesting in a new societal identity and in social and political system change among member states (Hall 2002, 122). New intellectual systems and associational participatory politics of the CEI alter the character of public life in CEI member states fundamentally. In addition, $\mathrm{CEI}$ economic programs contribute to the development of free markets, the economic foundation for democratic consolidation, through transfer of know-how and technology from the further developed countries to the less advanced CEI member states, the promotion of investment, scientific research and post-graduate training in economics, computer science and public administration and the development of internal and export markets. The institutional assistance arranged through CEI programs proved useful to the democratic consolidation process in $\mathrm{CE}$ by providing a supportive external/international environment and supporting integrated foreign actors (such as epistemic communities, NGOs and other IGOs) supportive of democratic consolidation. The CEI through its programs within an international regime structure helped foster both polity and civil society and create institutional structures which could influence the behavior of political actors facilitating the actors' understanding of the democratic world and formulating new cognitive and belief systems. It enabled learning through international cooperation by providing the environment for collective social learning, innovation, and the institutionalization of collective understandings of democracy. Institutional assistance not only provides information, coordinates transnational programs, and creates trust and 
confidence, but it also contributes to the solution of problems (such as crime, poverty, public health and lacking state structures) and related policy coordination.

These strategies are aimed at creating a more cooperative, safe and stable Europe of sovereign peoples united in a community of shared values, rules, norms and principles reciprocally constructed nationally and transnationally through international regime structure and a regional entitativity, overlapping with West-European norms and culture. The fact that several CEI member states were able to join the EU and that several other member states have currently EU applicant status suggests that significant democratic stabilization has taken place in several CE countries.

The CEI has a significant effect on the populations in CE in terms of conveying behavior, norms, and institutional rules conducive to the development of a free and lively civil society, a relatively autonomous and valued political society, rule of law to ensure legal guarantees for citizens' freedoms and independent associational life, a state bureaucracy that is usable by the new democratic government and an institutionalized civil society. The CEI has successfully contributed during its very short seventeen year existence in the wake of the radical geo-political destabilization following the dissolution of the Soviet Union to the regional cooperation and considerable democratic consolidation in an area which now encompasses eighteen countries and which had the potential of further escalating violent socio-political conflicts.

The resurgence of communist parties in several Central European countries is viewed as a democratic expression in these countries. While a few CEI members are decidedly not (yet) democratic, the votes received by communist parties in democratic countries are considered by scholars as the swinging of the multi-party pendulum in a 
democracy (Linz and Stepan 1996). It is not considered a failure of a young democracy but rather an indication of its consolidation.

The assistance from other parts of the world, notably the US, e.g. in the form of technical know how transfer through NGOs, no doubt played a significant role in stabilizing the newly democratizing countries of Central- and South-Eastern Europe as do the development parameters established by the UN. The sheer depth and breadth of CEI involvement in this region on a consistent basis from almost the beginning of Soviet disintegration through today can probably be credited not only for preventing a much greater spread of regional instabilities in the 1990s but for having contributed significantly to the democratic consolidation of many of its member countries.

The CEI's approach to reforms for the purpose of democratic consolidation and regional stabilization is supported by findings of the UN Department of Economic and Social Affairs report (Vos 2006) which state that

widening income gaps between countries, particularly since 1980, a dual divergence [of a] widening gap between developed and developing countries and a divergence among developing countries ... make it more difficult to achieve the [UN] Millennium Development Goals... sustained productivity growth requires structural change and economic diversification [and although] institutions matter ... gradual governance reforms may be better than 'big bang' transformations ... sustained growth in successful countries was accompanied by structural change of output and labor from low- to high-productivity sectors.

This UN-study confirms the desirability of the gradual progress taken by the CEI to avoid diverging (regional) growth and development and the potential for an IGO's role in containing it in developing countries through a

flexible agenda for development [by] fostering active trade and production sector policies for economic diversification, improving the international trade environment, ... ensuring sustained levels of public spending to make necessary 
investments in infrastructure and human capital, and promoting gradual, country-specific and home-made institutional reforms (Ibid).

While the extensive projects of the CEI continue to be a work in progress, partially because several members have only joined very recently and have not had the benefit of long-term participation in CEI programs, the considerable efficacy of the CEI in undertaking regional cooperation and democratic consolidation continue.

This represents a significant alternative to shot-gun (both in a temporal, material and in a military sense) approaches which are cost- and human life intensive with dubious long-term results in democratic consolidation. To paraphrase Madeleine Albright (speech on May 12, 2006 in Miami): democracy is not one size fits all - democracies are multidimensional and it is an oxymoron to impose democracy. And, echoing Huntington's emphasis on the significance of consolidating young democracies, Secretary Albright continues: "you can't take your eyes off a democratization process once undertaken" [or it may not succeed]... (Ibid). 
Ableson, Donald E. 2002. Do think tanks matter? Assessing the impact of public policy institutes. Montreal: McGill-Queen's University Press.

Adler, Emanuel, and Michael Barnett ed. 1998. Security communities. Cambridge: Cambridge University Press.

Adler, Emanuel, Peter Haas. 1992. Conclusion: Epistemic Communities, World Order, and the Creation of a Reflective Research Program. International Organization 46, no. 1:367-390.

Albright, Madeleine. 2006. Speech in Miami on June 19, 2006.

Agh, Attila. 1998. The politics of central Europe. London: Sage Publications.

Answers.com by Columbia University Press. Central European Initiative. Internet online. Available from $<$ http://www.answers.com/topic/central-european-initiative $>$. [February 4, 2006].

Arato, Andrew. 2000. Civil society, constitution, and legitimacy. Lanham: Rowman \& Littlefield Publishers, Inc.

Balkan countries. Aneki.com. Available from http://www.aneki.com/Balkan Countries.html.Accessed July 11, 2006.

Baroncelli, Leonardo. 2004. Promoting trade and enterprise in a changing European economy. In UNECE executive forum on competing in a changing europe1-3. Trieste, Italy: Central European Initiative.

Berengaut, Julian, Katrin Elgorgh-Woytek. 2005. Anarchy and Dictorship (From: Who is Still Haunted by the Spector of Communism? Explaining Relative Output Contractions Under Transition, IMF Working Paper No. 05/68). IMF Survey 34, no. 16: 259 .

Berg-Schlosser, Dirk and Raivo Vetik, eds. 2001. Perspectives on democratic consolidation in central and eastern Europe. Boulder: East European Monographs. 
Biro, Ana-Maria and Petra Kovacs. 2001. Diversity in action: Local public management of multi-ethnic communities in central and eastern Europe. Budapest: Local Government and Public Service Reform Initiative.

Brusis, Martin. 2003. L'echelon egional en Europe Centrale et Orientale: Institutions, Competences et Ressources. Revue d'etudes comparatives Est-Ouest 34, no. 2: 145171.

Brusis, Martin. 2003. L'Echelon REgional en Europe Centrale et Orientale: Institutions, Competences et Ressources. Revue d'etudes comparatives Est-Ouest 34, no. 2: 145171.

Bunting, Madeleine. Regime change, European-style, is a measure of our civilisation. The Guardian 2005.

Burch, Kurt. 2002. Toward a constructivist comparative politics. In Constructivism and comparative politics. Armonk and London: M.E. Sharpe.

Buzan, Barry. 1993. From International System to International Society Structural Realism and Regime Theory Meet the English School. International Organization 47, no. 3: 352-377.

Central Europe. Wikipedia, the free encyclopedia. Available from http://en.wikipedia.org/wiki/Central_Europe. Accessed July 11, 2006.

Central European Initiative. 2004. Know-how exchange program.

Central European Initiative. Organization website. Internet on-line. Available from $<$ http://www.ceinet.org/main.php?pageID $=25>$. [January 6, 2006].

Central European Initiative. Organization website: Secretariat for projects in London. Internet on-line. Available from $<$ http://www.ceinet.or/main?pagelD=16>. [November 29, 2005].

Central European Initiative. Organization website: Education. Internet on-line. Available from $<$ http://www.ceinet.org/main.php?pageID $=58>$. [November 29, 2005].

Central European Initiative Executive Secratariat. 2005. CEI youth orchestra. 
Central European Initiative Executive Secratariat. CEI university network - knowledge through mobility. 6.

Central European Initiative Executive Secretariat. 2005. Central European Initiative: Goals, Structure, Activities, Funds. Trieste, Italy: CEI.

Central European Initiative Newsletter. 2006. Volume 44: June.

Central European Initiative Secretariat for Projects. 2005. Know-how exchange programme.

Cerny, Philip. 1990. The changing architecture of politics: Structure, agency, and the future of the state. London: Sage.

Cerny, Philip G. 1995. Globalization and the Changing Logic of Collective Action. International Organization 49: 595.

Christiansen, Thomas, Knud E. Jorgensen, and Antje Wiedner. 1999. The Social Construction of Europe. Journal of European Public Policy special issue 6, no. 4: 528-544.

Dahl, Robert A. 1971. Polyarchy: Participation and opposition. New Haven: Yale University Press.

Della Porta, Donatela, and Mario Diani. 1999. Social movements: An introduction. Oxford: Blackwell Publishers.

Deutsch, Karl W., Sidney A. Burrell, Robert A. Kann, Maurice J. Lee, Martin Lichtermann, Lindgren, Raymond, E., Loewenheim, Francis, L., and Van Wagenen, Richard W. 1957. Political community and the north Atlantic area. Princeton: Princeton University Press.

Dunay, Pal, Przemyslaw Grudinski, Andris Ozolins, Dan Pavel, and Stefan Tafrov. 1995. A Lasting Peace in Central Europe? Institute for Security Studies of WEU.

EastAgri Member - Central European Initiative. Rural finance and learning center. Internet on-line. Available from $<$ http://www.eastagri.org/member_details.asp?id=12)>. [February 4, 2006]. 
Eastern Europe - Wikipedia, the free encyclopedia. Available from

http://en.wikipedia.org/wiki/Eastern Europe. Accessed July 11, 2006

Elster, Jon, Claus Offe, and Ulrich K. Preuss. 1998. Institutional design in postcommunist societies: Rebuilding the ship at sea. Cambridge: Cambridge University Press.

European Union. INTERREG III B CADSES neighbourhood programme.Internet on-line. Available from

$<$ http://www.cadses.net/en/programme.html?PHPSESSID =5bd00576fdae69e14162a 78ff07d2...). $>$. [February 4, 2006].

Finnemore, Martha. 1996. National interests in international society. Ithaca, NY and London: Cornell University Press.

Foucault, Michel. 1979. Discipline and punishment: The birth of the prison. New York: Vintage Books.

Friedham, Daniel V. 1993. Bringing Society Back into Democratic Transition Theory after 1989: Pact-Making and Regime Collapse. East European Politics and Societies 7, no. 3: 482-512.

Gilpin, Robert. 2001. Global political economy. Princeton: Princeton University Press.

Glasnost - Wikipedia, the free encyclopedia. Available from

http://en.wikipedia.org/wiki/Glasnost. Accessed July 11, 2006.

Green, Daniel M. ed. 2002. Constructivism and comparative politics. Armonk and London: M.E. Sharpe.

Gunther, Richard, P. N. Diamandouros, and Hans-Juergen Phule. 1995. The politics of democratic consolidation: Southern Europe in comparative perspective. Baltimore: The Johns Hopkins University Press.

Haas, Ernst. 1964. Beyond the nation state: Functionalism and international organization. Stanford: Stanford University Press.

Haas, Ernst. 1961. International Integration: The European and the Universal Process. International Organisation , no. 15: 366-392. 
Haas, Ernst. 1958. The uniting of Europe: Political, social, and economic forces, 1950 1957. Stanford: Stanford University Press.

Haas, Peter. 1992. Knowledge, Power, and International Policy Coordination. International Organization 46, no. 1: Special Issue.

Haas, Peter M. 1992. Introduction: Epistemic Communities and International Policy Coordination. International Organization 46: 1-36.

Habermas, Juergen. 1996. Der europaeische nationalstaat - zu vergangenheit und zukunft von souveraenitaet und staatsbuergerschaft. In Die einbeziehung des anderen. Frankfurt/M: Suhrkamp.

Haftendorn, Helga, Robert O. Keohane, and Celeste A. Wallander. 1999. Imperfect unions. Oxford: Oxford University Press.

Haggard, Stephan, and Robert R. Kaufmann. 1995. The political economy of democratic transitions. Princeton: Princeton University Press.

Hall, P., R. Taylor. 1996. Political Science and the Three New Institutionalisms. Political Studies 44: 936-957.

Hall, Rodney B. 2002. The socially constructed contexts of comparative politics. In Constructivism and comparative politics. Armonk, NY and London: M.E. Sharpe.

Hay, Colin, Daniel Wincott. 1998. Structure, Agency and Historical Institutionalism. Political Studies 46: 951-957.

Held, David. 1996. Models of democracy. Stanford: Stanford University Press.

Herrmann, Richard K., Thomas Risse, and Marilynn B. Brewer ed. 2004. Transnational identities. Lanham, Boulder: Rowman \& Littlefield Publishers, Inc.

Hewson, Martin, and Timothy J. Sinclair ed. 1999. Global governance theory. Albany, NY: State University of New York Press.

Hobbs, Thomas. 1974. Leviathan. In Leviathan. New York and London: Collier Macmillan. 
Huntington, Samuel P. 1991-2. How Countries Democratize. Political Science Quarterly 106, no. 4: 579-616.

Huntington, Samuel P. 1991. The third wave: Democratization in the late twentieth century. Norman: University of Oklahoma Press.

Hurrell, Andrew. 1993. International society and the study of regimes. In Regime theory and international relations. Oxford: Clarendon Press.

Ikenberrry, G. J., David A. Lake, and Michael Mastanduno. 1988. Introduction, Approaches to Explaining American Foreign Economic Policy. International Organization 42, no. 1: 1-14.

Inglehart, Ronald, and Christian Welzel. 2005. Modernization, cultural change, and democracy. Cambridge, NY: Cambridge University Press.

International Centre for Theoretical Physics. What's new: Going east. Internet on-line. Available from $<$ http://www.ictp.triest.it/ sci_info/News_from_ICTP/News_113/whatsnew.html $>$. [February 4, 2006].

Jackson, Patrick T., Daniel Nexon. 2002. Globalization, the comparative method, and comparing constructions. In Constructivism and comparative politics. Armonk and London: M.E. Sharpe.

Jervis, Robert. 1999. Realism, Neoliberalism, and Cooperation: Understanding the Debate. International Security 24, no. 1: 42-63.

Johnson, James T. 1992. Does Democracy 'Travel'? Some Thoughts on Democracy and Its Cultural Context. Ethics and International Affairs 6: 41-55.

Kant, Immanuel. 1957. Morality, politics, and perpetual peace. In Indianapolis and New York: Bobbs-Merrill Company.

Katzenstein, Peter. 1996. The culture of national security. New York: Columbia University Press.

Keck, Margaret E., and Kathryn Sikkink. 1998. Activists beyond borders: Advocacy networks in international politics. Ithaca: Cornell University Press. 
Keohane, Robert O. 1988. International Institutions: Two Approaches. International Studies Quarterly 32: 379-396.

Keohane, Robert O. 1984. After hegemony. Princeton: Princeton University Press.

Keohane, Robert O., and Stanley Hoffmann. 1991. The new European community. Boulder: Westview Press.

Koehane, Robert O., Joseph Nye. 1971. Transnational Relations and World Politics: an Introduction. International Organization 25, no. 3: 329-350.

Keylor, Willam R. 2001. The twentieth-Century World. Oxford: Oxford University Press.

Kohler-Koch, Beate. 2000. Framing: The Bottleneck of Constructing Legitimate Institutions. Journal of European Public Policy 7, no. 4: 513-531.

Kopecky, Petr. 2000. What has Eastern Europe Taught Us about the Democratisation Literature (and Vice Versa)? European Journal of political research 37, no. 4: 517 539.

Krasner, Stephen D. 1983. International regimes. Ithaca: Cornell University Press.

Krasner, Stephen D. 1978. Defending the national interest. Princeton, NJ: Princeton University Press.

Kratchowil, Friedrich, John G. Ruggie. 1986. International Organization: A State of the Art on an Art of the State. International Organization 40, no. 4: 753-775.

Kratochwil, Friedrich. 1996. Is the ship of cultures at sea or returning? In The realm of culture and identity in international relations theory. Boulder: Lynne Rienner.

Kratochwil, Friedrich V. 1993. Contract and Regimes. Do Issue Specificity and Variations of Formality Matter? Tuebingen/Germany Center for International Relation/Peace and Conflict Studies, Institute for Political Science, University of Tuebingen.

Kratochwill, Friedrich V. 1988. Regimes, Interpretation and the 'Science' of Politics: A Reappraisal. Millennium: Journal of International Relations 17: 263-284. 
Kratochwil, Friedrich V. 1982. On the notion of "interest" in international relations. International Organization 36, no. 1:30.

Kreid, Harald. 2006. Major CEI Annual Working Meeting. CEI Newsletter No. 44 (June): 4.

Kreid, Harald. 2005. Competitiveness - Innovation - Human Resources.

Kubalkova, Vendulka, Nicholas Onuf, and Paul Kowert. 1998. International relations in a constructed world. Armonck, NY: M.E. Sharpe.

Kupchan, Charles, Clifford Kupchan. 1991. Concerts, Collective Security and the Future of Europe. International Security 16, no. 1, summer.

Lampe, Ronald H. (ed.). 1993. East European security reconsidered. Washington: The Woodrow Wilson Center Press.

Lapid, Yself and Friedrich Kratochwil ed. 1996. The return of culture and identity in IR theory. Boulder: Lynne Rienner.

Lewis, Martin, and Karen Wigen. 1997. The myth of continents: A critique of metageography. Berkeley: University of California Press.

Lijphard, Arend. 1992. Democratization and Constitutional Choices in Czechoslovakia, Hungary, and Poland, 1989-1991. Journal of Theoretical Politics 4, no. 2.

Limbach, Jutta. 2005. Making multiculturalism work.

Linden, Ronald H. (ed.). 2002. Norms and nannies: The impact of international organizations on the central and east European states. Lanham: Rowman \& Littlefield Publishers, Inc.

Linz, Juan, and Alfred Stepan. 1996. Problems of democratic transition and consolidation. Baltimore: The Johns Hopkins University Press.

Lipset, Seymour M. 1959. Some Social Requisites of Democracy: Economic Development and Political legitimacy. American Political Science Review 53: 69104. 
Mansfield, Edward D., Helen V. Milner. 1999. The New Wave of Regionalism. International Organization 53, no. 3: 589.

Maravall, Jose M. 1997. Regimes, politics and markets: Democratization and economic change in southern and eastern Europe. Oxford: University Press.

March, J. D. and J. P. Olsen. 1998. Rediscovering institutions. New York: Free Press.

Marks, Bary, Doug McAdam. 1996. Social movements and the changing structure of political opportunity in the European Union. In Governance in the European Union. London: Sage.

Marks, Gary, Doug McAdam. 1999. On the relationship of political opportunities to the form of collective action: The case of the European union. In Social movements in a globalizing world. London: McMillan.

Martin, Lisa. 1992. Interests, Power, and Multilateralism. International Organization 46: 765.

Mazey, Sonia. 1998. The European Union and Women's Rights: From the Europeanization of National Agendas to the Nationalization of a European Agenda? Journal of European Public Policy 5, no. 1: 131-152.

McAdam, Doug, John D. McCarthy, and Mayer N. Zald. 1996. Introduction: Opportunities, mobilizing structures, and framing processes - toward a synthetic, comparative perspective on social movements. In Comparative perspectives on social movements: Political opportunities, mobilizing structures, and cultural framings. New York: Cambridge University Press.

McAdam, Doug, John D. McCarthy, and Mayer N. Zald. 1988. Social movements. In Handbook of sociology. Newbury Park: Sage.

McGann, and Weaver. 2000. Think tanks and civil societies. New Brunswick: Transaction Publishers.

Miller, William, Ase B. Gordeland, and Ttyana Y. Koshekina. 2001. A culture of corruption: Coping with government in post-communist Europe. New York: Central European University Press. 
Moravcsik, Andrew. 1998. The choice for Europe: Social purpose and state power from Messina to Maastricht. Ithaca: Cornell University Press.

Moravcsik, Andrew. 1997. Taking Preferences Seriously: A Liberal Theory of International Politics. International Organization 51, no. 4: 513-553.

Moravcsik, Andrew, Milada A. Vachudova. 2003. National Interests, State Power, and EU Enlargement. East European Politics and Societies 17, no. 1: 42.

Muller, Edward N., Mitchell A. Seligson. 1994. Civic Culture and Democracy: The question of Causal Relationships. American Political Science Review 88, no. 3: 635652.

Norris, Pippa. 2004. Building Knowledge Societies: The renewal of democratic practices in knowledge societies. Cambridge: John F. Kennedy School of Government, Harvard University.

North, Douglass C. 20005. Understanding the process of economic change. Princeton: Princeton University Press.

O'Donnell, Guillermo, and Philippe C. Schmitter. 1986. Transitions from authoritarian rule: Tentative conclusions about uncertain democracies. Baltimore: The Johns Hopkins University Press.

O'Donnell, Guillermo, Philippe C. Schmitter, and Laurence Whitehead. 1986. Transitions from authoritarian rule: Prospects for democracy. Baltimore: The Johns Hopkins University Press.

OECD. LEED program. Internet on-line. Available from

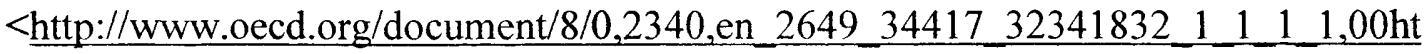
ml>. [April 27, 2006].

OECD: Organisation for Economic Co-operation and Development. Building partnerships for progress: LEED programme. Internet on-line. Available from <www.oecd.org/document/8/0,2340,en_2649 $34417 \quad 32341832 \quad 1 \quad 1 \quad 1 \quad 1,00 \mathrm{html}>$. [February 4, 2006].

Oliver, P. E., G. Marwell. 1992. Mobilizing technologies for collective action. In Frontiers in social movement theory. New Haven: Yale University Press. 
Olson, Marcur. 1971. The logic of collective action. New York: Schocken Books.

Onuf, Nicholas. 1989. World of our making: Rules and rule in social theory and international relations. Columbia: University of South Carolina Press.

Organisation for Economic Co-operation and Development. Building partnerships for progress: LEED programme. Internet on-line. Available from <www.oecd.org/document/8/0,2340,en_2649_34417_32341832_1_1_1_1,00html >. [April 27, 2006].

Oye, Kenneth. 1986. Cooperation under anarchy. Princeton University Press: Princeton.

Pietrzyk, Dorota I. 2003. Democracy or civil Society? Politics 23, no. 1: 38-45.

Plasser, Fritz, Peter A. Ulram, and Harald Waldrauch. 1998. Democratic consolidation in east-central Europe. New York: St. Martin's Press, Inc.

Pollack, Mark A. 1997. Representing Diffuse Interests in EC Policymaking. Journal of European Public Policy 4, no. 4: 572-590.

Powell, Robert. 1994. Anarchy in International Relations Theory: The NeorealistNeoliberal Debate. International Organization 48, no. 2: 313-344.

Puchala, Donald. 2003. Theory and history in international relations. New York: Routledge.

Puchala, Donald J. 1999. Institutionalism, Intergovernmentalism and European Integration: A Review Article. Journal of Common Market Studies 37, no. 2: $317-$ 331.

Putnam, Robert D. 1993. Making democracy work: Civic traditions in modern Italy. Princeton, NJ: Princeton University Press.

Quigley, Kevin F. F. For democracy's sake: Foundations and democracy assistance in central Europe. Washington: The Woodrow Wilson Center Press.

R.A.V.E.: Raising Awareness about the Value of Space Project. Home: About the project. Internet on-line. Available from $<$ http://ww.ravespace.org/RaveSpace/default.aspx/Sez1.aspx>. [February 4, 2006]. 
Reinicke, Wolfgang H. 1998. Global public policy. governing without government? Washington, DC: Brookings Institute.

Rempel, Gerhard. 1995. Revolution in Eastern Europe: 1989. Available from http://mars.wnec.edu/ grempel/courses/wc2/lectures/rev89.html. [July 11, 2006].

Revolutions of 1989 - Wikipedia, the free encyclopedia. Available from $<$ http://en.wikipedia.org/wiki/Revolutions_of 1989>, Accessed July 11, 2006.

Risse, Thomas. 2004. European institutions and identity change: What have we learned? In Transnational identities: Becoming European in the EU. Lanham: Rowman \& Littlefield Publishers, Inc.

Risse-Kappen, Thomas. 1996. Exploring the Nature of the Beast: International Relations Theory and Comparative Policy analysis meet the European Union. Journal of Common Market Studies 34, no. March.

Risse-Kappen, Thomas. 1995. Cooperation among democracies: The European influence on U.S. foreign policy. Princeton: Princeton University Press.

Rose, Richard, William Mishler, and Christian Haerpfer. 1998. Democracy and its alternatives. Baltimore: The Johns Hopkins University Press.

Rosenau, James N. 1997. Along the domestic-foreign frontier. exploring governance in a turbulent world. Cambridge: Cambridge University Press.

Rosenau, James N. 1990. Turbulence in world politics. A theory of change and continuity. Princeton: Princeton University Press.

Ruggie, John G. 1998. Constructing the world polity. New York: Routledge.

Russett, Bruce M., and John R. Oneal. 2001. Triangulating peace: Democracy, interdependence, and international organizations. New York: Norton.

Rustow, Dankwart A. 1970. Transitions to Democracy: Toward a Dynamic Model. Comparative Politics, April: 337-363.

Schedler, Andreas. 1998. What is Democratic consolidation. Journal of Democracy 9, no. 2: 91-107. 
Schmitter, Philippe, Terry L. Karl. 1991. What Democracy is ... and Is Not. Journal of Democracy 2, no. 3: 75-88.

Schroeder, Paul W. 1994. Historical Reality vs. Neorealist Theory. International Security 19, no. 1: 108-145.

Secretary-General. 2002. Integration of the Human Rights of Women and the Gender Perspective. United Nations Economic and Social Council, Commission on Human Rights - Fifty-Eighths session, Item 12 of the provisional agenda.

Serbia and Montenegro - Wikipedia, the free encyclopedia. Available from $<$ http://en.wikipedia.org/Servia_and_Montenegro>. Accessed July 11, 2006.

Skocpol, Theda. 1979. States and social revolutions. Cambridge, UK: Cambridge University Press.

Sledzinski, Janusz. 2004. GPS news from CEI. In 1-6. Warsaw: Civil GPS Service Interface Committee, International Information Subcommittee.

Slovenian Foreign Ministry. Minister dr. Ruppel to attend the CEI meeting in Milan on 22 June 2001. 19 June 2001Internet on-line. Available from $<$ http://www.gov.si/mzz/eng/news_room/news/01061901.html $>$, accessed $1 / 19 / 2006$.

Snidal, Duncan. 1985. Coordination versus Prisoners' Dilemma: Implications for International Cooperation and Regimes. American Political Science Review 79: 923.

Snow, D. A., E. B. Rochford Jr., S. K. Worden, and R. D. Benford. 1986. Frame Alignment Processes, Micromobilization, and Movement Participation. American Sociological Review 51: 464-481.

Stein, Arthur A. 1983. Coordination and collaboration: Regimes in an anarchic world. In International regimes. Ithaca: Cornell University Press.

Stone, Diane. 2000. Banking on knowledge: The genesis of the global development network. London: Routledge.

Stone, Diane, Heidi Ulrich. 2003. Policy Research Institutes and Think Tanks in Western Europe: Development Trends and Perspectives. Budapest: Local Government and Public Service Reform Initiative. 
Southern Europe - Wikipedia, the free encyclopedia. Available from http://en.wikipedia.org/wiki/Southern_Europe. Accessed July 11, 2006.

Surel, Ives. 2000. The Role of Cognitive and Normative Frames in Policy-Making. Journal of European Public Policy 7: 495-512.

Tarrow, Sidney. 1996. Making Social Science Work Across Spce and Time: A Critical Reflection on Robert Putnam's Making Democracy Work. American Political Science Review 90, no. 2.

Tarrow, Sidney. 1994. Power in movement: Social movements, collective action and politics. New York: Cambridge University Press.

Thelen, K., and S. Steinmo. 1992. Historical institutionalism in comparative politics. In Structuring politics:Historical institutionalism in comparative analysis. Cambridge: Cambridge University Press.

Tilly, Charles. 1985. War making and state making as organized crime. In Bringing the state back in. Cambridge: Cambridge University Press.

Tilly, Charles. 1975. The formation of the nation state. Princeton, NJ: Princeton University Press.

Tilly, Virginia Q. 2002. The role of the state in ethnic conflict: A constructivist reassessment. In Constructivism and comparative politics. Armonk, NY and London: M.E. Sharpe.

Treeck, Wolfgang, Philippe C. Schmitter. 1991. From National Corporatism to Transnational Pluralism: Organized Interests in the Single European Market. Politics and Society 19: 133-164.

Viotti, Paul R., and Mark V. Kauppi. 2005. International relations theory. Boston and London: Allyn and Bacon.

Volten, Peter e. 1990. Uncertain futures: Eastern Europe and democracy. New York: Institute for East-West Security Studies.

Vos, Robert. 2006. Diverging Growth and Development and the UN's Role in Containing it. Speech at the UN Headquarters on 19 July 2006 to Seton Hall University Summer 
UN Program through the UN Development Policy and Analysis Division, Department of Economic and Social Affairs.

Waltz, Kenneth. 1979. Theory of international politics. Boston: McGraw-Hill.

Waltz, Kenneth N. 1979. Theory of international politics. New York: McGraw Hill.

Weber, Max. 1949. Essays in sociology. New York: Oxford University Press.

Weber, Max. 1949. The theory of social and economic organization. New York: The Free Press.

Wendt, Alexander. 1999. Social theory of international politics. Cambridge, UK:

Cambridge University Press.

Wendt, Alexander. 1992. Anarchy is What States Make of It: The Social Construction of Power Politics. International Organization 46: 391-425.

Wendt, Alexander. 1987. The Agent-Structure Problem in International Relations Theory. International Organization 41, no. 3: 335-370.

Whitehead, Laurence. 1996. Three international dimensions of democratization: Eastcentral Europe. In The international dimensions of democratization: Europe and the Americas. Oxford: Oxford University Press.

Wolf, Dieter and Bernhard Zangl. 1996. The European Economic and Monetary Union: 'Two-level games' and the Formation of International Institutions. European Journal of International Relations 2, no. 3: 355-393.

Zito, Anthony. Comparing environmental policy-making in transnational institutions. Journal of European Public Policy 5, no. 4: 671-690.

Zuern, Michael. 1997. Assessing State Preferences and Explaining Institutional choice: The Case of Intra-German Trade. International Studies Quarterly 41, no. 2: 295-320. 
Appendix 1 - Institutional Review Board Approval and Completion Record for Course in the Protection of Human Subject Research Subjects 


\section{MEMORANDUM}

To:

Astrid Boening

CC:

Dr. Lisa Prugl

File

From:

Date:

Chris Grayson, CIM, Institutional Review Board Coordinator

August 31, 2005

Proposal Title: Democratization of Eastern Europe.

Approval \# 052605-01

Your study was deemed Exempt by the Institutional Review Board at Florida International University on May 26, 2005.

As a requirement of IRB approval you are required to:

1) Submit a completion report (Form B-2) upon completion of your project in order for the file to be closed.

2) Submit a proposal and receive approval for any additions or changes in the procedures involving human subjects.

3) Provide immediate written notification to the IRB of every serious or unusual or unanticipated adverse event as well as problems with the rights or welfare of the human subjects. You must confirm the receipt of serious AE reports with the IRB office.

Special Conditions: N/A

Please note your approval number is indicated above. For further information, you may contact the IRB Coordinator by email at irbiacuc@fiu.edu or visit the OSRA - Human Subjects website at www.osra.fiu.edu. 
FLORIDA INTERNATTONAL UNITERSTIT

\section{Consent to Participate in Research - Verbal Presentation}

\section{Dear Madam or Sir,}

I would like to introduce myself, Astrid Boening, as a graduate student at Florida International University in Miami/FL, USA. As a representative of a European government or a nongovernmental organization, I request your participation in a brief interview on the role of $\mathrm{NGO}^{\circ}$ s in the democratization of Eastern European countries.

The purpose of my study is the field work required for my Master's Thesis on "The role of NonGovernmental Organizations (NGOs), by example of the Central European Initiative in Triest/Italy and others in the Czech Republic and Slovakia in knowledge transfer from democratic institutions to newly democratized countries."

This interview will take approximately 30-60 minutes of your time in your office.

There are no loresecable risks or benefits to you for participation in this study. There is no cost or payment to you. If you have questions while taking part, please stop me and ask. You will remain anonymous and your answers are confidential.

If you have questions after we have finished you may call me at $+001-786-325-5597$ and we will answer your questions. If you have questions about being in a study or you feel as if you were not treated well during this study, call Dr. Jonathan Tubman at 305-348-2494. Ile is the Chair of the Institutional Review Board at Florida International University in Miami/FI. USA.

Your participation in this research is voluntary, and you will not be penalized or lose benctits if you refuse to participate or decide to stop. May I continue? 


\section{CITI Course in The Protection of Human Research Subjects}

\section{Print This Report}

Friday, May 20, $2 C$

\section{Cril Course Completion Record for Astrid Boening}

To whom it may concern:

On 5/20/2005, Astrid Boening (usemame=astridboening1 @aol.com; UM ID Number=000) completed all CITI Program requirements for the Basic CITI Course in The Protection of Huma Research Subjects.

Leamer Institurtion: University of Miami

Leamer Group: Group 4.

Learner Group Description: Investigators and staff conducting Social / Behavioral Research only who:

- Have direct contact with subjects or subject rocords

- Work ONLY at the $U$ of Miami.

\section{Contuct Information:}

Gender. Female

Site: Other

Department: European Studies Center

Which course do you plan to take?: Social \& Behavioral Investigator Course Only

Role in human subjects research: Principal Investigator

May we re-contact you to complete a course survey?: Yes

Mailing Address:

20335 W. Country Club Dr. \#106

Aventura

FL

33180

USA

Email: astridboening1@ad.com

Office Phone: 7886-325-5597

Home Phone: 305-933-9321

The Required Modules for Group 4. are:

Date completed

Introduction

05/09/05

https://www.citiprogram.org/members/courseandexam/certificate.asp?strKeyID $=7209892 \mathrm{~F} . . \quad 5 / 20 / 2005$ 
History and Ethical Principles - SBR

$05 / 11 / 105$

Defining Research with Human Subjects - SBR

05/11/05

The Regulations and The Social and Behavioral Sciences - SBR

$05 / 11 / 105$

Assessing Risk in Social and Behavioral Sciences - SBR

$05 / 13 / 05$

Informed Consent - SBR

05/13/05

Privacy and Confidentiality - SBR

05/13/05

Research with Prisoners - SBR

05/15/05

Research with Children - SBR

05/15/05

Research in Public Elementary and Secondary Schools - SBR

05/17/05

International Research - SBR

05/17/05

Internet Research - SBR

05/18/05

HIPAA and Human Subjects Research

05/19/05

Conflicts of Interest in Research Imvolving Human Subjects

05/20/05

University of Miami

05/20/05

Additional optional modules completed:

Date completed

For this Completion Report to be valid, the learner listed above must be affilinted with a I participating institurtion. Falsified information and unauthorized use of the CITI course si is unothical, and may be considered scientific misconduct by your inatitution.

Paut Braunschweiger Ph.D.

Professor, University of Miami

Director Office of Research Education

CITI Course Coordinator

CRe 100730

https:/www.citiprogram.org/members/courseandexam/certificate.asp?stKeyID=7209892F... 5/20/2005 
Appendix 2 - Intergovernmental Organization Elite Interview Questionnaire 


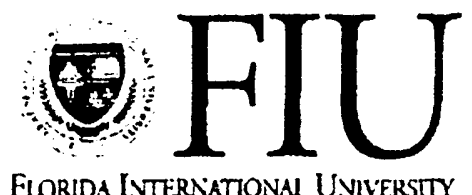

\section{Consent to Participate in Research - Verbal Presentation}

\section{Dear Madam or Sir,}

I would like to introduce myself, Astrid Boening, as a graduate student at Florida International University in Miami/FL, USA. As a representative of a European government or a nongovernmental organization. I request your participation in a brief interview on the role of NGO's in the democratization of Eastern European countries.

The purpose of my study is the field work required for my Master's Thesis on "The role of NonGovernmental Organizations (NGOs), by example of the Central European Initiative in Triest'Italy and others in the Czech Republic and Sluvakia in knowledge transfer from democratic institutions to newly democratized countries."

This interview will take approximately 30-60 minutes of your time in your office.

There are no foreseeable risks or benefits to you for participation in this study. There is no cost or payment to you. If you have questions while taking part, please stop me and ask. You will remain anonymous and your answers are confidential.

If you have questions after we have finished you may call me at +001-786-325-5597 and we will answer your questions. If you have questions about being in a study or you feel as if you were not treated well during this study, call Dr. Jonathan Tubman at 305-348-2494. He is the Chair of the Institutional Review Board at Florida International University in Miami/FI, USA.

Your participation in this research is voluntary. and you will not be penalized or lose benefits if you refuse to participate or decide to stop. May I continue? 


\section{IGO OUESTIONNAIRE}

\section{Political Alliance.}

1. What type of program does your organization develop/back?

2. What is democracy in your organization's understanding?

3. Who are your collaborators/counterparts/partner organizations?

4. What is their relationship in defining the programs?

5. Is there a mutual definition of programs with them?

6.Who defines the program ideas in your organization?

7. Who in your organization develops them?

8. Who implements them?

\section{Activities/Programs}

1. What theoretical approach do you pursue in your organization?

2. What practical approach do you pursue in your organization?

3. What assistance do you receive and from which agencies?

4. What recommendations do you have for future activities/programs?

5. What areas do your programs focus on?

6. Do the topics of your programs change or remain focused? On what?

7. How do these compare to the past?

8. How do these compare to the future?

9. How do your programs relate to think tanks?

10. Would you describe your activities as lobbyist? 


\section{Criteria for Success}

1. What are your organizaiton's criteria for success of your programs?

\section{Prospects for Involvement in European Neighborhood Program?}

1. How does your program differ from similar institutions, especially within the European Union?

\section{Funding}

1. Do you receive proceeds only from a grant?

2. To whom are fund disbursements accountable? 
Appendix 3 - Central European Initiative Guidelines and Rules of Procedure 


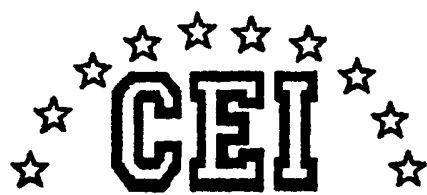 \\ CENTRAL EUROPEAN INTTATTVE \\ Central European Initiative \\ Guidelines and Rules of Procedure}

\section{Principles and objectives}

1. The Central European Initiative (CEI) is a regional forum for co-operation and consultation among and between lts Member States.

Member States of the CEI are: Albanis, Austria, Belarus, Bosnla and Herzegovina, Bulgaria, Croatla, the Czech Republic, Hungary, Italy, Macedonla, Moldova, Poland, Romania, Slovakla, Slovenla, Ukraine and the Federal Republic of Yugoslavia.

2. The Member States of the CEI are guided by the principles of the UN Charter, of all the documents of the Helsinkl process/OSCE. They are guided as well by final declarations and documents of the meetings of the Heads of Government and the Foreign Ministers of the CEI (including those of the predecessor initiatives: Quadrilateral, Pentagonal, Hexagonal).

3. The CEI, as a part of the European integration process, endeavours to co-operate with European organisations and Institutions, in particular with the European Union, the Cound of Europe and the OSCE as well as with other regional co-operation inituatives In areas of mutual Interest.

The CEI also co-operates with the UN system and with other relevant Intemational organisations, in particular the UNECE, the OECD as well as with international financial institutions, especially the EBRD.

4. The strategic goals of the CEI are:

a) to work for cohesion of a united Europe, without dividing lines, a Europe with shared values, embracing all countries, reglons, peoples and citizens of the continent;

b) to focus co-operation within the framework of the CEI In particular on assistance to strengthen the capacitles of the least advanced member countries and of those having the greatest need for accelerated economic development or recovery.

5. The co-operation within the framework of the CEI shall alm at the following princlpal objectives:

a) strengthening co-operation among and between Member States,

b) strengthening the participation of all Member States in the process of European integration,

c) strengthening economic, soclal, legal and other aspects of the transformation processes.

6. The co-operation within the framework of the CEI shall include, Inter alla, the following areas:

- consultations on political matters of mutual interest,

- economic and technical co-operation,

- development of infrastructure in transport, energy, telecommunication, agrkulture,

- strengthening the democratic instluttions and observance of human rights, including the rights of persons belonging to national minorities as well as humanitarian matters,

- protection of human emvironment,

- co-operation in the field of sdence and technology, medla, culture, education, youth exchange, tourism

- cross-border and interregional co-operation. 


\section{Membership and participation in the CEI}

7. The CEI can invite any interested third State, regional entity and internationat organisation to partidpate in CEI activitles, events, programmes and projects.

The CEI can also confer the status of spedal guest or other forms of partnershlp as approprate.

8. The CEI shall promote co-operation with NGOs, professional assoclations, academic and other institutions willing to co-operate on matters of mutual interest.

9. Any Member State of the CEI which has seriously violated the princlples referred to in Art. 2 of the present Guidelines may be suspended from Its rights of representation by the Forelgn Ministers. If such Member State persists in these violations, the Heads of Government may decide that it has ceased to be a Member of the CEI. The decision on that matter should be taken following the rule of consensus minus one.

\section{Organisation and structure}

10. The CEI operates in a flexible manner through several bodies.

11. The Governmental Dimension of the CEI consists of the following bodies:

- Meeting of the Heads of Government (CEI Summit),

- Meeting of the Ministers of Foreign Affairs (MFA Meeting),

- Meeting of the Polltical Directors of the Ministries of Forelgn Affairs of CEI Member States (PoD Meeting)

- Committee of National Co-ordinators (CNC),

- Working bodies (Working Groups, Expert Groups, Project Groups etc.),

- Executive Secretariat (CEI-ES) and

- as specialised instrument the Secretarlat for CEI Projects (CEI/EBRD Secretarlat) ${ }^{2}$.

12. The Parliamentary Dimension of the CEI functions according to Its structure and rules of procedure. It consists of the following bodies:

- The Conference of the Speakers of Parllaments

- The Parliamentary Assembly

- The Parliamentary Committee

- Working bodies (Ad Hoc Committees etc.).

13. The Business Dimension of the CEI, which functions according to its own modalities, consists of the following bodies:

- the Annual Presidents' Conference of the Central European Chambers of Commerce Inttatlve (CECCI)

- the Secretariat of the Annual Presidents' Conference of CECCI.

14. The Meating of the Heads of Government (CEI Summit) shall be convened once a year in autumn. The following matters shall be decided by the CEI Summit:

- principles and objectives of the CEI,

- amendments to the "CEI Guidelines and Rules of Procedure",

- political and economic orientation for the co-operation within the framework of the Initlative, including adoption of the Plan of Action,

- suspension of membership.

- epproval of the Annual Report of the CEI-ES DG.

15. The Meting of the Ministers of Foretan Affairs (MFA Meeting) shall be convened once a year in spring. The MFA Meeting shall decide upon specific issues of the CEI $\infty$-operation, including:

- political co-operation,

- participation in CEI activities, as referred to in Art. 7,

\footnotetext{
1 The CEIEBRD Secretariat is functioning on the basts of the Secretarlat Agreement of 21 July 1998, conduded between the CEI and the EBRD and the Fund Agreement conduded between the Government of Italy and the EBRD on a CEI Fund. The fund Agreement was concluded on 14 Aprll 1992 and emended on 23 July 1997.
} 
- the organisational structure, areas and ways of co-operation,

- matters concerning the establishment and the operational structure of the working bodies.

- the formula of the annual contributions, annual budget and scale of contributions of the CEI Co-operation Fund,

- the appointment and recall of the CEI-ES Director General and Deputy Directors General.

16. The Meting of Polltical Directors of the Ministres of Forelgn Affairs of CEI Member States (POD) shall be convened at least once a year. As a rule, it will take place in Rome. Additlonal meetings can be convened on an ad hoc basis in response to specific situations that might arise in the CEI region or within the organisation.

17. The Committee of National_Co-ordinaters (CNC) is the key body responsible for the management of CEI co-operation and the implementation of CEI programmes and projects through approprlate structures. The CNC is convened regularty, in princlple once a month, to discuss and to co-ordinate co-operation within the varlous bodies of the CEI as well as in relation with other International organisations and regional groupings.

The CNC, assisted by the CEI-ES, shall prepare the documents to be approved by the CEI Summit or by the MFA Meeting.

The CNC shall discuss and review the activitles of the CEI working bodies and shall provide appropriate guidance to them.

The CNC, In consultation with the Director General of the CEI-ES, shall decide upon the structure and the staff of the CEI-ES.

18. In case of need the CNC can entrust specific tasks to a committee with reduced membershlp, dealing, Inter alia, with questlons relating to technical and financial aspects of CEI activities Including those concerning co-operation with the EU/EC and other internatlonal organisations and financial institutions.

The CEI-Executive Secretariat and the Secretariat for CEI projects shall participate in the meetings of this committee.

19. The Chaimanshlp of the CEI (Presidency) shall rotate annually at the beginning of the calendar year based on the alphabetical order of the English names, of CEI Member States, unless decided otherwise. Regarding the chairmanship of the CEI working bodies see Art. 20 .

The Chalman-in-office shall be supported by the former and the next Chairman, which form the Troika of the CEI.

The Presidency shall convene the meetings of the Heads of Government, the Ministers of Forelgn Affairs, the Political Directors and the CNC. The meetings of the CNC may be convened also in other countries. In case of Impediment of the Chairman-in-office meetings of the CNC shall be chalred, at the discretion of the Presidency, by one of the Troika members or by the CEI-ES Director General.

20. The principles and objectlves of CEI co-operation shall be accomplished through appropriate activities of a flexible structure of working bodles, meeting on expert, high official or ministerial level.

Different forms of working bodles (ad hoc or permanent Working Groups, Expert or Project Groups, advisory bodles etc.) can be proposed to be set up upon the initlative of one or more CEI Member States; their establishment, structure and field of activity shall be decided by the MFA Meeting upon CNC recommendation.

As a general rule each Member State shall assume at least one chaimanshlp or $\infty$ chairmanship of a working body.

The CEI Member State chairing a working body or applying for chairmanship shall present the draft terms of reference, a draft programme of activities as well as a quallied candidate for the chairperson to the CNC for approval. Where appropriate, a co-chalrperson from another Member State should be appointed.

The working bodies shall be assisted by the CEI-ES and by the Secretarlat for CEI Projects in performing their duties.

If a working body is not carrying out actlvities during one calendar year the CNC shall decide upon appropriate measures, including l.a. a rotation of the chair, adaptation of the terms of reference or dissolution. 
21. The CEI - Executive Secretarlat (CEI-ES) is located in Trieste, Italy, and shall be headed by - Director General.

The CEI-ES, as permanent CEI body, shall provide continuous administrative and conceptual support to both the decislon-making and operational structures of the CEI and shall take any appropriate Inltiatives aimed at promoting the realisation of the CEI co-operation objectives.

The tasks of the CEI-ES shall comprise, inter alla, the following areas:

- Information and documentation

- organisattion, preparation and follow-up of meetings

- partidpation in CEI meetings and other CEI-related events

- CEI programmes and projects.

The CEI-ES shall also fulfil other tasks assigned to it by the CEI Summit, MFA Meeting, the Chairman-In-office and the CNC.

The structure and staff of the CEI-ES shall be decided by the CNC in consultation with the Director General. The CEI-ES structure and activity, especially in the field of personnel and finance should be consistent with the law of the recelving state.

In performing its dutles the CEI-ES shall co-operate with National Co-ordinators, chairpersons of the working bodles, other persons and subjects which are involved in CEI activitles.

The authoritles of the recelving state shail finance activities of the CEI-ES as well as the staff's salaries. Any Member State designating any official of the staff (Including the Director General and the Deputy Directors General) shall cover the respective costs. Any CEI Member State can voluntarily allocate financial and material resources for the CEI-ES activities.

22. The CEI-ES Director General (CEI-ES DG) shall be selected among candidates nominated by the CEI Member States and shall be appointed/recalled by the MFA Meeting upon recommendation of the CNC. HIs/her term shall last three years with the option of a one time renewal of up to three more years.

The CEI-ES DG shall participate in the CEI Summit, MFA Meeting, POD Meeting, CNC meetings, meetings of working bodies at ministerial level, the Steering Committee of the Secretariat for CEI Projects and in other major CEI events.

In $\infty$-ordination with the Chairman-in-office the CEI-ES DG or his/her representative shall participate on behalf of the CEI in relevant activities of other European and International organisations and institutions.

The CEI-ES DG shall prepare an annual report on activitles of the CEI-ES including financial aspects, which shall be subject to acceptance by the MFA Meeting upon recommendation of the CNC.

23. The CEI-ES DG is supported by up to two Deputy Directors General (CEI-ES DDGs). The DG and the DDGs represent the Executtive Level of the CEI-ES.

One of the posts of the Executive Level will be flled by the host country of the organisation. The DDGs shall be selected among candidates nominated by the CEI Member States and shall be appointed/recalled by the MFA Meeting upon recommendation of the CNC. The term of office of the DDGs shail last three years with the option of a one-time renewal of up to three more years.

24. For the duration of the Agreements on which it is based, the Secretariat for CEL Prolects (CEIEBRD Secretarlat) is assuming tasks aimed primarily at investment projects and, l.a., the following areas:

- economic co-operation

- CEI Fund management and moblisation of financlal resources,

- investment project promotion, identification, and preparation assistance

- technical support for investment projects

- system development and insttutional programme support (e.g. organisation of international events, training, advisory services, and information systems).

The Secretariat for CEI Projects is linked institutionally to the CEI-ES and is located in the CEI-ES Headquarters in Trleste, Italy, maintoining also a permanent office at the EBRD, London.

The CNC together with the Directors representing Member States in the Board of Directors of the European Bank for Reconstruction and Development form the Steering Committee of the Secretariat for Cel Projects.

25. The co-operation between the Governmental and Parliamentary Dimensions will be guided, 1.a., by the following modalities: 
- A joint session of the enlarged CEI Troika ${ }^{2}$ at the level of Ministers of Forelgn Affalrs and the enlanged Trolka of the CEI Parliamentary Committee will be organised on the occasion of the MFA Meeting to permit'a general debate on the strategic goals and challenges of the CEI as well as on the contributions of the Parllamentary Dimension to the overall work of the organisation.

- The Presidency of the CEI Parliamentary Dimension will be invited to participate in all high-level meetings organised by the CEI with the right to take part in the debate.

- The Chairpersons of the CEI Working Groups and the Chairpersons of the respective ad hoc Committees of the CEI Parliamentary Dimension will establish a close working relationship, exchange information on their mutual work programme and dedicate, in each of their sessions, an agenda item to their co-operation.

- Back to back with the last CNC meeting of each year, there will be a one day meeting between the enlarged CEI Trolka at the level of National Co-ordinators, the CEI Parllamentary Dimenslon at appropriate level, the CECCI at approprlate level, the CEI-ES and the CEI/EBRD Secretariat to revlew the work of the past year and to harmonise the activitles of the incoming year.

- Under no clraumstance will the enhanced co-operation with the Parliamentary Dimension entall any financial commitments of the Govemments of the CEI Member States or the CEI Secretariats.

26. The co-operation between the Governmental and Business Dimensions will be gulded, l.a., by the following modalities:

- The Presidency of CECCI will be Invited to participate in all high level meetings organised by the CEI and in the meetings of CEI working bodies according to CECCI's interest.

- The Presidency of CECCI will be invited to participate in specific missions of the CEI Presidency or Troika as approprlate.

- Back to back with the last CNC meeting of each year, there will be a one day meeting between the enlarged CEI Trolka at the level of National Co-ordinators, the CEI Parliamentary Dimension at appropriate level, the CECCI at approprlate level, the CEI-ES and the CEI/EBRD Secretariat to review the work of the past year and to harmonise the activities of the incoming year.

- The structures of CECCI in CEI member countries shall actively co-operate in the promotion and organisation of the CEI Summit Economic Forum (SEF) by marketing actlvities of the SEF at national level, organisation of SEF sesslons, parallel events and networking receptions.

- Under no circumstances will the enhanced co-operation with CECCI entall any financial commitments of the Governments of the CEI Member States or the CEI Secretarlats.

\section{Decision making procedure}

27. Subject to the provisions of Art. 9 and 18 the decisions within the CEI are taken by consensus as a general rule.

Consensus shall be understood to mean the absence of any objection expressed by a Member State and submitted by it as constituting an obstacle to the taking of the decision in question.

States.

Questions artsing under procedural matters shall be decided by a simple majortty of Member

\footnotetext{
2 The entarged CEI Trolka consists of the CEI Trolka plus the host country.
} 


\section{Signing of Agreements}

28. CEI Agreements to be concluded with thind partles shall be signed on behalf of the CEI by the CEI Presidency and the CEI-ES DG.

\section{Financing}

29. Each Member State is responsible for financing its own expenses connected with CEI activities.

The costs incurred for the organisation of meetings shall, as a rule, be borne by the host country.

Member States shall facilitate the implementation of CEI programmes and projects through annual financlal contributions to the CEI Co-operation Fund. The formula of the annual contributions, annual budget and scale of contributions of the CEI Co-operatton Fund shall be decided by the MFA Meeting.

In order to faclitate the participation of all Member States in CEI and CEI-sponsored events assistance can be provided for covering travel and accommodation expenses through the Solidarity Fund managed by the CEI-ES In accordance with the Guidelines of the Solidarity Fund approved by the CNC.

\section{Flag and language}

30. The CEI flag represents a blue field with the officlal CEI logo in the middle. The CEI logo consists of the block letters "CEI" with a block transcription "CENTRAL EUROPEAN INITIATIVE", surrounded by a semicircle composed by 10 yellow stars.

31. The working language of the CEI is English. CEI documents are produced in English.

If a participant in a CEI event wishes to use another language the translation has to be provided by himself.

\section{Amending the CEI Guidelines}

32. Any amendment proposed by a Member State shall be examined by the CNC. If agreed upon, the CNC shall submit a recommendation to the Meeting of the Heads of Government for approval. 
Appendix 4 - Central European Initiative Document on Working Procedures

Of the Parliamentary Dimension 


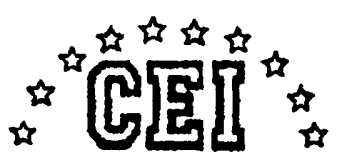

CENTRAL EUROPEN INTIUTIVE

\section{DOCUMENT ON WORKNG PROCEDURES \\ OF THE PARLIANENTARY DIMENSION}

\section{Partiamentary dimension}

A parliamentary dimension of the CEI shall be established, which shall be regulated by the following Working Procedures.

The partiamentary dimension consists of:

- the Parliamentary Committee, which shall meet in spring.

- the Parliamentary Aseombly, which shall meet in autumn, and

- the Conference of the Speakers of Parliaments of the member States, composed of the Speakers of the House or Houses of each Member State.

Ad hoc Committees may be established.

\section{Oblectives}

The Parliamentary dimension of CEI shall pursue the following objectlves:

- to strengthen multilateral co-operation among the C.E.I. member States at parliamentary leved, complemented by bilateral relations,

- to establish and deepen partnerehip structure based on principles of parliamentary democracy and of guaranteding human rights,

- to promote and make easier the reform process and transition in Central and Eastern Europe through the creative collaboration of the countries involved,

- to improve the European environment in the member States and strengthen the Helsinki process.

\section{Membership}

All C.E.I. member States shall be invited to nominate Members of Parliament as their delegates to the Parliamentary Committee and Parliamentary Assembly. Invitations shall be restricted to those States, which have democratically elected Partiaments. The standard to be applied shall be the same criteria as for membership of the Council of Europe.

Except in the case of appointment of a new national delegation, the term of office of each delegate shall expire no later than six months after the first sitting of the national parliament following parliamentary elections. 


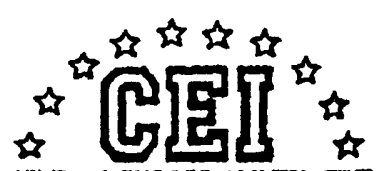

CENTRAL EUROPENN INITUTTVE

\section{Guests, observers, applicants for membership}

Members of the European Partiament and the Parliamentary Assembly of the Council of Europe may be invited by the chairholding country to the meetings or to the special events as guests with the right to speak. Non member States or other international organisations may be invited to the Parliamentary Committee or Assembly with the right to speak by the chairholding country with the consent of the Troika, $i$. $\theta$. the Chairpersons of delegations from the countries holding the previous, current and subsequent Chairmanship-in-office.

In organising partiamentary seminars, the chairhotding country may, at its discretion, invite guests and experts.

Concerning the admission of new members the Parliamentarians shall take account of the decisions of the Governments but shall put forward their opinion independently.

\section{Mestings}

At least two meetings shall be organised annually. They shall consist of - one meeting of the Parliamentary Committee in spring. These meotings shall take place at least 15 days before the meetings of the Foreign Ministers. Each state may send two delegates to Parliamentary Committeo meetings (the head of the partiamentary delegation and one other MP). Each delegation may be accompanied by lits secretary.

- one moeting of the Parliamentery Assembly in autumn. This shall take place at least 15 days before the meeting of the Head of Governments and Ministers of Forelgn Affairs. The size of delegations shall be calculated on the basis of three delegates for a population of up to 5 million, five delegates for a population between 5-12 million, and seven delegates for a population of more than 12 million. Each delegation may be accompanied by its secretary.

Within the Parliamentary Committee or Assembly, Ad HoC Committees may be set up, in some cases, upon proposal of any of the Parliamentary delegations. These Committees, which shall consist of up to nine members and nine alternates, shall be charged with the monitoring of specific projects carried out by the Working Groups. Each Ad Hoc Committee may hold joint meetinge with the relevant Working Group.

Each Ad Hoc Committeo shall appoint a Chairman who shall be responsible for the drafting of an opinion at the end of the project monitoring and for presenting it to the Parliamentary Committee or Assembly. The Chairman of an Ad Hoc Committee may also ask the Chairman of the relevant Working Group to submit written reports on the activity of his Group.

These meetings shall be held "in camera". 


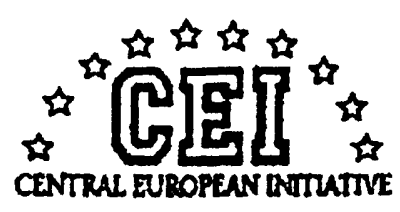

Where a partiament has two chambers it shall decide how to elect its delegates. The term of office of members of each delegetion shall be decided by each parliament in accordance with its own rules and practices.

The chairholding country may, at its discretion, organise parliamentary seminars.

Within the Assembly a Standing Committee is established, consisting of the Heads of the delegations making up the Troika and the Chairpersons of the ad hoc Committees. The meetings of the Standing Committee shall be organized, before or in the intervals between the annual sessions of the Partiamentary Committee and the Assembly, by the Parliament of the country holding the Chairmanship of the CEI, and with the agreement of the country holding the Chairmanship, by the request of any other member country of the Standing Committee.

\section{Special events}

In addition to the above meetings, speclal events may be organised with the consent of the Chairman, after consulting with the two Deputy Chairmen.

\section{Chaimenship}

The chairmanship of the Parliamentary Committee and Assembly shall rotate annually in line with the chairmanship at ministerial and hesds on government level. The head of the parliamentary delegation of the chairholding country shall be the Chairman of the partiamentary dimension of the C.E.I. and shall chair the two meetings. Two Deputy Chairmen for the Parliamentary Committee and Assembly shall be appointed. They shall be the Chairman of the parliamentary delegations whose countries hold the procesding and succeeding chaimanship. The two parliamentary meetings shall be organised by the parliament whose country holds the chairmanship. The Chairman of the parliamentary meetings shall draw up a report after each meeting. This report, together with the Final Document, shall be transmitted to all national delegations and presented at the meeting of the CEI Ministers of Foreign Affairs and of Heads of Government.

\section{Yenue of the meetings}

Venues of parliamentary meetings - up to the chairholding country - possibly shall take place in the building of the parliament holding the chair. 


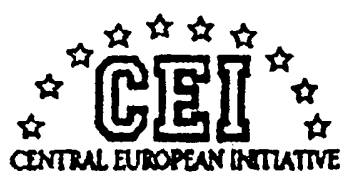

\section{Acenda of the meetings}

A dreft agenda shall be proposed by the chairholding partiament one month in advance of meetings. Appropriate proposals may be submitted by individual delegattons. In preparing the draft agenda due account shall atways be taken of the subjects which are going to be discussed at the meeting of Ministers of Foreign Affalis or Head of Government. The draft agenda may include a hearing of Government representatives of C.E.I. member States, upon invitation of the Chairman of the Parliamentary Committee or Assembly. The final egenda ahall be adopted by the Parliamentary Committeo or Assembly at the beginning of the meoting.

\section{Co-ordination}

The chief secretary of the parliamentary delegation of the chairholding country may be nominated as a delegate to the meeting of national co-ordinators of the C.E.I. who shall report to the Parliamentarians on results and future work. Delegations shall keep in touch continuously via their secretaries.

\section{Politlcal document or declaration}

The main subjects of the political document or declaration to be adopted at the meeting of the Foreign Ministers or Heads of Govemment may be discussed and commented on at the meeting of Parliamentarians, though not amended. The Partiamentary Assemblies or Committeas, however, may prepare and isous a joint statement. This statement shall be annexed to the political document or declaration of the forelgn ministers or heads of government. This guarantees the independence of the partiamentary dimension of the C.E.I. However, continuous co-operation between the parliamentary bodies and the ministerial and heads of government fora is considered indispensable.

\section{Voting}

Each delegation shall have a single vote. When taking decisions, efforts thall be made to reach a consensus. If a consensus cannot be reached then a twothirds majority shall be required to take decisions. In such cases a separate opinion shall be expressed to the fors of the Foreign Ministers and Heads of Government. 


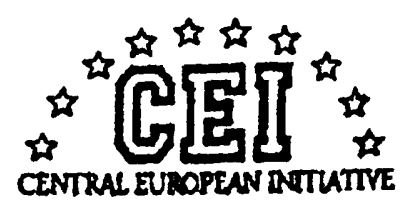

\section{Relations with other C.E.I. forg}

The Chairman of the Partiamentary Committee or Assembly shall acquaint Foreign Ministers or Heads of Governments with the work of the Parliamentary Committee or Assembly and the Parliamentarlans' comments concerning the political document or declaration. The Chairman shall participate in the press conference together with the Forelgn Ministers or Heads of Government.

The Chairman may be accompanied by the delegates representing the countries of "Troiks".

The Chairman of the Parliamentary Committe or Assembly shall invite the Director General of the CEI - Executive Secretariat to at least one of the annual meetings of the parliamentary dimension where he shall report on the activity of the Executive Secretariat.

Furthermore, the Director General of the CEI - Executtve Secretariat may be asked to send written reports to provide additional explanations on the questions raised.

The Chairman shall invite the National Co-ordinators from the countries represented in the Financial Committes to at loast one of the annual meetings of the parliamentary dimension, where they shall provide information and answer the questions asked by the Parliamentarians concerning both the programmes and resources of the Initiative and specific projects of the Working Groups.

The Chairman of the Partiamentary Committee or Assembly may invite a representative of the European Bank for Reconstruction and Development and a representative of the C.E.I. Secretariat of the Chambers of Commerce to one of the annual meetings of the parliamentary dimension where they shall report on the activity of their organisations.

\section{Lanquage}

The working language of the meetings in English. Interpreting, if desired by a delegation, shall be at its own costs. Interpreting requirements should be conveyed suffictently early to the host country, to allow it to provide the technical facilities for interpretation.

\section{Costs}

Parliamentary delegations shall bear their own costs, while organisation costs and the framework programme shall be paid by the organising country. 
Appendix 5 - Samples of CEI Projects and Funding 


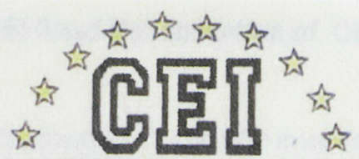

CENTRAL EUROPEAN INITLATTVE

The Central European Initiative (CEI) supports regional co-operation at economic and political level in central and eastern Europe. Founded in 1989, the CEI now counts 17 member countries:

\section{Albania, Austria, Belarus, Bosnia and}

Herzegovina, Bulgaria, Croatia, Czech Republic. Hungary, Italy, Macedonia, Moldova, Poland

Romania, Serbia and Montenegro. Slovakia

Slovenia and Ukraine

Since the establishment of the institutional and technical cooperation link with the European Bank for Reconstruction and Development (EBRD) in 1991, the joint CEI - EBRD Secretariat has been funded by the Italian government with a total of approximately $€ 27$ million for the implementation of technical cooperation assignments alongside EBRD investments and for development and training activities in the region. So far, almost $€ 17$ million have been utilised by the CEI for technical assistance and co-financing projects. EBRD's investments supported by the CEI amount to over $€ 330$ million, with a total project value of over $€ 1.7$ billion

\section{CEI-PS co-financing and TC contribution by sector 1993 - 2004 (€ mil)}

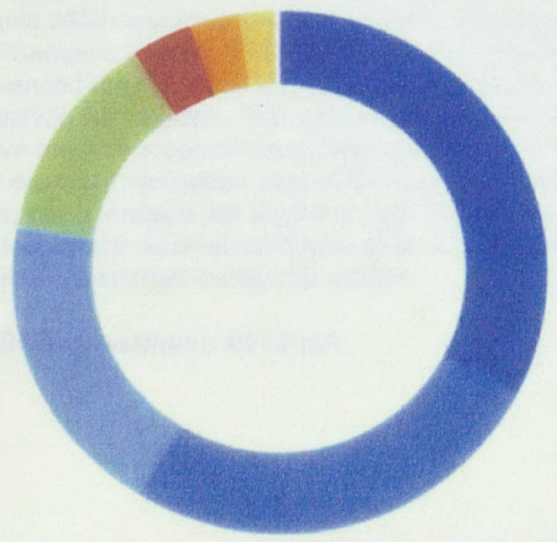

Transport \& Infrastructure $(5.48)$

SMEs $(4.47)$

Municipal infrastructure $(0.64)$

Institutional 13.17

Agriculture (2.19)
Financialinsurance $(0.50)$

Energy (0.40)
SECRETARIAT FOR CEI PROJECTS (CEI-PS)

\section{CEI-PS Co-financing and TC contribution by} country 1993 - 2004 (€ mil)

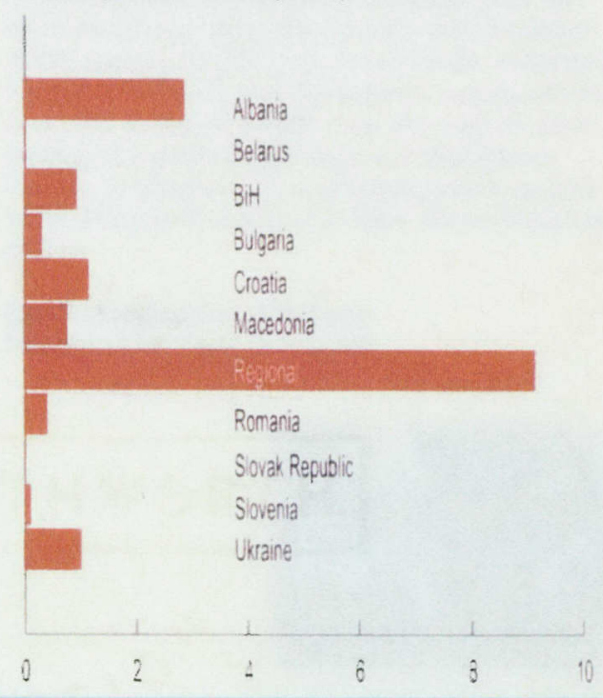

\section{The Economic and Technical Dimension of the CEI Project Secretariat (CEI-PS):}

In its efforts to ensure the realisation of the CEI cooperation objectives of working towards a united Europe and supporting the least advanced members of the Initiative in their path to a market economy and a multiparty democracy, the CEI-PS operations focus on

* Providing Technical Co-operation assistance for specific projects alongside EBRD investments:

* Supporting institutional development through the Know-how Exchange Programme (KEP) for know-how and skill transfer between CEI countries through specific cooperation activities:

- Supporting international events and training thematically linked to the CEI areas of priority intervention. namely south-eastern Europe and the CEI countries in the European Neighbourhood Policy (ENP), and in SMEs, agriculture infrastructure and energy:

- Promoting project opportunities through the business "Match-making programme", a database of projects seeking partners. 
Albania: CEI Road Rehabilitation of Corridor VIII in Albania

The CEI-PS provided $€ 1,700,000$ in co-financing for the EBRD Road Rehabilitation Project in Albania for the improvement of the Elbasan - Librazhd $(30 \mathrm{~km})$ section of the national road in the East-West Corridor of Albania between the Port of Durres and the FYR Macedonian border (EU Corridor VIII). Grant money was provided by: EU-Phare ( $€ 1.8$ million); Italian Co-operation Fund ( $€ 2.3$ million); Albania (EUR 0.3 million).

Co-financiers were: International Development Association ( $€ 12.2$ million); Government of Albania ( $€ 12.2$ million); Kuwait Fund for Arab Economic Development ( $€ 7.5$ million): EU-Phare ( $€ 21.8$ million) and European Investment Bank ( $€ 23.0$ million).

\section{EBRD Investment: $\mathbf{6 1 0} \mathrm{mil}$} Total Project Cost: $€ 85 \mathrm{mil}$

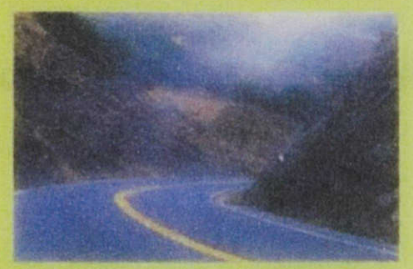

\section{Bosnia and Herzegovina: Sarajevo Airport}

The CEI-PS contributed $€ 607,412$ to assist with the preparation of a Master Plan for the medium term (until 2008) and long term (up to 2020) development of Sarajevo International Airport. The CEI-PS also financed the purchase and installation of sequenced flashing light system. This project included extensive reconstruction of the runway and replacement of essential navigation aids of Sarajevo International Airport. It enabled the airport to open for scheduled international commercial flights after having been largely destroyed during the conflict.

\section{EBRD Investment: $611.2 \mathrm{mil}$}

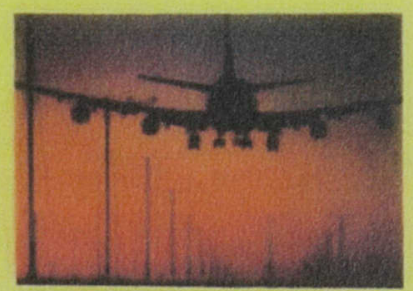

Macedonia: CEI Assistance to Macedonia Air Navigation

The CEI-PS provided $€ 350,000$ to support the Macedonian Civil Aviation Authority to comply with the International Civil Aviation Organisation standards for the training of air traffic controllers. The CEI-PS assistance was a part of a large EBRD investment project comprising of a series of investments aiming at enhancing the safety of commercial aviation in Macedonia. Project objectives include: enhancing the safety of flights over Macedonia, coping with the expected increase of traffic over the medium-term, keeping the second main airport of Macedonia (Ohrid) in operation and providing general support to the development of civil aviation and institutional reform.

EBRD Investment : $€ 11.2 \mathrm{mil}$ Total Project Cost: $€ 14.38 \mathrm{mil}$

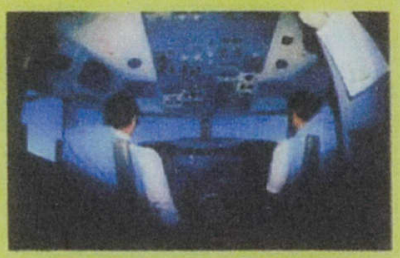

\section{CEI Project Secretariat Strategy}

The following sectors remain priority areas for the activities of the CEI-PS at the EBRD:

- Transport, in particular for projects linked to the development of corridors in central and southeastern Europe, including road and railway transport links, port and airport development, and urban transport development;

- Infrastructure, in particular municipalities, urban regeneration, real estate and development of infrastructures in the energy and environmental sector; infrastructure for water management;

- Finance, in particular support to micro and smallmedium size enterprises, support to the internalisation of enterprises;

- Agriculture, including development of agribusinesses and support to wholesale markets and micro-finance.

Priority countries for CEI-PS intervention remain those of south-eastern Europe (Bosnia-Herzegovina, Serbia and Montenegro, Macedonia, Albania, Romania and Bulgaria); and those included in the European Neighbourhood Policy (Belarus, Ukraine and Moldova). The CEI-PS would also consider investing in the new EU member countries if proposed projects have a regional impact and are preferably co-financed by the countries themselves. 
Appendix 6 - CEI Funding Unit - Samples of Activities and Results 


\section{C樞" \\ CEMTRLi BUROPEAN NRTATIVE \\ Executive Secretariat \\ - CEI Funding Unit - \\ Cooperating in a Wider Europe Activities and Results}

\section{BRIEF DESCRIPTION}

The CEI Funding Unit was created in January 2004, with a view to evaluate the possibilities of attracting EU funding for CEI projects and to join it with the CEI funds. This was linked aiso to the increased number of CEI countries, which after the EU enlargement became ellgible for EU funding. The CEI indeed now encompasses:

-2 old EU Members (Italy, Austrla);

-5 new EU Members (Slovenia, Hungary, Slovakja, Czech Republic, Poland);

- 3 EU Candidate Countrles (Bulgarla, Romania, Croatia);

- 4 Western Balkans Countries (Bosnia Herzegovina, Serbia Montenegro, Albania, Macedonia);

- 3 NiS countries (Moldova, Ukraine, Belarus).

\section{FUNDING UNIT TASKS}

1. PROMOTING CEI PARTICIPATION IN EU PROGRAMMES AND PROJECTS

2. DISSEMINATION OF INFORMATION

3. PARTNER SEARCH ASSISTANCE

4. FACILITATING AND SUPPORTING NON EU COUNTRY PARTICIPATION

\section{PROJECTS AFTER FIRST YEAR OF ACTIVITY}

\begin{tabular}{|l|l|}
\hline Number of Projects submitted & 16 \\
\hline Number of Projects approved & 5 \\
\hline Number of Projects in pipeline & 3 \\
\hline Sectors concerned & $\begin{array}{l}\text { Transport, environment, information soclety } \\
\text { technologies, SMEs, cross border cooperation, } \\
\text { energy, cultural heritage, higher education }\end{array}$ \\
\hline Total value of submitted projects & $15 \mathrm{~m}$ EUR approx. \\
\hline Total value of approved projects & 6.858 .229 EUR \\
\hline CEI Invoivement in the approved projects & 499.763 EUR \\
\hline
\end{tabular}

\section{CONTACTS}

CEI - Executive Secretariat

Vla Genova 9

34121 Trieste, ITALY

www.ceinet.org

Ms. Lara Tassan Zanin

Tel. +390407786731

Fax. +390407786766

E-mall: tassanzanin@cei-es.ors

Ms. Izabela Gostisa Pasic

Tel. +390407786741

Fax. +390407786783

E-mall: gostisa@cei-es.org 


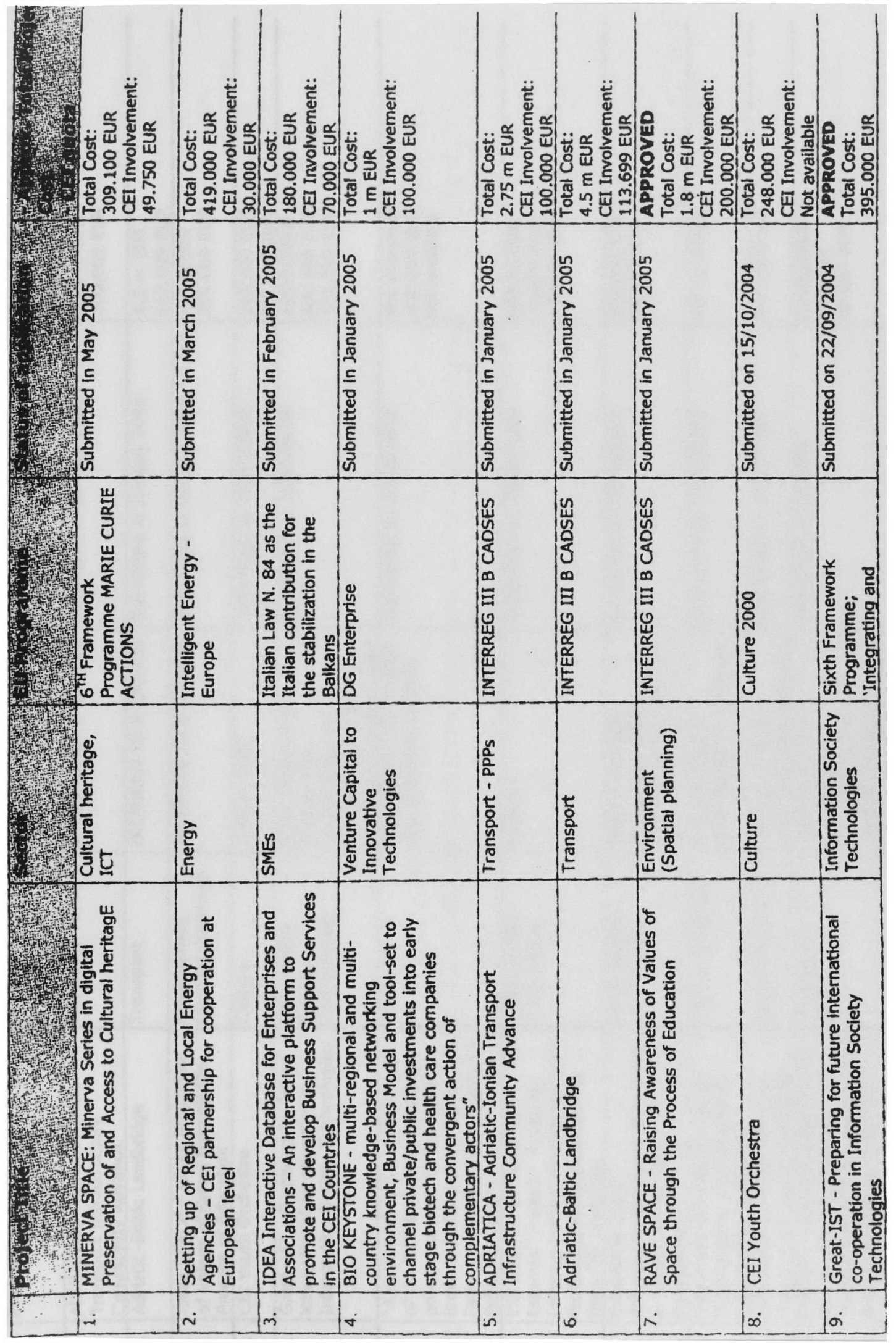




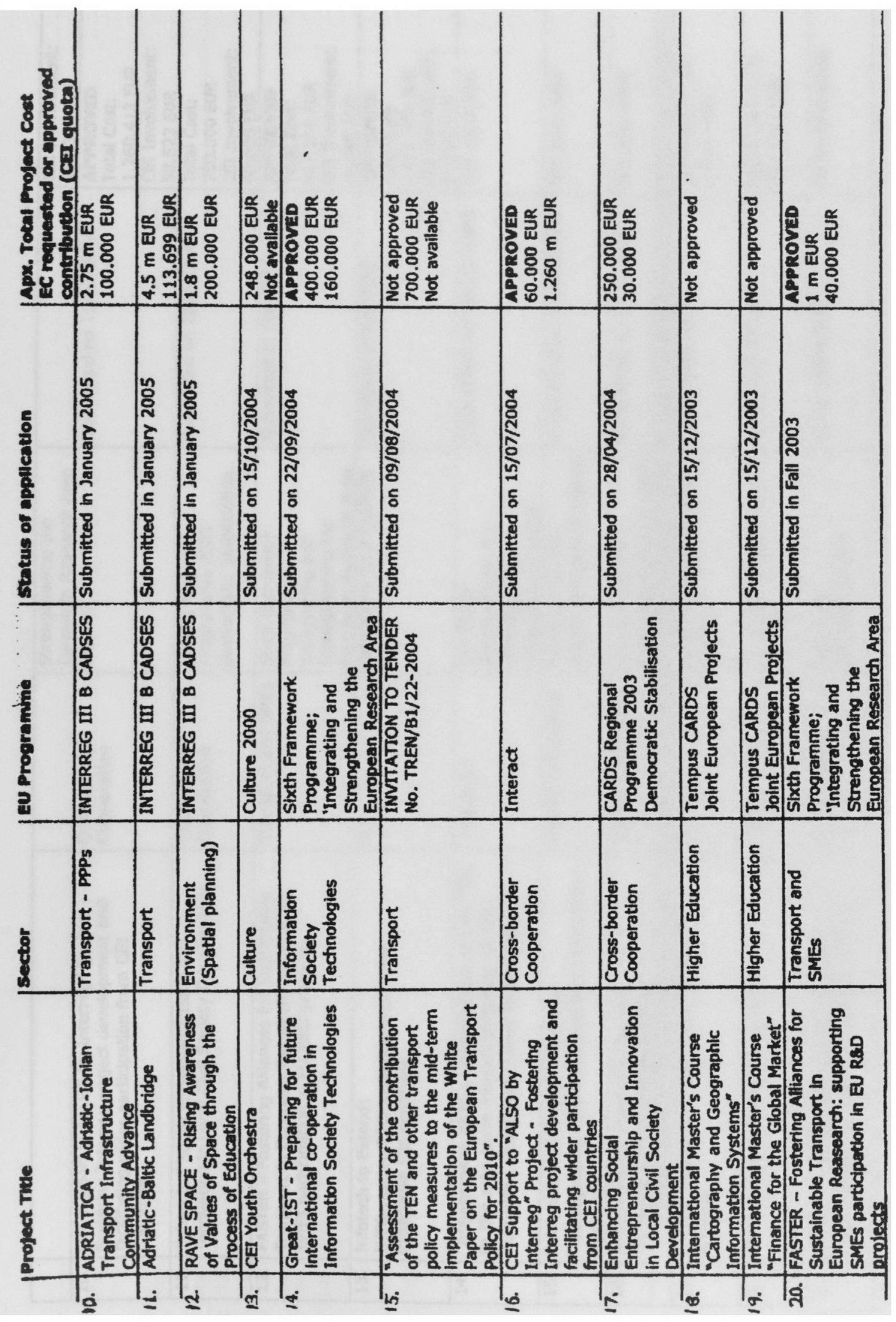




\begin{tabular}{|c|c|c|c|c|c|c|c|c|c|}
\hline 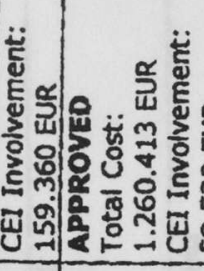 & 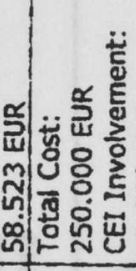 & 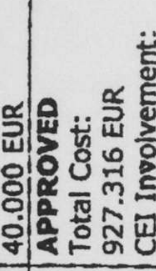 & 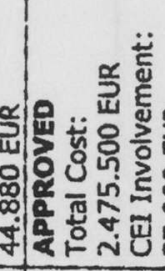 & 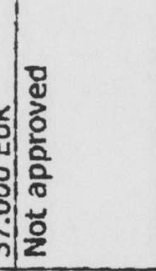 & 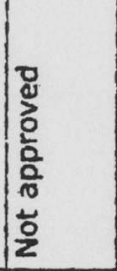 & 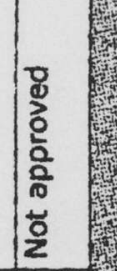 & 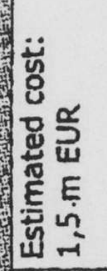 & 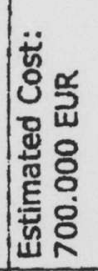 & 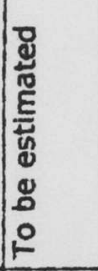 \\
\hline 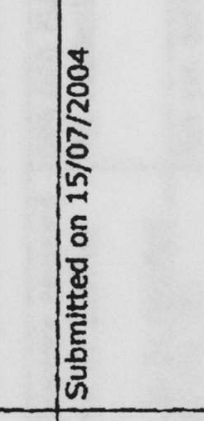 & 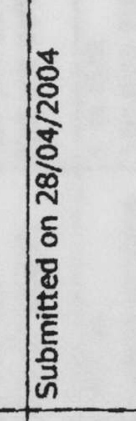 & 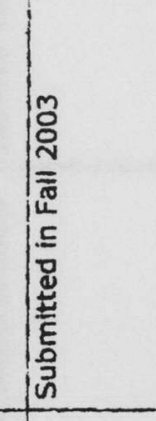 & 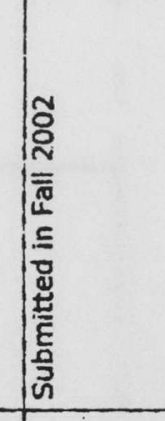 & 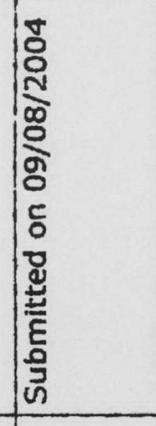 & 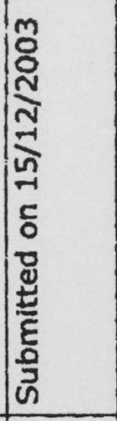 & 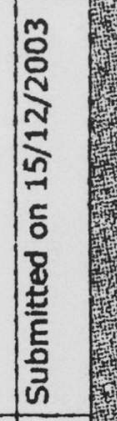 & 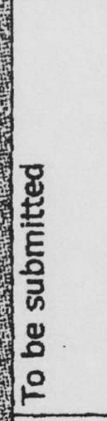 & 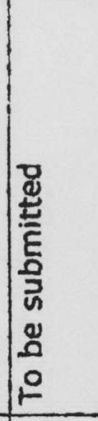 & 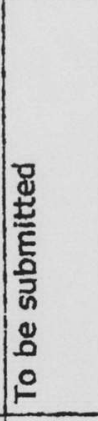 \\
\hline 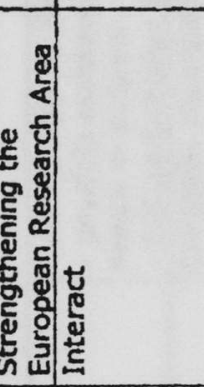 & 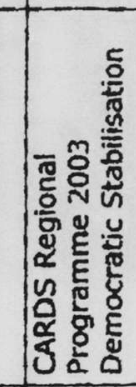 & 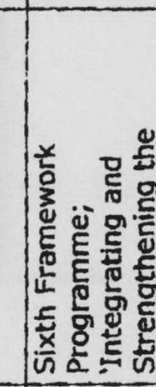 & & 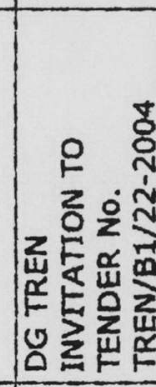 & 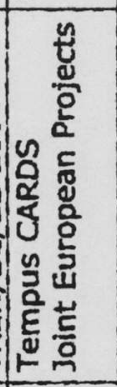 & 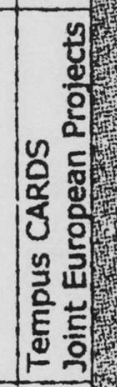 & 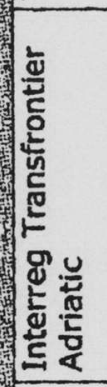 & 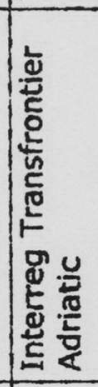 & 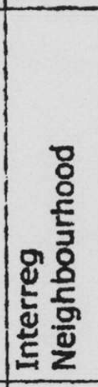 \\
\hline 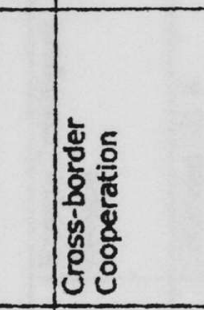 & 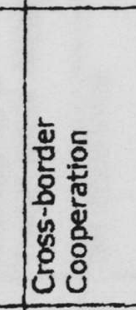 & 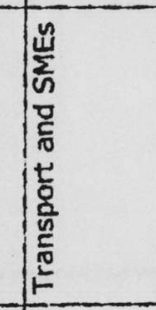 & $t$ & 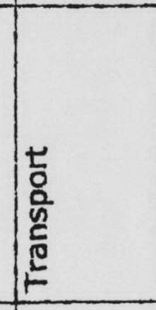 & 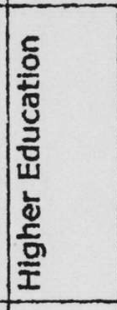 & 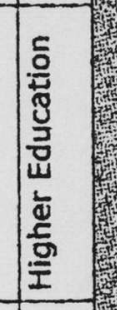 & 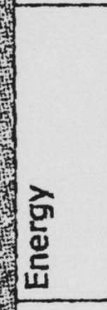 & 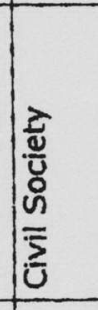 & 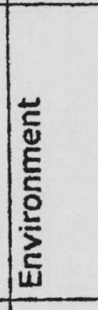 \\
\hline 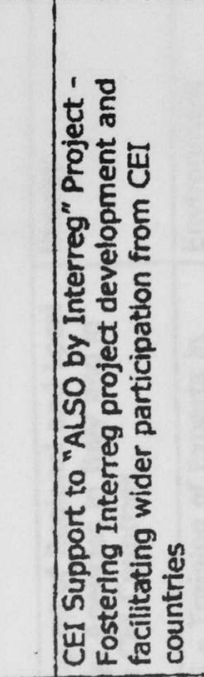 & 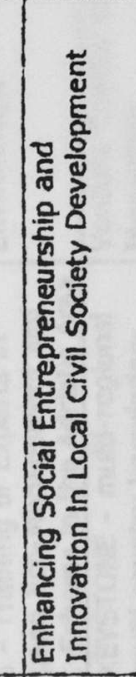 & 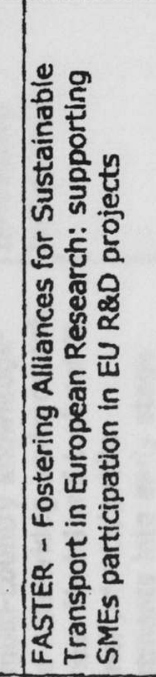 & 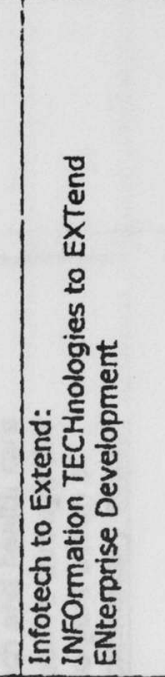 & 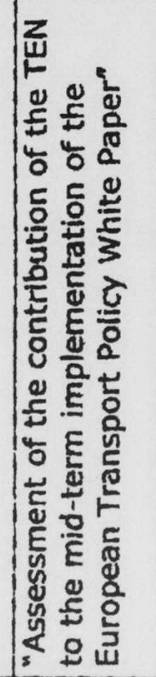 & 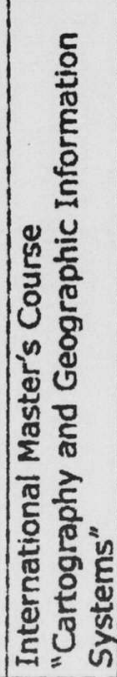 & 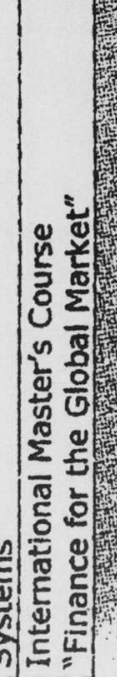 & 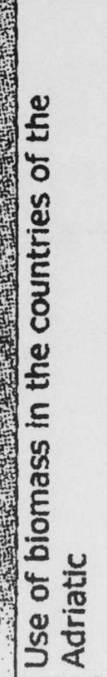 & 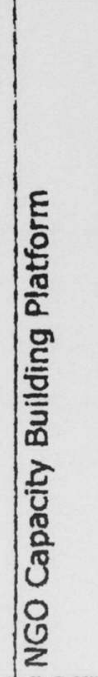 & 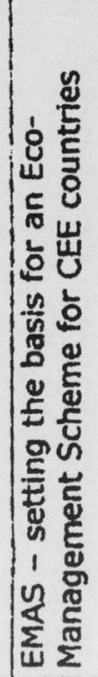 \\
\hline I & \pm & $\underline{\underline{a}}$ & $\stackrel{m}{m}$ & \pm & in & $\dot{0}$ & I- & $i$ & |m \\
\hline
\end{tabular}




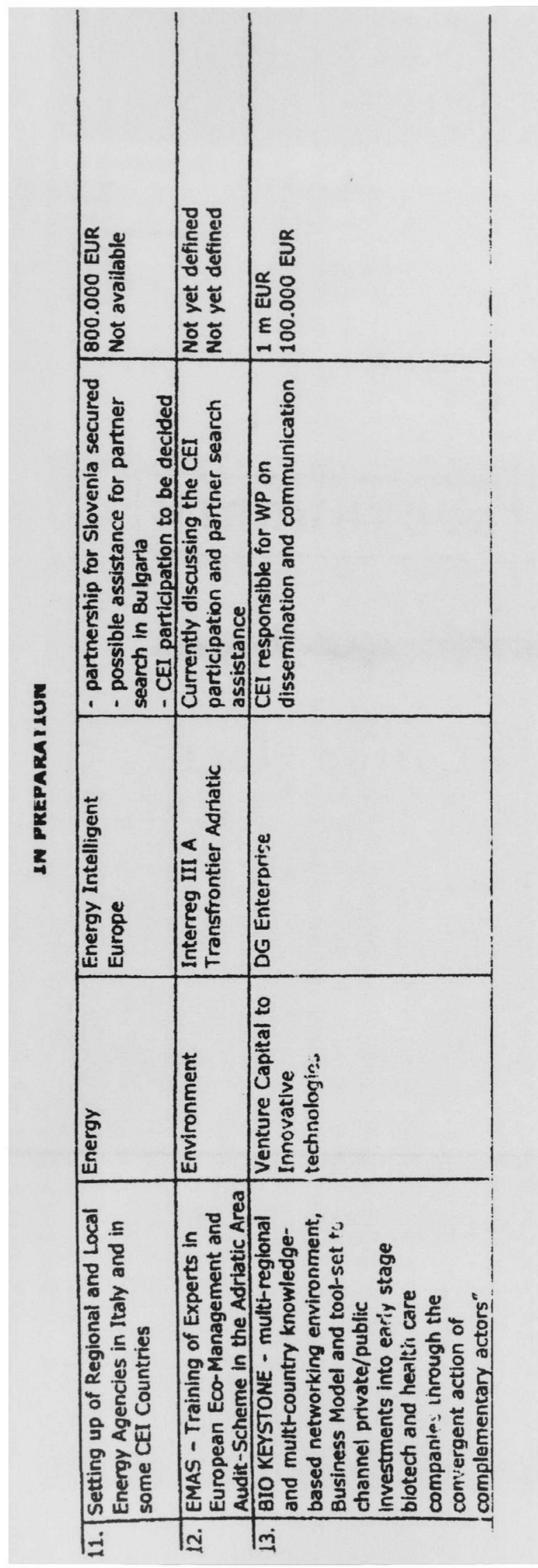


Appendix 7 - Sample of CEI Cooperative Technical Projects (2002) 


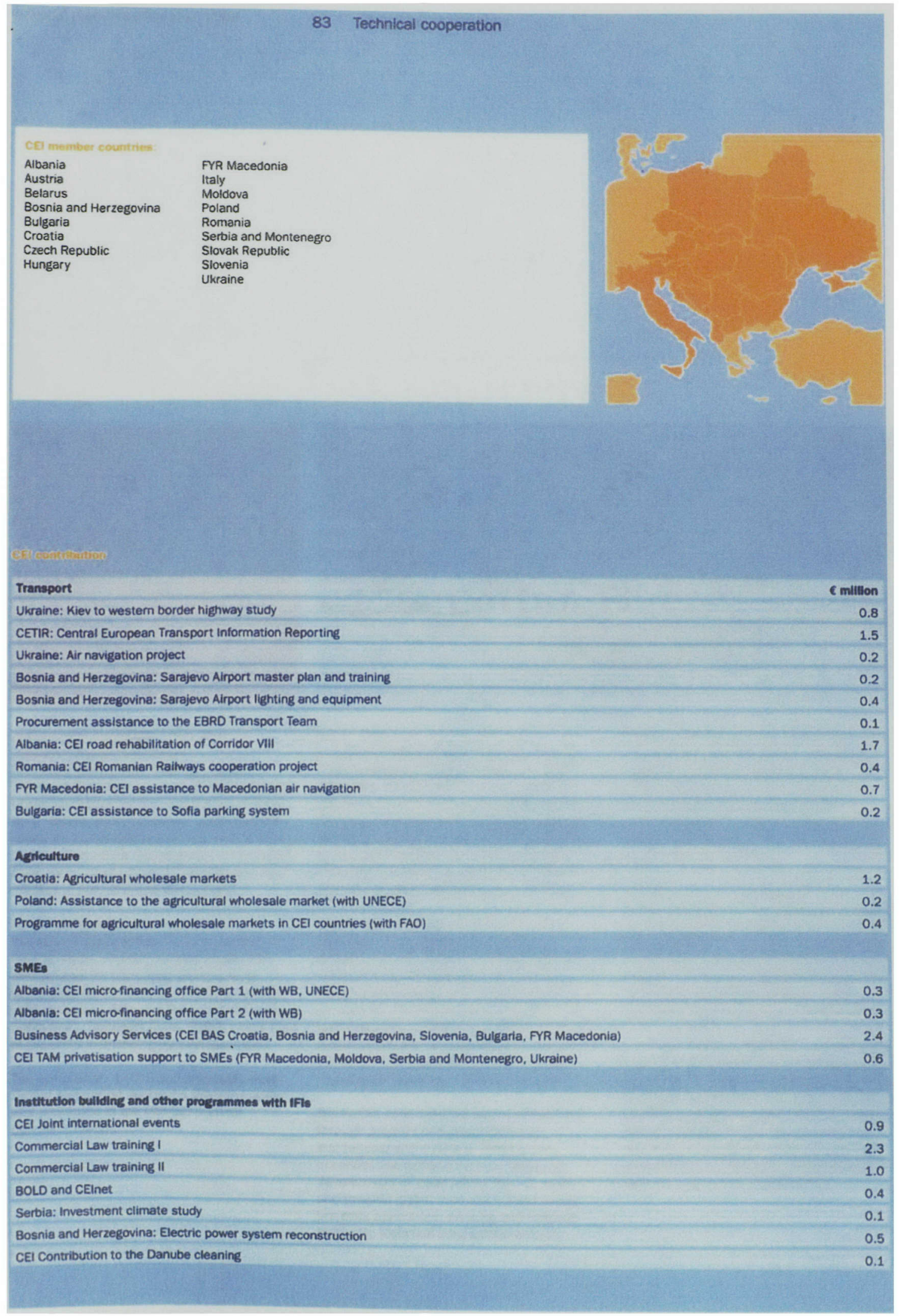




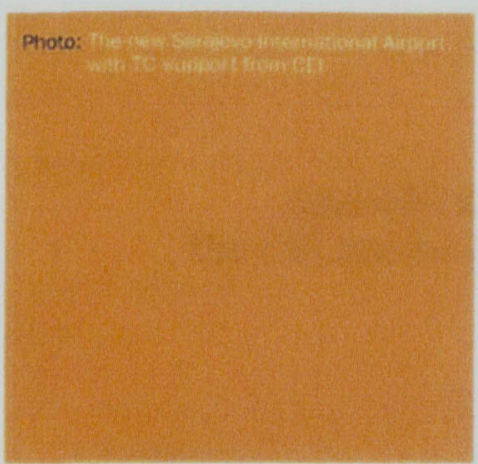

International Symposium "Port phannins Unbainism, sconomics, design?

The Secretariat for CEI Projects and the Transport Economic Institute (ISTIEE) of Trieste University organised this symposium, inviting port experts. port authorities, urban planners. young graduates and academics from various European countries (particularly CEI countries). Subjects covered advanced theories and best practice in port planning and design.

Part of the symposium was devoted to investment opportunities for port planning in the $\mathrm{CEI}$ region, covering methodologies and best practice for identifying and financing bankable projects. Several specific proposals were presented. following the presentation by Robin Earle (Transport Team. EBRD) on the Role of the EBRD in financing port infrastructure.

The symposium results and proposals were fur ther elaborated during the following weeks. and presented at the fifth CEI Summit Economic Forum.

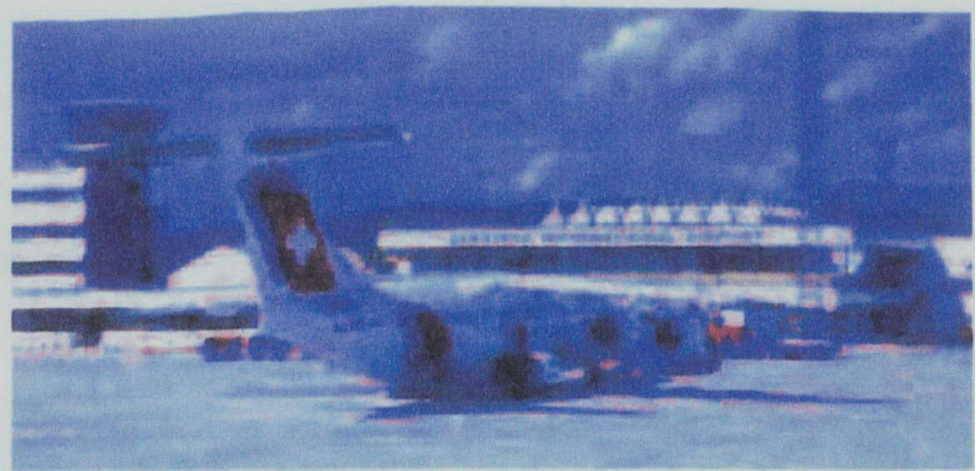

CEI Summit Ecanomic forum

The fifth CEI Summit Economic Forum took place in Skopje, FYR Macedonia, on 13-15 November 2002. Traditionally, it is held in parallel with the CEI Summit Meeting of the 17 heads of government. organised under the CEI Macedonian Presidency for 2002, attended by Italian Prime Minister Berlusconi, EBRD President Lemierre, heads of governments and presidents of international institutions.

The Forum attracted 1.200 participants. including: senior government officials. industry leaders, regional cooperations. national and international organisations, financial institutions and IFIs, chambers of commerce, investment promotion agencies. professionals, consultants and hundreds of business people. The Ministers of Economy for the $17 \mathrm{CEI}$ countries held their annual round table focusing on SME development.

The forum addressed the issues of transition through projects and programmes for institutional and business development in central and eastern Europe, including: development of trade within the $\mathrm{CE}$ region and towards global markets; infrastructure projects; agriculture; banking and financial products: technical cooperation projects: development of technology and human resources: local development systems: programmes for EU integration and crossborder cooperation: and EU enlargement. There were numerous presentations of privatisation and investment projects, private sector projects, joint ventures and project opportunities by country.

The Bank was actively involved in the preparation of the Forum. Fifteen EBRD officials and bankers represented the Bank, chaired sessions and spoke in the Forum panels on infrastructure. port development, municipal finance and services. pension and insurance reforms, consolidation of banks, trade facilitation and SME support programmes.

The Forum conclusions include lists of projects where interested partners have been identified (business, infrastructure, transport, technology). strategies and programmes for the development of SMEs, local employment promotion schemes. special support to countries that are not in the next EU enlargement (via cross-border cooperation and industrial out-sourcing across borders), and further matchmaking! 
Appendix 8-Memorandum of Understanding between The CEI and the United Nations Economic Commission for Europe 


\section{MEMORANDUM OF UNDERSTANDING}

between

the Central European Infitinttve

Regional grouping comprising 16 States in Central and Eastem Europe, represented by the CEI Chairman-in-office

and the CEI - Executive Secretariat based in Trieste, Italy, represented by the Director General,

Thereinafter called CEI and CEI - Erecuttve Secretariat (CEI-ES) respectively

and

the Unitted Nations Economic Comminsion for Europe

Regional Commission of the United Nations based in Ceneva, Switzerland, represented by the Executive Secretary,

Thereinafter called UN/ECE

Considering that the cooperation within the $C E I$ shall include inter alia the following areas':

- economic and technical co-operation;

- development of infrastructure in transport, energy, telecommunication, agriculture;

- strengthening the democratic institutions and observance of human rights, including the rights of persons belonging to national minorities as well as humanitarian matters;

- protection of human environment;

- co-operation in the field of science and tochnology, media, culture, education, youth exchange, tourism;

- cross-border and interregional co-operation;

- consultations on political matters of mutual interest;

and shall aim at implementing the comprehensive CEI strategy as defined in the "Sarajevo Declaration", adopted by the CEI Summit Sarajevo, 29 November 1997;

Considering also that the CEI Member State which chairs the CEI is supported by the CEI - Executive Secretariat ${ }^{2}$ which operates in accordance with the Guidelines for Operations of the CEI-ES, specifying its mandate;

Guidelines for Activitles and Rules of Procedure of the Central Europeen Initiative, Art. 3

${ }^{2}$ Guidelines for Activities and Rules of Procedure of the Central European Initiacive, Art. 11 
Considering that the mandate and aims of the UN/ECE include the following principles contained in the ECE Plan of Action adopted at its 52nd jubilee session:

- to support activities which are initiated by sub-regional groupings and which relate to the ECE areas of expertise;

- to facilitate tho dissemination and implementation of ECE norms and conventions through cooperation with sub-regional groupings;

- to develop further the cooperation with organisations which have spocific activities or projects in the same field of work and in the same countries as ECE, on the basis of comparative advantages. This include activities supported by financing institution such as EBRD, World Bank, European Investment Bank and UNDP;

- to provide a forum for dialogue aimed at bringing about a better understanding of different aspects of the transition process and for the negotiation of normative frameworks in these areas;

- to involve the private sector in its activities, taking particular account of the development of the business sector in countries in transition;

- to further diversify its activities and methods designed to assist the integration of Central and East European countries into the European and world economies especially through seminars, workshops and advisory services in such fields as economic analysis, statistics, transport, environment, human settloments, population, trade facilitation, investment promotion and energy;

The CEI, supported by the CEI - Executtve Secretariat, will:

- keep the UN/ECE informed of its current and planned activities of common interest to both organisations, in particular those relating to:

- the country specific strategies

- trado and transport facllitation

- small and medium enterprises

- trensport

- environment

- secure continuous interaction between UN/ECE and the CEI Working Groups/Project Groups and the Secretariat for CEI Projects at the EBRD

- exchange information, publications and workprogrammes, as well as schedules of meetings so as to secure UN/ECE attendance at the meetings of mutual interest;

- give public information coverage to those meetings or activities organised jointly by the UN/ECE and the CEl;

- make arrangements in concert with the UN/ECE regarding the appointment of a UN/ECE staff member who shall act as "focal point" for cooperation with the CEL, its Executive Secretariat, the Secretariat for CEI Projects at the EBRD (CEVEBRD Secretariat) and the various Working/Project Groups. The function of the focal point will start as soon as appropriate financial resources covering also support costs are made available to the UN/ECE by the EBRD through its Secretariat for CEI Projects and recruitment of the focal point is completed in accondance with UN rules and regulations. Its terms of reference are specified in 
the relevant Cooperation Agreement between the UN/ECE and the CEI/EBRD Secretariat on Technical Support to the CEL Any other financial implications of the cooperation agreed upon will be the subject of separate agreements.

\section{The UN/ECE will:}

- within the limits of its own resources and in line with the policy of the Commission and the Economic and Social Council make available its expertise especially in the fields of economic analysis, statistics, environment, energy, transport, trado facilitation and enterprise development;

- make avaitable the ECE conventions, norms and standards, as well as other technical knowledge relevant for the agreed areas of cooperation;

- invite the CEI, through the CEI - Executive Secretariat to take part in the UN/ECE meetings of mutual interest;

- provide advisory services and professional support to the CEI Working/Project Groups within the limits of its own resources;

- secure synergies between its cooperation with the CEI and other subregional groupings and special initiatives.

- meet the requirements specified in the cooperation agreement between the UN/ECE and the CEI/EBRD Secretariat related to the use of the CEI Italian Trust Fund at the EBRD, and aimed at the development of CEI project ideas into bankable projects.

The Memorandum of Understanding will be renewed each year by tacit Agreement unless either Party advises otherwise in writing.

For the CEI Presidency:

For the UN/ECE:

For the CEI-Executive Secretariat: 
Appendix 9 - The CEI Plan of Action 2004-2006 
I. Economk Development

I.1. Agrtaulture

1.1.1. CEl Mlcro-financing Project

1.2. Enempy

1.1.2. CEI Wholesale Morket Programme

1.3. Environmental Protection

1.3.1. Implamentation of "EST goes EAST" pllot projects

1.3.2. Estmblishment of the EST clearing-house

1.4. SME development

1.4.1. Ca Enterprise Propromma (CEj-EP)

1.5. Tourism 1.4.2. Extension of the BAS programme

1.5.1. Tourism management

1.5.2. Development of tour-programmes encompassing vartous CEI countries (e.g. Amber

1.6. Transport Route, Crusing the Danube Valley, sass in CEI countries)

1.6.1. Technical asistance in the field of air navigation and road natwork development in Member States in special need

1.6.2. Support to port development and to the rehablitation and quality standards improvement of ralliway networks to promote combined transport in the cel region.

1.7. Finenciel instituttons
1.7.1. Assistance to hsurance companies

II. Auman development

II.1. Culture

II.1.1. Conservation of tangible and intangible cuttural heritage

II.1.2. Know-how transfer in the field of cultural management

II.2. Educatton

I. 1.1. The CEI University Network

11. 3. Human Resource Develosment and Training

II.3.1. Ufe-tong learning, Including vocattonal training and adult education

11.3.2. Training programmes for young entrepreneurs

II.4. Sclence and Technology

II.4.1. The CEl Selentific and Tectnological Metwork

II.4.2. Information Soclety

11.5. Youth Affairs

II.5.1. Youth Involvement in Polltical Life

II.5.2. Youth Crime Prevention and Youth Unemployment

III. Institutional development

III.1. Civil Protection

III.1.1 Protection against the effects of natural and technological disasters

III.1.2 Cross-border procesdures in case of emergencles

III.2. Combating Organised Crime

III.2.1 Financlal freuds, with particular regard to liticit credtc card use and money laundering in the CEI area

II1.2.2 Ullicit trafficking (human beinos end stolen vehicles)

in.3. Information and Media

III.3.1. Cross-border television

III.3.2. Review of medla legislation

III.4. Migration

ill.4.1. Training of migration and paltce officers

III.5. Minorities

II.5.1. Celebration of the 10" Anniversary of the CEI instrument

III-5.2. Support for the protection and promotion of minority languages

N. Horkzontal ksues

N.1. Cross-bonder Cooperation and Local Development

IV.1.1. Promoting and spreading knowledges bout the advantages of interreglonal and crossborder cooperation and demonstrating best practices in this field

IV.1.2. Bullding a network of coopereton for a "hortzontal" flow of experience and know-how

IV.2. Mayor Conferences and Events

IV.2.1. Summit Economic Forum

iv.2.2. Youth Forum 
Appendix 10 - Samples Joint CEI University Programs 
According to the Founding Charter, the Rectors of the Co-ordinating Universities constitute the CEI University Network Executive Board; this body is responsible for the approval and the monitoring of the so-called "Joint Programmes" carried out within the Network.

On 23 Aprll, 2004 the first CEI University Network Executive Board meeting took place at the CEI-ES premises and was chalred by the Rector of the Trieste University, in hls capaclty of the CEI University Network Secretary General. The meeting was attended by the representatives of seven Universities. Decisions were taken on the following items:

- relations to the Advisory Board

- functioning of the Executive Board

- Identification of Participating Universities

- the Joint Programmes

- Implementation of Joint Programmes

- outslde Funding

- USE of CEI Logo

- cooperation with UNIADRION and other similar Academic Networks

- Web-page representing the CEI University Network

In 2004 the following Joint Programmes have been approved:

\begin{tabular}{|c|c|c|}
\hline $\begin{array}{l}\text { Applleant } \\
\text { Unlversity }\end{array}$ & W. Joint programme $\mathrm{s}$ & of portipating Univeraties o \\
\hline Trieste & $\begin{array}{l}\text { Cartography and Geographical Information } \\
\text { Systems }\end{array}$ & $\begin{array}{l}\text { University of Trana (Albania); University of Prague (Czech Republic); } \\
\text { Betarussian State University; University of Trieste; University of } \\
\text { Bucharest (Romania); Univeristy of Ljubjana (Stovenia). }\end{array}$ \\
\hline Trieste & $\begin{array}{l}\text { e-Business (Business to Business - Business } \\
\text { to Consumer) in the framework of the } \\
\text { Master's on "e-Business and e-Government } \\
\text { Technologles }\end{array}$ & $\begin{array}{l}\text { University of Graz (Austria); University of Maribor (Slovenia); } \\
\text { Univeristy of Rijeka (Croatia), University of Trleste (Italy). }\end{array}$ \\
\hline Trieste & $\begin{array}{l}\text { Seminar on the Geodynamical Madel of } \\
\text { Central Eurape for Sate Development of } \\
\text { Ground Transportation Systerns }\end{array}$ & $\begin{array}{l}\text { University of Trieste; The Abdus Salam International Centre of } \\
\text { Theoretical Physics, (ICTP) Trieste (Italy); } \\
\text { Geophysicai Instltute, Academy of Sciences, Prague (Czech Republic); } \\
\text { National Instltute for Earth Physics, Calugarent Bucharest-Magurele, } \\
\text { (Romania); } \\
\text { Institute of Mathematics and Informatics, Bulgarian Academy of } \\
\text { Sciences, Sofia (Bulgarta); } \\
\text { Central Laboratory for Selsmic Mechanics and Earthquake Engineering, } \\
\text { BAS, Sofla (Bulgaria); } \\
\text { Seismological Observatory of GGRI, Hungarian Academy of Sclences, } \\
\text { Budapest (Hungary). }\end{array}$ \\
\hline Trieste & Summer School of Classics & $\begin{array}{l}\text { University of Trieste (Italy), University of Ljubljana (Slovenia), } \\
\text { University of Zagreb (Croatia) }\end{array}$ \\
\hline Dologna & $\begin{array}{l}\text { MIREES (Master's in Eastem European } \\
\text { Studies) }\end{array}$ & 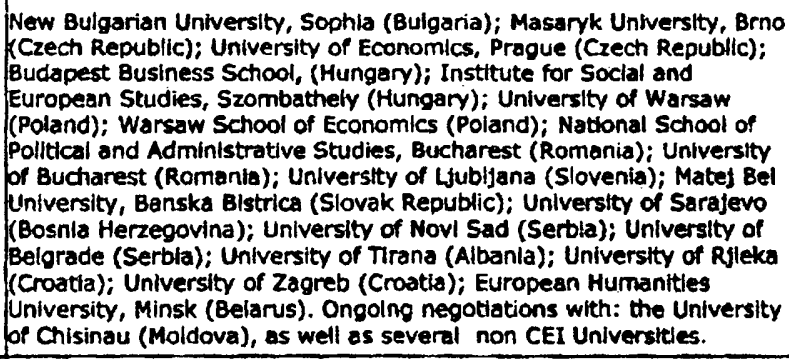 \\
\hline Vienna & Wpen idria Summer University & $\begin{array}{l}\text { Vienna University of Economics (Austria); University of Zagreb } \\
\text { (Croatia); Unlveristy of Trleste (Italy); University of Ljubljans } \\
\text { (Slovenia). }\end{array}$ \\
\hline
\end{tabular}

Within the activities related to the CEI University Network, the Seminar "University Networks, Education and Reseanch in Central and South Eastern European Countries" (Trieste 12-13 November), organized by the "Jacques Marltain Institute" In Trieste in co-operation with the Secretariat of the CEI University Network, deserves particular attention. The event was attended by 
various polltical and academic authoritles, Rectors of Universities of CEI countries, as well as representatives of the financial and business milieu.

\section{Other Activities}

The TF approved several, already implemented, Initiatives in 2004.

The International Summer School: "Beyond the Enlargement. The Wider. Europe and the new Neighbourhoodwis', submitted by Italy, was held in Cervla-Ravenna on 5-18 September. The School provided for two different courses, corresponding to 2 main study areas:

1 - Democracy, Human Rights and Political Institutions;

2 - Economics, Sustainable Development and Environmental Protection.

The Co-operation Activity" "European Cultural Identity in the Past and Present" - (IDEURO) ${ }^{40}$, submitted by the University Of Udine - Italy, within the Erasmus Intensive Programme, took place in Udine from 28 June to 11 July 2004. The event aimed at: a) promoting dialogue and understanding between "Western" Europe and the countries to join the EU acceding countries; and b) enabling to look for new opportunities in the labour market.

"Key-elements of Train the Trainers in Education for Democratic Citlzenship - using ICT Support" was a Co-operation Activity submitted by Austria. The event, involving SEE and CEI countries, took place in Budapest on 17 - 19 September and the outcomes can be summarized as follows:

- Dissemination of the project results (EDC toolbox available via web side) on the regional level to strengthen and widen the network of EDC institutions

- Dissemination in SEE-countries which have not taken part in the project so far

- Enlargement of the established EDC-network in SEE- (and CEI-) countries

- Enhanced exchange of experience between EDC-decision makers

- More people will have access to EDC through the promotion of the tool box

The 1st International Seminar "Humanitaria "12, held in 2004 in Lovetc (Bulgaria) on 25-31 July 2004 aimed at contributing to the further development of humanitarian studies and civil soclety in CEI countries as well as supporting young people and experts from countries undergoing serious economic difficulties.

"Health, Ageing and Work: Strategles for the New Welfare Society in the larger Europe "w, submitted by Italy, was an event held in Trleste on 21-23 October. It dealt with the new trends due to the extended life span. The speakers illustrated the current and future welfare policies linked to the extension of the life span of the elderly (work, pensions, education and health).

Serbla and Montenegro organized a Summer School of European Studies 2004 Introducing the EU: A crash course From Community to Union? The political and economic development of European integration ${ }^{44}$ from 21 August to 5 September in Novi Sad. The School aimed at promoting the European dimension in the process of teaching and learning at the University of Novl Sad. The Summer School represented a valuable multidisciplinary activity creating ties among students from different parts of Europe.

The "EUROPACS-MIR 2004 in the Enlarged Europe" "an event promoted by the University of Trieste (16-18 September 2004), was represented in the 22th International Conference of EuroPACS, combined in 2004 with the MIR (Management in Radiology). The Conference also hosted the DICOM (Digital Imaging and Communication in Medlcine), the IHE Europe (Integrating the Health Enterprise) and the AURE (Academic University Radiologists Europe) meetings.

Ref. No. 1202.013-04

10 Ref. No. $1202.032-04$

4 Ref. No. 1202.034-04

42 Ref. No. 1202.035-04

${ }^{43}$ Ref. No. $1202.046-04$

".. Ref. No. 1202.051-04 
Appendix 11 - CEI Instrument for the Protection of Minority Rights 
The Member States of the Central European Initiative signatory hereto,

- recognising that the question relating to national minorities can only be resolved satisfactorily in a truly democratic political framework which is based on the rule of law and guarantees full respect for human rights and fundamental freedoms, equal rights and status for all citizens,

- reafirming that the protection of national minorities concerns only citizens of the respective state, who will enjoy the same rights and have the eame duties of citizenship as the rest of the population,

- convinced that national minorities form an integral part of the society of the States in which they live and that they are a factor of enrichment of cach respective State and society,

- bearing in mind that a very effective remedy to achieve stability in the region are good relations between neighbours, and being conscious of the need to avold any encouragement of separatist tendencies of national minorities in the region,

- confirming that issues concerning the rights of persons belonging to national minorities are matters of legitimate international concern and consequently do not constitute exclusively an internal affair of the respective State,

- considering that respect for the rights of persons belonging to national minorities, as part of universally recognised human rights, is an essential factor for peace, justice, stability and democracy in the States,

- Convinced that the international protection of the rights of persons belonging to national minorities, as enshrined in the present Instrument, does not permit any activity, which is contrary to the fundamental principles of international law and in particular of sovereignty, territorial integrity and political independence of States,

- recognising the particular importance of increasing constructive co-operation among themselves on questions relating to national minorities, and that euch co-operation seeks to promote mutual understanding and confidence, 
friendly and good-neighbourly relations, international peace, security and justice,

expressing their condemnation of aggressive nationaliam, racial and ethnic batred, anti-Semitiam, xenophobia and discrimination against any person or group and of persecution on religious an ideological grounds

have agreed as follows:

ART. 1

States recognise the existence of national minorities as such, considering them integral parts of the society in which they live and guarantee the appropriate conditions for the promotion of their identity.

For the purpose of this Instrument the term "national minority" shall mean a group that is smaller in number than the rest of the population of a State, whose members being nationals of that State, have ethnical, religious or linguistic features different from those of the rest of the population, and are guided by the will to safeguard their culture, traditions, religion or language.

ART. 2

To belong to a national minority is a matter of free individual choice and no disadvantage shall arise from the exercise or nonexercise of such a choice.

ART. 3

States recognise that persons belonging to national minorities have the right to exercise fully and effectively their human rights and fundamental freedoms, individually or in common with others, without any discrimination and in full equality before the law. Those persons shall be able to enjoy the rights foreseen by the present Instrument individually or in common with others and to benefit from the measures ensuring those rights.

ART. 4

States guarantee the right of persons belonging to national minorities to express, preserve an develop their ethnic, cultural, linguistic or religious identity and maintain and develog their culture in all its aspects.

ART. 5

The adoption of special measures in favour of persons belonging to national minorities aimed at promotion equality between them and the rest of the population or at taking due 
account of their specific conditions shall not be considered as an act of discrimination.

ART. 6

States shall take effective measures to provide protection against any acts that constitute incitement to violence against persons or roup based on national, racial, ethnic or religious discrimination, hostility or hatred, including anti-Semitism;

ART. 7

States recognise the particular problems of Roma (gypsies). They undertake to adopt all the legal administrative or educational measures as foreseen in the present Instrument in order to preserve and to develop the identity of Roma, to facilitate by specific measures the social integration of persons belonging to Roma (gypsies) and to elliminate all forms of intolerance against such persons.

ART. 8

Without prejudice to democratic principles, States, taking measures in pursuance of their general integration policy, shall refrain from pursuing or encouraging policies aimed at the asaimilation of persone belonging to national minorities against their will and shall protect these persons against any action aimed at such assimilation.

ART. 9

In case of modification of administrative, judicial or electoral subdivisions States should take into account that such modifications, among other criteria, will respect the existing rights of the persons belonging to national minorities and the exercise of those rights. In any case, they should consult, according to national legialation, with the populations directly affected before adopting any modification in the matter.

ART. 10

Any person belonging to a national minority shall have the right to use his or her language freely, in public as well as in private, orally and in writing.

\section{ART. 11}

Any person belonging to a national minority shall have the right to use his or her surname and first names in his or her language and the right to official acceptance and registration of such sumame and names.

ART. 12 
Whenever in an area the number of persons belonging to a national minority reaches, according to the latest census or other methods of ascertaining its consistency, a significant level, those persons shall have the right, wherever possible, to use, in conformity with applicable national legislation, their own language in oral and in written form, in their contacts with the public authorities of the said area. These authorities may reply as far as possible, in the same language.

ART. 13

In conformity with their national legislation States may allow, where necessary through bilateral agreements with other interested States, in particular with neighbouring States, the display of bilingual or phurilingual local names, street names and other topographical indications in areas where the number of persons belonging to a national minority reaches, according to the latest census or other methods of ascertaining its consistency, a significant level. The display of signs, inscriptions or other similar information of private nature also in the minority language should not be subject to specific restrictions, other than those generally applied in this Iield.

ART. 14

Any person belonging to a national minority, exercising religious freedom, shall have the right to use his or her own language in worship, teaching, religious practice or observance.

ART. 15

Whenever in an area the number of persons belonging to a national minority reaches, according to the latest census or other methods of ascertaining its consistency, the majority of the population in an area, States will promote the knowledge of the minority language among officers of the local and decentralised state administrative offices. Endeavours should be made to recruit, if possible, officers, who, in addition to the knowledge of the official language, have sufficient knowledge of the minority language.

\section{ART. 16}

States recognise the right of persons belonging to national minorities to establish and maintain their own cultural and religious institutions, organisations or associations, which are entitled to acek voluntary financial and other contributions as well as public assistance, in conformity with national legialation.

ART. 17 
States recognise the right of persons belonging to national minorities to establiah and maintain their own private preschools, ochools and educational establiahment and possibly obtain their recognition in conformity with the relevant national legislation. Such establishments may seek public financing or other contributions.

ART. 18

Notwithstanding the need to learn the official language of the State concerned, every person belonging to a national minority shall have the right to learn his or her own language and receive an education in his or her own language. The States shall endeavour to ensure the appropriate types and levels of public oducation in conformity with national legislation, whenever in an area the number of persone belonging to national minority, according to the latest census or other methods of ascertaining ite consistency, is at significant level. In the context of the teaching of history and culture in such public educational establishment, adequate teaching of history and culture of the national minorities should be ensured.

ART. 19

States guarantee the right of persons belonging to a national minority to avail themselves of the media in their own language, in conformity with relevant State regulations and with possible financial assistance. In case of TV and radio in public ownerahip, the States will assure, whenever appropriate and posaible, that persons belonging to national minorities have the right of free access to such media including the production of such programmes in their own language.

ART. 20

States shall guarantee the right of persons belonging to. national minorities to participate without discrimination in the political, economic, social and cultural life of the society of the State of which they are citizens and shall promote the conditions for exerciaing those rights.

ART. 21

States ahall allow persons belonging to a national minority to eatablish political parties.

ART. 22

In accordance with the policies of the States concerned, States will respect the right of perwons belonging to national minorities to effective participation in public affairs, in particular in the decision-making process on matters affecting them. Therefore, States note the efforts undertaken to protect and create conditions for the promotion of the ethnic, cultural, linguistic and religious identity of certain national minorities by adopting appropriate 
measures correaponding to the specific circumstances of such minorities as foreseen in the CSCE documents.

ART. 23

Every person belonging to a national minority, while duly respecting the territorial integrity of the State, shall have the right to have free and unimpeded contacts with the citizens of another country with whom this minority ahares ethnic, religious or linguistic features or a cultaral identity. States shal not unduly restrict the free exercise of those rights. Furthermore, States will encourage tranafrontier arrangements at national, regional and local levels.

\section{ART. 24}

Every person belonging to a national minority shall have an effective remedy before a national judicial authority against any violation of rights set forth in the present instrument, provided that those rights are enacted in national legislation.

ART. 25

In any area where those who belong to a national minority represent the majority of the population, states shall take the necessery measures to ensure that those who do not belong to this minority shall not suffer from any disadvantage, including such that may result from the implementation of the measures of protection foreseen by the present Instrument.

ART. 26

None of these commitments shall be interpreted as implying any right to engage in any activity in contravention of the fundamental principles of international law and, in particular, of the sovereign equality, territorial integrity and political independence of State. Nothing in the present Instrument shall affect the duties related to persons belonging to national minorities as citizens of the States concerned.

Persons belonging to national minorities will also respect, in the exercise of their rights, the rights of others, including those of persons belonging to the majority population of the reopective State or to other national minorities.

ART. 27

This Instrument shall not prejudice the provisions of domestic law or any international agreement which provide greater protection for national minorities or persons belonging to them. 